\title{
Gold Nanoparticle Mediated Phototherapy for Cancer
}

\author{
Cuiping Yao, Luwei Zhang, Jing Wang, Yulu He, Jing Xin, Sijia Wang, \\ Hao Xu, and Zhenxi Zhang
}

Key Laboratory of Biomedical Information Engineering of Ministry of Education, Institute of Biomedical Analytical Technology and Instrumentation, School of Life Science and Technology, Xian Jiaotong University, 28 Xianning Xi Road, Xian, Shaanxi 710049, China

Correspondence should be addressed to Zhenxi Zhang; zxzhang@mail.xjtu.edu.cn

Received 14 March 2016; Revised 30 June 2016; Accepted 15 November 2016

Academic Editor: Laura M. Maestro

Copyright (C) 2016 Cuiping Yao et al. This is an open access article distributed under the Creative Commons Attribution License, which permits unrestricted use, distribution, and reproduction in any medium, provided the original work is properly cited.

Gold nanoparticles exhibit very unique physiochemical and optical properties, which now are extensively studied in range of medical diagnostic and therapeutic applications. In particular, gold nanoparticles show promise in the advancement of cancer treatments. This review will provide insights into the four different cancer treatments such as photothermal therapy, gold nanoparticle-aided photodynamic therapy, gold nanoparticle-aided radiation therapy, and their use as drug carrier. We also discuss the mechanism of every method and the adverse effects and its limitations.

\section{Introduction}

Cancer is one of the main leading causes of death all over the world. Currently the most successful cancer treatment method usually involves intrusive processes including chemotherapy, radiation, and surgery to remove the tumor if possible, followed by more chemotherapy and radiation. Even if the scientists have made tremendous efforts to enhance these traditional methods, selective methods are still required which can harm cancer cells hardly without destroying the healthy tissue. The research field of nanomedicine which has rapidly developed has great promise in fighting against cancer [1-7]. Nanoparticles such as dendrimers, liposomes, polymers, quantum dots, perfluorocarbons, nanotubes, iron oxide, nanowires, and gold nanoparticles (GNPs) are mostly used for cancer nanotechnology [5]. Especially over the last decade researches have made many efforts to use GNPs for cancer treatment. It is demonstrated that gold nanoparticles have an immense potential to enhance the efficiency of cancer treatment [8-19].

As to the currently available gold nanoparticle-based therapeutic approaches, they can be classified into four main types: (1) photothermal therapy: upon irradiation of surface plasmon resonant gold nanoparticles by light, surface electrons are excited and resonate intensely, and fast conversion of light into heat takes place in about 1 ps [20]. GNPs can be delivered into cancer cells by different methods such as physiological transportation, conjugation with antibodies, and once these GNPs are delivered they self-assemble large clusters inside cells. This results in bubble formation that is more effective for killing cells (or using CW laser to induce hyperthermia that is a condition under which cells are subject to temperature in the range of $41-47^{\circ} \mathrm{C}$ for tens of minutes). Such a condition will cause irreversible damage to the cells due to denaturing of proteins and/or destruction of cell membranes [21]. This application is based on their unique plasmonic properties with well-controlled sizes, shapes, and surface properties. The localized surface plasmon resonance (LSPR) peaks of AuNPs can be easily turned to the near-infrared (NIR) region for better treatment due to the high transparency of the tissues. (2) GNPsaided photodynamic therapy (PDT): PDT has emerged as one of the important therapeutic selections for treatment of cancer and other diseases [22]. Most photosensitizers (PSs) are highly hydrophobic and require delivery systems. It was showed that GNPs can enhance singlet oxygen generation or photodynamic therapy efficiency of different photosensitizers [23-25], which may be due to localized surface plasmon resonance (LSPR) of the metal nanoparticles according to most of the scientists [26, 27]. However, our group demonstrated that the cancer cell killing enhancement is mainly due to GNPs' efficient drug delivery [28]. Furthermore, the 


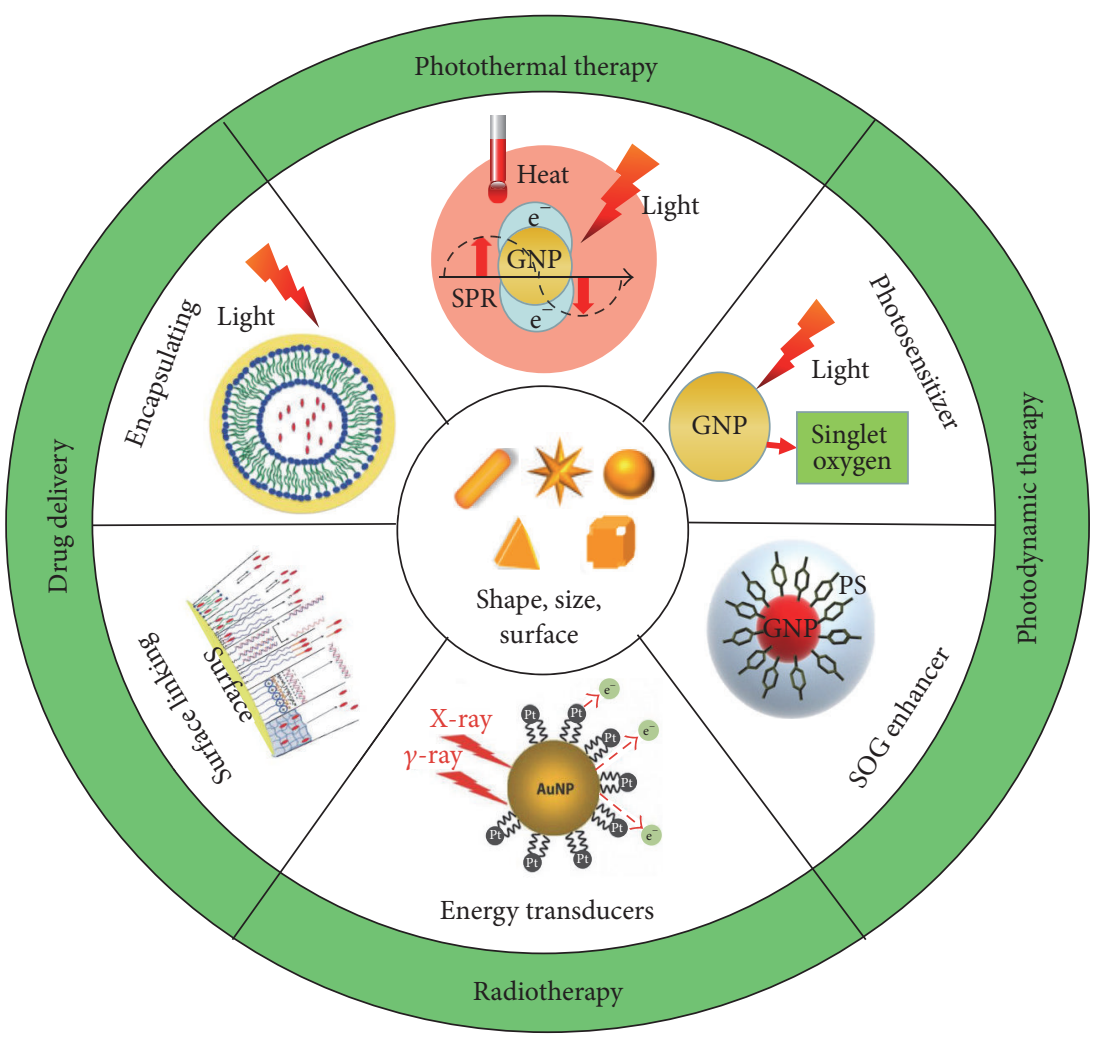

FIGURE 1: Schematic diagram of different therapies.

gold nanoparticles alone can generate singlet oxygen [29]. So combination of GNPs-mediated photothermal therapy (PTT) and photosensitizers-mediated photodynamic therapy (PDT) was reported to achieve synergistic PTT and PDT effects on destroying cancer cells by many groups [7, 3033]. (3) The gold nanoparticles can enhance radiosensitivity of cancer cells; this effect is shown in vivo and in vitro, at kilovoltage or megavoltage energies [34]. Furthermore, radiosensitization of GNPs depends on nanoparticles' size, concentration, type, used energy, intracellular localization, and used cell line [35]. (4) Gold nanostructure can be as carrier to deliver drugs into tumor cells. Gold nanoparticles can be developed as versatile nontoxic carriers for drug and gene delivery because they can be conjugated with antibodies, peptides, folate, ligands, and so on to help the higher concentration in the tumor region. Furthermore, the AuNPs loaded with a drug have been delivered to the tumor, which can be triggered by the photothermal effect to control release of drug molecules. With the platform, the monolayer is responsible for tuning of surface properties such as hydrophobicity and charge, while the gold core renders the assembly stability [36]. Functionalization of GNPs with thiolated polymers can provide an effective and selective means of controlled intracellular release, and researchers found that the size of nanoparticles and presence of galactose ligands significantly impact the targeting efficiency [37].

To date, although several excellent reviews have been presented to introduce the synthesis and modification of gold nanoparticles as well as their applications in biosensing and bioimaging and also excellent reviews about cancer treatment of nanoparticles have been presented [38-40], however, with respect to therapy of cancer, none of them has focused on a systematic and complete review of the advancement in the field of phototherapy of cancer with gold nanoparticles. Thus, we present this review on the AuNPs-based phototherapy systems in the past 10 years to summarize the comment on their development and advances. Particularly, we restrict our discussions to the therapy strategies rather than synthesis and surface modification, which have been summarized extensively in many reviews. The therapy strategies will be mainly categorized by different mechanisms including thermal therapy, PDT, radiotherapy, and drug delivery. The schematic diagram of different therapies was showed in Figure 1.

\section{Applications of Gold Nanoparticles for Phototherapy}

2.1. Gold Nanoparticles for Photothermal Therapy. PTT is a very important application of GNPs in nanomedicine. Gold nanoparticles have been used to harm bacteria, viruses, and cancer cells based on their heating effects under laser irradiation due to the enhanced absorption induced by localized surface plasmon resonance (LSPR); this is defined as photothermal therapy [41, 52-54]. Through the control of the geometric and physical parameters of nanostructures such as size and shape, the plasmon resonance peaks of GNPs 
could be tuned to the near-infrared region [55] and the light absorption efficiency of GNPs in the near-infrared region is high (extinction coefficient is about $10^{-9} \mathrm{M}^{-1} \mathrm{~cm}^{-1}$ ) which imparts high depth photothermal therapy in tissues because of the high penetration of infrared light [56, 57]. Many researchers have focused on the photothermal therapy of gold nanoparticles with different size and morphology, such as gold nanorods (GNRs), gold nanostars, gold nanorings, gold nanocages, and hollow gold nanoshells [58-62].

Using pulsed or continuous wave $(\mathrm{cw})$ lasers in both the visible and near-infrared wavelength region, photothermal therapy (PTT) with gold nanospheres can be reached owing to the SPR absorption in the visible region and its nonlinear properties [7, 54,63-67]. In 2003, Lin et al. used gold nanospheres and nanosecond pulsed laser to implement comprehensive research of selective and highly localized photothermolysis of targeted lymphocytes. In their study, lymphocytes incubated with antibody conjugated gold nanoparticles were irradiated by 100 laser pulses at an energy of $0.5 \mathrm{~J} / \mathrm{cm}^{2}$, which resulted in extensive cellular damage. Adjacent cells without nanoparticles within a few micrometers, were intact [68]. El-Sayed and coworkers firstly employed antiepidermal growth factor receptor (anti-EGFR) antibody conjugated gold nanospheres to image and treat oral tumor cells in vitro, in which a continuous argon laser at $514 \mathrm{~nm}$, the peak absorbance of $40 \mathrm{~nm}$ particles, was used. Compared with normal, noncancerous cells, it was showed that cancerous cells targeted with nanoparticles were destroyed with 2-3 times lower laser power [65]. Their group obtained similar results with gold nanorods (Figure 2) [41]. Our group also have conducted similar studies on human lymphoma cell. Our results showed that at relatively low GNPs concentration and short incubation time, there was little cytotoxicity of gold on cell. Upon irradiation of proper power, gold-targeted L- 428 cells can be killed with high efficiency, while little damage was done to nontargeted cancer cells [18]. Lapotko et al. used specific monoclonal antibodies to treat tumor cells; Ig conjugated $30 \mathrm{~nm}$ gold nanoparticles could form clusters of 10-20 on the surface of cell membrane. And the nanoparticulate clusters inside the cells can be found by electron microscopy (Figure 3). K562 cells were irradiated by single laser pulses with optical fluence of $5 \mathrm{~J} / \mathrm{cm}^{2}$ at the wavelength of $532 \mathrm{~nm}$, and the cells without specific antibodies were hardly damaged, while cells targeted with specific antibodies were totally destroyed [69]. Their results showed once gold nanoparticles are delivered they form selfassembled large clusters directly inside cells, which results in laser-induced bubble formation that is more effective for eliminating cells. Moreover, SPR shift from visible region to near-infrared region could happen [70]. Another group also observed GNPs cluster in the cells [42].

Although gold nanospheres have been proven to be useful for photothermal therapy of surface type tumors, in which the visible pulsed or CW lasers with wavelength of the peak of surface plasmon resonant absorption were used, for its deeper penetration in tissues, near-infrared light must be used treating internal tumors for in vivo applications. In order to shift the absorbance of gold nanospheres from the visible range into the NIR, EI-Sayed et al. used the nonlinear properties of GNPs. In their study, HSC oral cancer cells were targeted by anti-EGFR antibodies conjugated spherical GNPs, a femtosecond Ti: Sapphire laser at $800 \mathrm{~nm}(100-$ femtosecond pulse duration, $1 \mathrm{kHz}$ repetition rate) was used to photothermally destruct the nanoparticle treated cancer cells. Their results showed that the laser power needed to kill the normal cells was approximately 20 times more than that needed to destroy cancer cells. They demonstrated that during experiments there exists a second harmonic generation (SHM) or a two-photon absorption (TPA) process. Moreover, with dependence on the gold nanoparticle concentration the nanoparticles can be aggregated or clustered together in close proximity [66]. Alternatively, Zharov et al. found when the antibody conjugated GNPs were selectively attached to MDA-MB-231 breast-cancer cells by means of secondary antibodies, the GNPs can be self-assembled into cancer cells. The assembly of gold nanoclusters on the cell membrane inducing absorbance peak shift from visible region to the NIR region. As a result, laser-induced bubble formation can be significantly increased and cancer cells were killed by irradiation of near-IR lasers (1064 nm) [70].

Since the gold nanoclusters depended on the nanoparticles concentration or self-assembly that need certain conditions (e.g., secondary antibodies) $[66,70]$ and when the distance between the two particles exceeds about 2.5 times the particle diameter, the red shift of the nanocluster could be negligible [71], and it seemed that it is difficult to control the shift of SPR wavelength of gold clusters from visible region to near-infrared region. However, since only near-infrared light can penetrate inside living tissues, gold nanoshells, gold nanorods, and gold nanocages which have SPR absorption of 650-900 $\mathrm{nm}$ are ideal for in vivo imaging or therapy. The preparation of gold nanorods with different aspect ratios (length divided by width), which enables the tune of its plasmonic absorption peak in the NIR region, is simple and well established. And the size of gold nanorods is very small which makes it easier to be internalized by cancer cells [7274]. The photothermal effect of gold nanorods on cancer cells were firstly demonstrated by Huang and coworkers in 2006 [41], during this research, where the antiepidermal growth factor receptor (anti-EGFR) monoclonal antibodies conjugated gold nanorods were synthesized and utilized to inactivate cancer cells. It is found that, after irradiation by continuous red laser at $800 \mathrm{~nm}$, nonmalignant cells require about double the laser energy to be photothermally destroyed compared to the malignant cells. From then on many groups began to use gold nanorods or modified gold nanorods in tumor cells photothermal therapy research [75-78].

Recently, there are still many researches concerned on the improvement of gold nanorods photothermal effect on cancer cells. $\mathrm{Li}$ and the coworkers employed macrophage vehicles to transport $7 \mathrm{~nm}$ diameter Au nanorods (AuNRs) to improve photothermal efficiency in vivo [58], where they found that photothermal conversion almost throughout the tumor can be improved by BSA-coated AuNRs-laden-macrophages, which minimized tumor recurrence rates compared to free BSA-coated AuNRs. Popp et al. implemented gold nanorodmediated PPT employing NIR light-emitting diode (LED) 

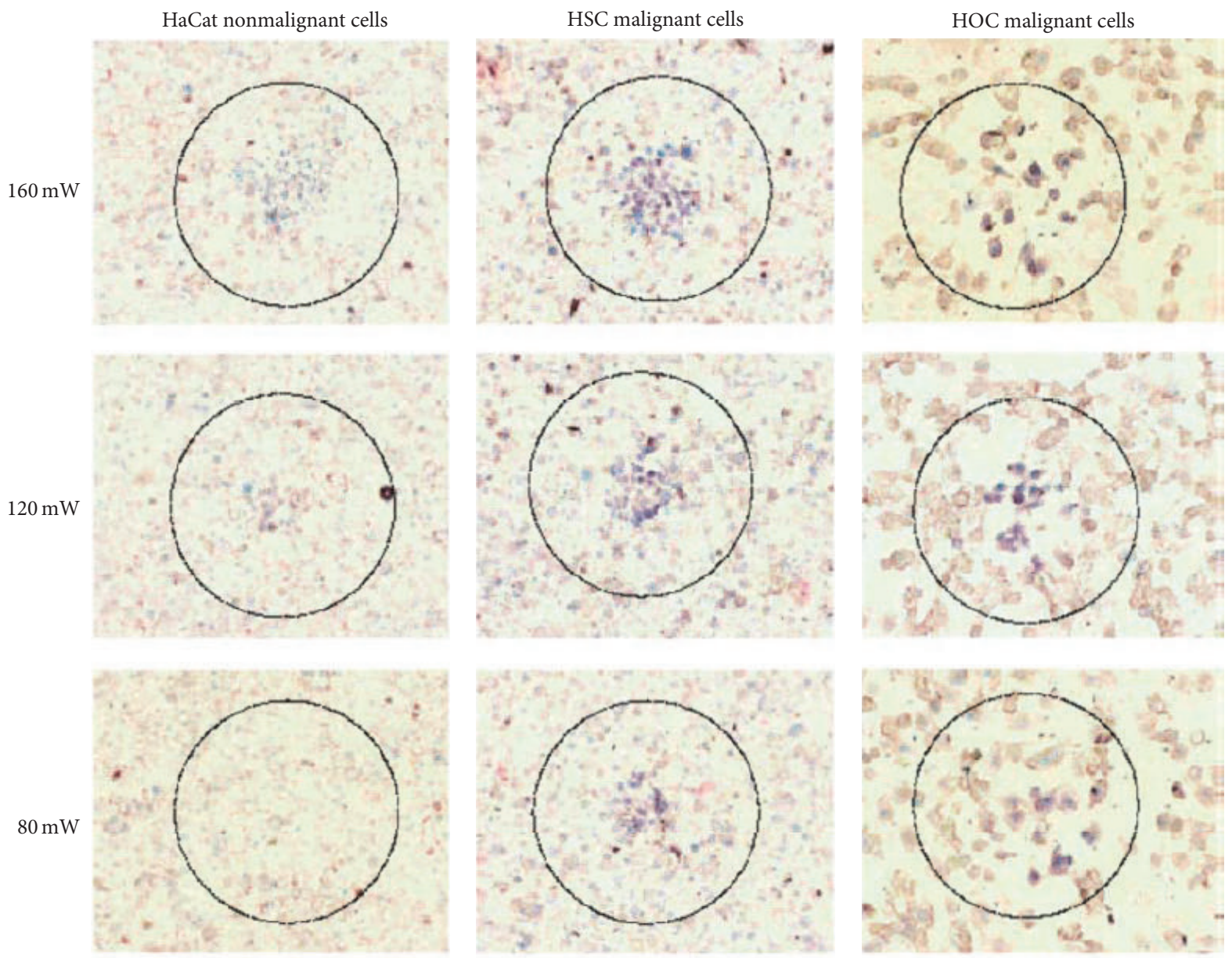

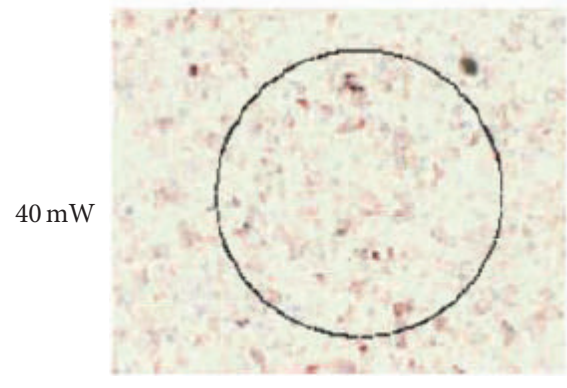

(a)

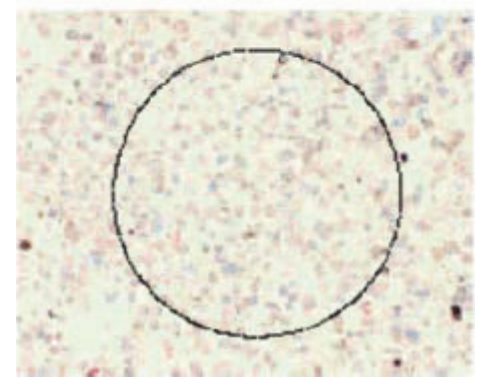

(b)

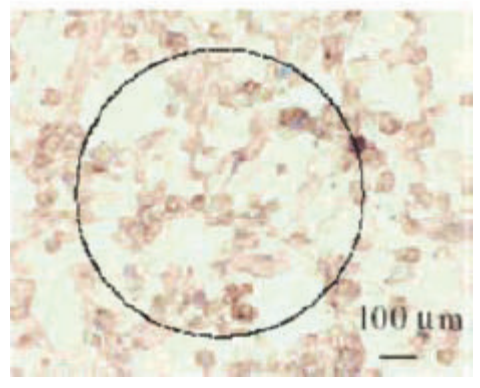

(c)

FIGURE 2: HaCaT benign cells (a), HSC malignant cells (b), and HOC malignant cells (c) irradiated at different laser powers and then stained with trypan blue. HaCaT benign cells were killed at and above $57 \mathrm{~W} / \mathrm{cm}^{2}$, HSC malignant cells were killed at and above $25 \mathrm{~W} / \mathrm{cm}^{2}$, and $\mathrm{HOC}$ malignant cells were killed at and above $19 \mathrm{~W} / \mathrm{cm}^{2}$. Scale bar: $60 \mu \mathrm{m}$ for all images. Reprinted with permission from [41]. Copyright (2016) American Chemical Society.

light source in vitro and in vivo. Their study demonstrated that the PTT strategy induces tumor volume shrinking and higher animal survival rate compared to that of melanoma drugs in a murine melanoma model (Figure 4) [43]. Du and coworkers fabricated a core-shell composite that consisted of gold nanorods covered by polypyrrole (PPy) with two-photon photothermal efficiency, and the composite also possessed good photostability due to a facile interfacial polymerization [79]. They found that the Au-PPy nanorods with high photothermal efficiency can cause the inhibition of cancer cell proliferation; thus normal tissues photothermal damage can be minimized. As to the clinical usage of gold nanorods PTT effect, Tetsuya Kodama and coworkers proposed a novel PTT technique. For this clinical application technique to work, the GNRs and infrared laser light had to be used. This novel PPT can treat metastatic lymph nodes located within or outside the area accessible for surgical dissection and without skin damage due to controlled surface cooling [80]. Utile now the usage of gold nanorods in cancer nanotechnology including imaging and therapy is also a very active field of research. 


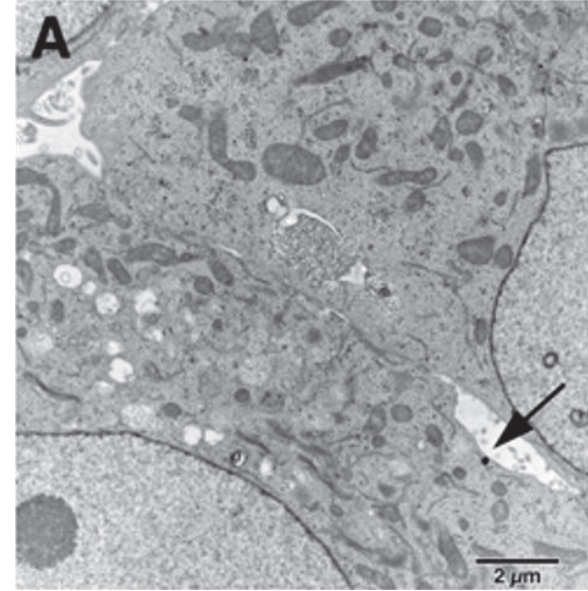

(a)

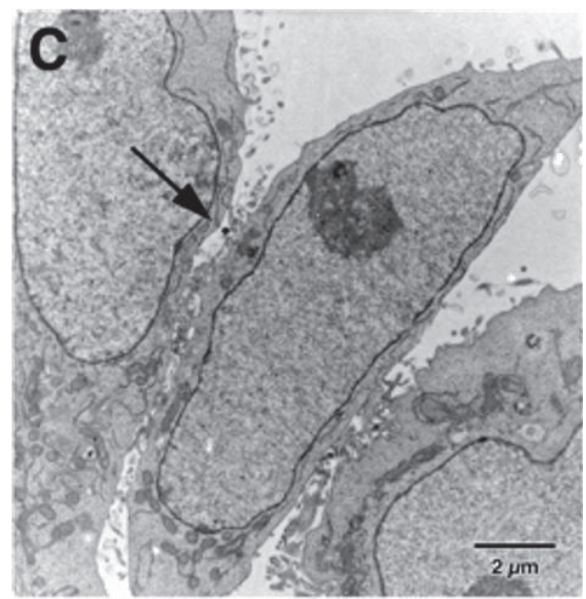

(c)

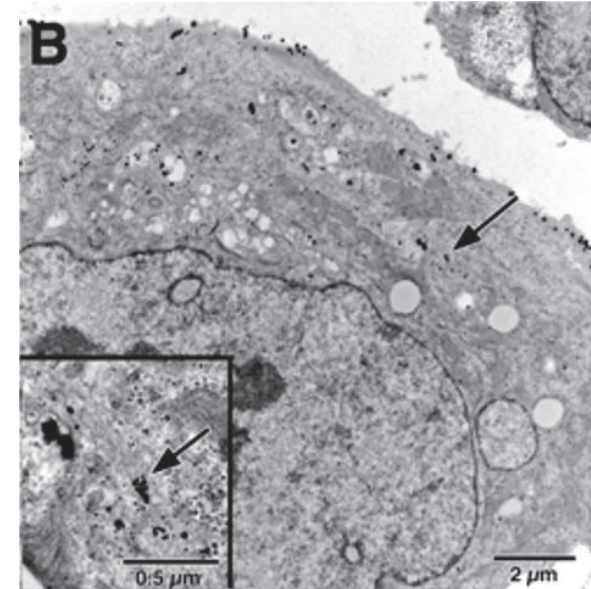

(b)

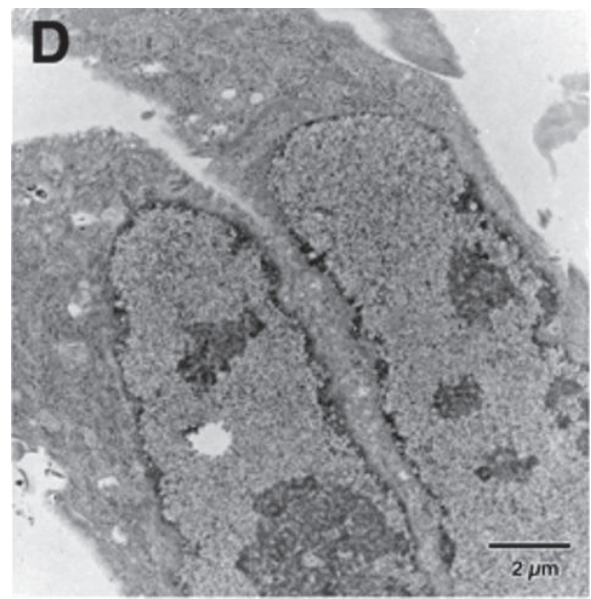

(d)

FIGURE 3: TEM micrographs of thin sections of cells that were incubated for $2 \mathrm{~h}$ with various AuNP constructs. Magnification of primary images is 6000x; the inset is shown at 28000x. (a) KB cells incubated with mPEG2000-T:AuNP. Occasionally, AuNPs are found adjacent to the cell plasma membrane (arrow), but most are removed by washes during sample preparation. (b) KB cells incubated with F-PEG1500T:AuNP. Region corresponding to the higher magnification inset is denoted by the arrow which shows significant uptake of nanoparticles throughout the cytoplasm. (c) KB cells incubated with F-PEG-T:AuNP in the presence of excess folic acid. (d) WI-38 cells incubated with F-PEG-T:AuNP. Reprinted with permission from [42]. Copyright (2006) American Chemical Society.

Gold nanoshells consisting of a dielectric core covered by a thin gold shell possess SPR peaks in the NIR region [81, 82]. Hirsch et al. firstly conducted the photothermal therapy utilizing gold nanoshells in in vivo and in vitro experiments $[52,83]$. In their research, breast carcinoma cells were incubated with nontargeted PEGylated gold nanoshells with tunable absorption in the NIR region; after being exposed to $\mathrm{cw} 820 \mathrm{~nm}$ diode laser $\left(35 \mathrm{~W} / \mathrm{cm}^{2}\right)$ the cells undergo irreversible photothermal damage. They used magnetic resonance technology to measure the increased temperature. In the following years, they also used nonspecific PEGylated nanoshells to conduct tumor thermotherapy in vivo by means of injection via tail vein $[52,67,83]$. Magnetic resonance temperature imaging (MRTI) was applied to analyze the temperature increase of the gold nanoshell treated tumor, and the results correlated well with gross pathology. The tumor tissue also displayed coagulation, cell shrinkage, and loss of nuclear staining, indicating thermal damage in NIR-nanoshell-treated tumors. PC3 human prostate cancer xenografts were treated by this similar approach with $110 \mathrm{~nm}$ PEGylated gold nanoshells and laser irradiation [84, 85]. Gobin et al. have combined imaging via Optical Coherence Tomography (OCT) with therapy in vivo using nonspecific PEGylated gold nanoshells [86]. In this method nanoshells were accumulated passively in tumors and subsequent ablation depends on nanoshell amount accumulated in the tumor [87]. The influence of nanoshell concentration on tumor ablation has been evaluated by Stern et al. in a human prostate cancer model in mice; they got the same result like Lal in [87, 88]. In 2005, Drezek et al. used immune-targeted nanoshells for integrated cancer imaging and therapy in vitro. In a proof of principle experiment, immune-targeted nanoshells are employed to detect and destroy breast carcinoma cells that overexpress cancer biomarker HER2 [89]. The same 


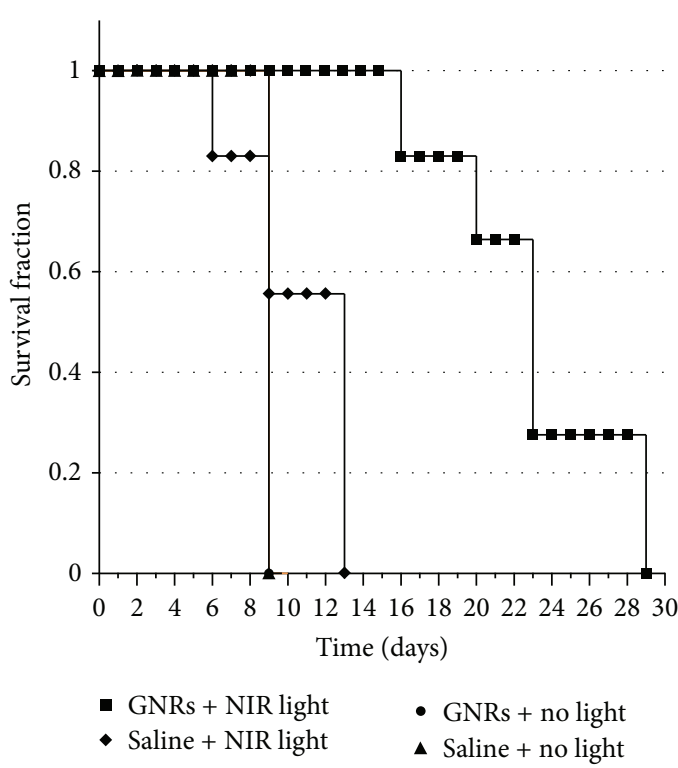

(a)

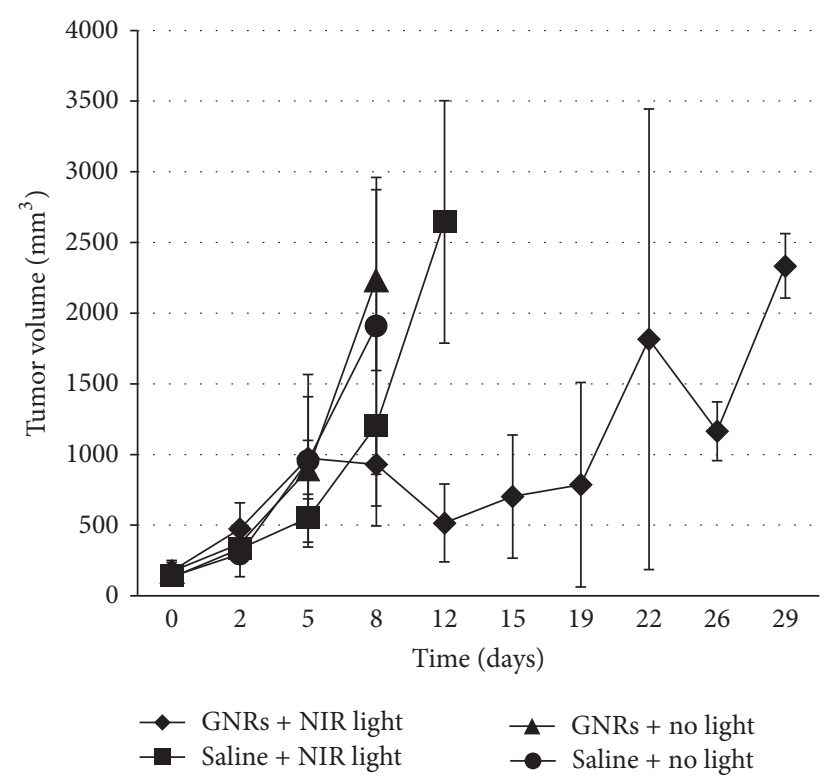

(b)

FIGURE 4: Efficacy of photothermal therapy demonstrated in the treatment of mice bearing murine melanoma tumors. C57BL/6 mice bearing F10B16 tumors were injected with either PEG-GNRs $(200 \mu \mathrm{L}$, OD60) or saline (200 $\mu \mathrm{L})$; the PEG-GNRs were then allowed 48 hrs to circulate within the body, and then half of the mice were exposed to NIR light to maintain ablation temperatures for 6 min $(n=6)$. Their overall survival and tumor volume were tracked throughout the entire length of the study (tumor measurements were taken every 2-3 days). (a) Survival of the mice is plotted against time (days), with day $=0$ signifying initial PEG-GNR/saline injection. (b) Tumor volume (mm ${ }^{3}$ ) is plotted versus time (days) after initial injection with PEG-GNRs/saline. The data in (a) and (b) were censored [43].

group also demonstrated the successful targeting and ablation of trastuzumab-resistant cells using anti-HER2-conjugated silica-gold nanoshells and a near-infrared laser [90]. On the other hand, the passive accumulation of nanoshells relies on the enhanced permeability and retention (EPR) effect [91]. However, the blood flow is normally reduced in the centers of large solid tumors with hypoxia, which results in nanoparticle accumulation resistance as well as conventional chemotherapy in these regions. Then a "Trojan Horse" strategy was built to deliver nanoshells to the centers of solid tumors by Choi's group. They have proven monocytes containing therapeutic gold nanoshells could serve as "Trojan Horses" for nanoparticle transport into these tumor regions [92], which was called "nanoshell targeting of tumor hypoxia" [87]. Madsen et al. investigated the efficacy of goldsilica nanoshells (AuSNS) and gold nanorods (AuNRs) for photothermal therapy in vitro. They utilized hybrid murine macrophages to deliver nanoparticles into human glioma spheroids; they found that gold-silica nanoshells have a much higher photothermal conversion compared to gold nanorods [93].

Another kind of gold nanoparticles absorbing NIR light is gold nanocages, which is developed by the Xia group $[61,94,95]$. The SPR absorption can be tuned from the visible region to the NIR region according to the thickness and size of gold shells $[96,97]$. The inactivation effect of gold nanocages on cancer cells has been investigated both in vitro and in vivo [95, 98-100]. The advantages of gold nanocages are the smaller size and higher specific surface area [97]. Wang and coworkers pointed out gold nanocages can efficiently convert NIR light into energy and have stable photothermal property [101]. Moreover, under irradiation of NIR light gold nanocages display higher temperature rise than that of nanospheres at the same concentration. There are still other gold nanostructures with NIR LSPR band that are useful for PTT. Like gold nanorings with the LSPR wavelength range between 1000 and $1300 \mathrm{~nm}$ [60], gold nanostars possess more SPR hot spots [59], hollow gold nanoshells [62], and gold-gold sulfide nanoparticles [102]. Chu et al. utilized gold nanorings functionalized with anti-EGFR antibody for successful targeting and inactivation of SAS oral cancer cells under irradiation of a $1065 \mathrm{~nm}$ laser [103]. Yang et al. and Zhang et al. have conducted NIR photothermal therapy mediated by citrate-capped gold nanoflowers and gamma $\mathrm{Fe}_{2} \mathrm{O}_{3} @ \mathrm{Au}$ core/shell-type magnetic gold nanoflower, respectively [44, 104]. Their results demonstrate that the photothermal therapy mediated by gold nanoflowers inhibits the proliferation of cancer cells effectively (Figure 5). Researchers synthesized a gamma $\mathrm{Fe}_{2} \mathrm{O}_{3} @$ Au core/shell-type magnetic gold nanoflower that integrates different properties, such as photothermal therapy capabilities, real-time magnetic resonance imaging, high-resolution photo acoustics imaging, and ultrasensitive surface-enhanced Raman scattering imaging. Iodice et al. have demonstrated that the encapsulation of small AuNPs into larger spherical nanostructures could enhance photothermal ablation and could favor tumor accumulation [105]. 

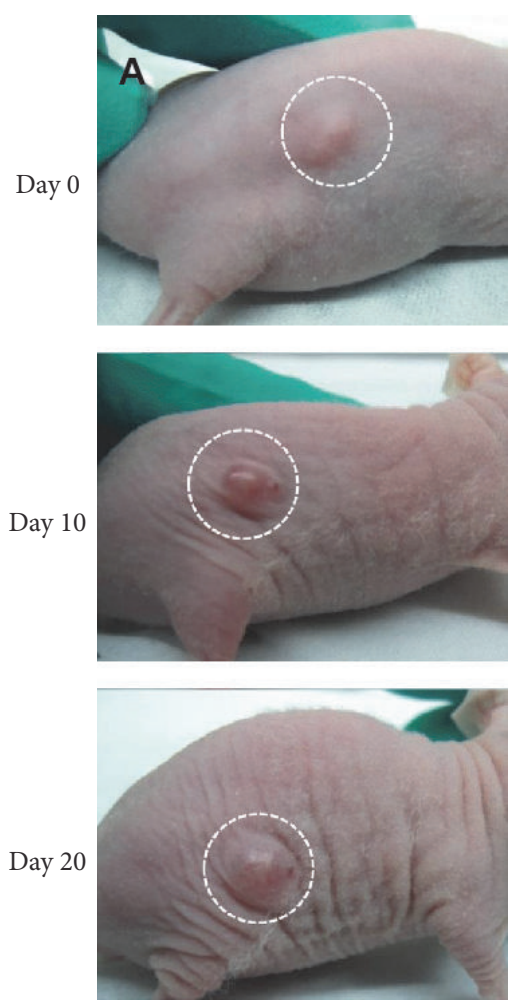

Under irradiation without AuNFs

(a)
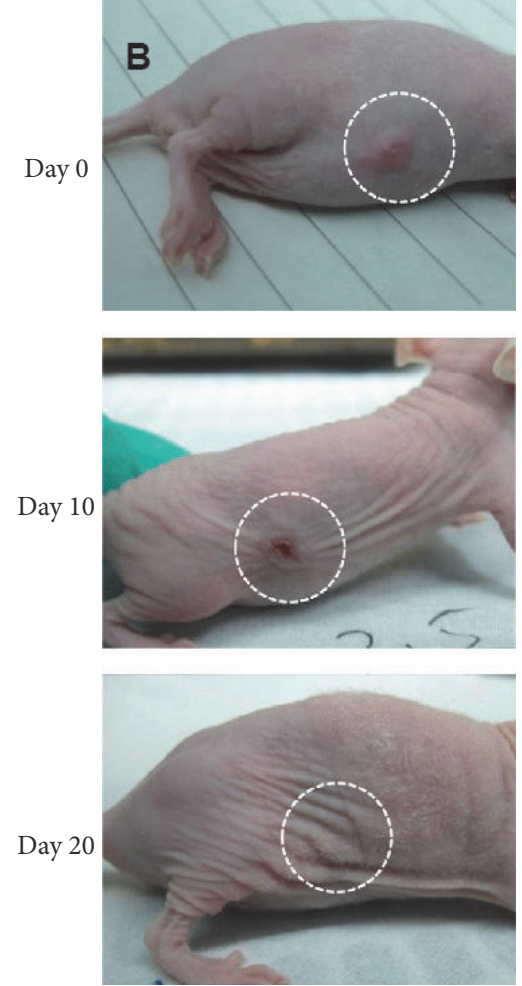

Under irradiation with AuNFs

(b)

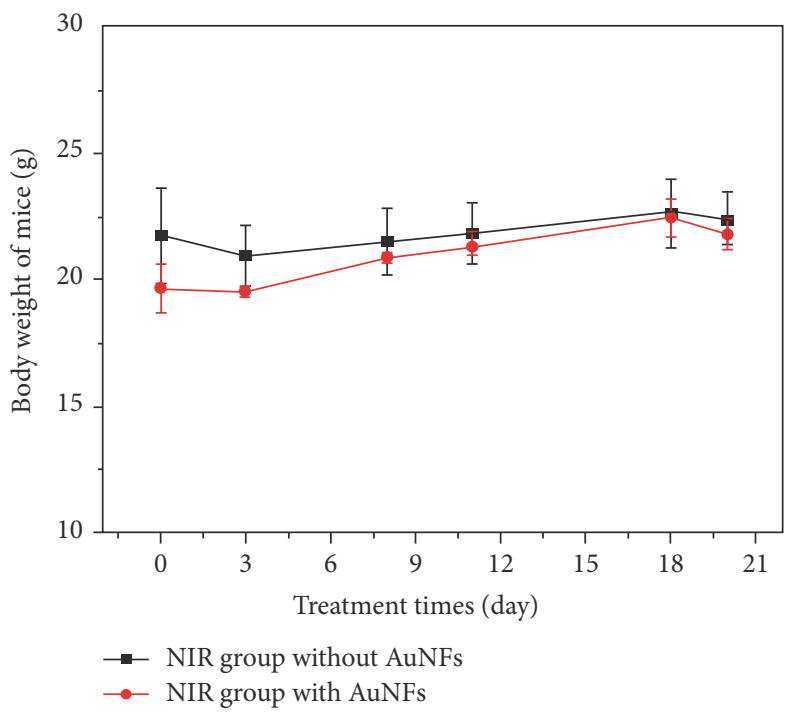

(c)

FIgURE 5: (a-c) Photothermal therapy effect on nude mouse under near-infrared (NIR) irradiation caused by the addition of Au nanoflowers (AuNFs). (a) HeLa tumor-bearing Balb/c nude mouse treated without addition of AuNFs; (b) HeLa tumor-bearing Balb/c nude mouse with the addition of AuNFs; (c) body weight change of mice with treatment time. Both experiments were performed under $808 \mathrm{~nm}$ NIR laser irradiation. Reproduced with permission of DOVE Medical Press via Copyright Clearance Center from [44].

To treat tumor with photothermal therapies, gold nanoparticles have to be introduced into cancer tissue, which induce significant absorption increases of laser energy and thereby heat the tissue. It was worth noting that the temperature increase is owing to high photothermal energy conversion by a large number of individual GNPs, which is due to surface plasmon resonance (SPR) of gold nanoparticles. And SPR properties of GNPs are mainly affected by their size and shape [39]. Furthermore, the photothermal conversion efficiency of GNPs is a crucial 
TABLE 1: Difference of experimental and theoretical photothermal conversion efficiencies.

\begin{tabular}{lccc}
\hline GNP nanostructure & Theoretical & Experimental & Ref. \\
\hline $20 \mathrm{~nm}$ sphere & $99 \%$ & $<10 \%$ & {$[39]$} \\
$20 \mathrm{~nm}$ sphere & $99 \%$ & $\sim 100 \%$ & {$[106]$} \\
$\mathrm{Au} \mathrm{Si}$ & $\sim 12 \%$ & $30 \%$ & {$[107]$} \\
$\mathrm{Au} @ \mathrm{Au}_{2} \mathrm{~S}$ & $>90 \%$ & $59 \%$ & {$[107]$} \\
$\mathrm{Au}$ nanorod & $>90 \%$ & $55 \%$ & {$[107]$} \\
\hline
\end{tabular}

parameter, and the conversion efficiency, for the particular case of GNPs, is strongly dependent on both shape and size of the GNPs. Photothermal conversion efficiencies of different sized and shaped particles were studied through temperature change in nanoparticle laden liquid droplets and stirred nanoparticle laden liquid in cuvette. Roper et al. have experimentally and theoretically studied the thermal energy conversion of aqueous suspensions of $20 \mathrm{~nm}$ gold particles irradiated by a continuous wave with $514 \mathrm{~nm}$ wavelength. The transduction efficiency was measured by modulating the incident continuous wave irradiation, and the values were increased from $3.4 \%$ to $9.9 \%$ [106]. Richardson et al. implemented similar work with CW laser excitation at $532 \mathrm{~nm}$ and $20 \mathrm{~nm}$ GNPs, but their study put emphasis on the particles concentration and irradiation intensity [107]. However, even for the same type of GNP different groups got very different photothermal transduction efficiencies in droplets versus cuvettes (Table 1). Cole et al. reported a comparative study of the photothermal conversion efficiency of $\mathrm{SiO}_{2} / \mathrm{Au}$ nanoshells, $\mathrm{Au}_{2} \mathrm{~S} / \mathrm{Au}$ nanoshells, and $\mathrm{Au}$ nanorods. In the study they compared experimental results and theoretical values for each nanoparticle type. It was showed that particle size is a very crucial factor to determining conversion efficiency, and larger particles are more effective for both scattering and absorption, which can enhance bioimaging contrast and photothermal treatment simultaneously [108]. Chen et al. directly measured and analyzed the temperature of gold nanocrystal solutions with a thermocouple according to energy balance theory in order to study the influence of particle volume, plasmon resonance wavelength, assembly, and shell coating on the photothermal transduction efficiency. They observed when the gold nanocrystals were illuminated by a laser at wavelength that is in accordance with plasmon resonance wavelength of the nanocrystal, the larger the nanocrystal is, the smaller the transduction efficiency becomes. Assembly and coating can change the plasmon resonance energy of gold nanocrystals, which can be used to control the photothermal conversion. They also found that the experimental results are smaller than the theoretical values, and the difference becomes larger with the size increasing [109]. This two-conversion efficiency difference is due to a variety of reasons. However, Qin and Bischof pointed that it is important to distinguish these two efficiencies; the measured conversion efficiency is a bulk property related to environmental factors, radiative transport, and nanoparticle, while theoretical value including extinction cross section and absorption cross section is suitable for single nanoparticle [110]. Also photothermal conversion efficiency can be used to compare heat generation ability among different GNPs except for in vivo applications. The more useful quantity is the specific absorption rate (SAR) distribution that includes the information of GNP's concentration and position of heat generation. Incorporating SAR into the bioheat equation, the temperature increases and thermal injury during photothermal therapy can be predicted and monitored as discussed in Qin and Bischof's critical review [110].

\subsection{Gold Nanoparticle-Aided Photodynamic Therapy. Since} photodynamic therapy (PDT) is characterized by, for example, its low morbidity, good tolerance, minimally invasive procedure, ability to be used repeatedly at the same site, minimum functional disturbance, and the fact that it is normally an outpatient therapy $[111,112]$, it is a promising treatment modality for cancers and other malignant diseases. The basis for cancer treatment using PDT is the oxidative nature of reactive oxygen species (ROS) [113], and photosensitizing NPs are an important tool to modulate ROS generation [114]. Many groups found that the GNPs can enhance SOG or the photodynamic therapy efficiency of different PSs, such as phthalocyanines, toluidine blue $\mathrm{O}$, indocyanine green, AlPcS4, and hematoporphyrin [115].

Hone et al. firstly demonstrated that phthalocyaninestabilized gold nanoparticles could generate cytotoxic singlet oxygen [23]. In their study, GNPs were functionalized with a photosensitizer phthalocyanine $(\mathrm{Pc})$; also the GNPs were combined with the TOAB phase transfer reagent that was used during synthesis. Compared with the free photosensitizer, the composites (photosensitizer/gold/phase transfer reagent) were demonstrated to achieve a higher singlet oxygen generation (SOG). They suggested that the gold nanoparticles could be used to efficiently deliver photosensitizer in photodynamic therapy to improve the cytotoxic efficacy of photosensitizer. However, they just synthesized the photosensitizer-stabilized nanoparticles without PDT experiments. Four years later, the work of the same group is the first report of the use of gold particles for PDT application in vitro [24]. A phthalocyanine derivative was used as the photosensitizer that is present in monomeric form on the gold nanoparticle surface. When GNP covered with phthalocyanine derivative monomeric molecule incubated with HeLa cells, the nanoparticle conjugates are taken up thus delivering the photosensitizer directly into the cell interior. Irradiation of the nanoparticle conjugates laden HeLa cells resulted in a decrease in cell viability to $43 \%$ as compared to the free phthalocyanine and 50\% increases of SOG observed for the phthalocyanine-nanoparticle conjugates as compared to the free photosensitizer. Wang et al. used biocompatible gold nanoparticles as a vehicle to deliver 5-aminolevulinic acid (5-ALA) for a new modality photodynamic therapy, and they demonstrated that tumor cells can be effectively and efficiently destructed by 5-ALA-conjugated nanoparticles, while fibroblasts were minimally damaged [116]. Our group also performed similar research and investigated the influence factor such as wavelength of the PDT efficiency [19]. We found that the different light could induce different results, 


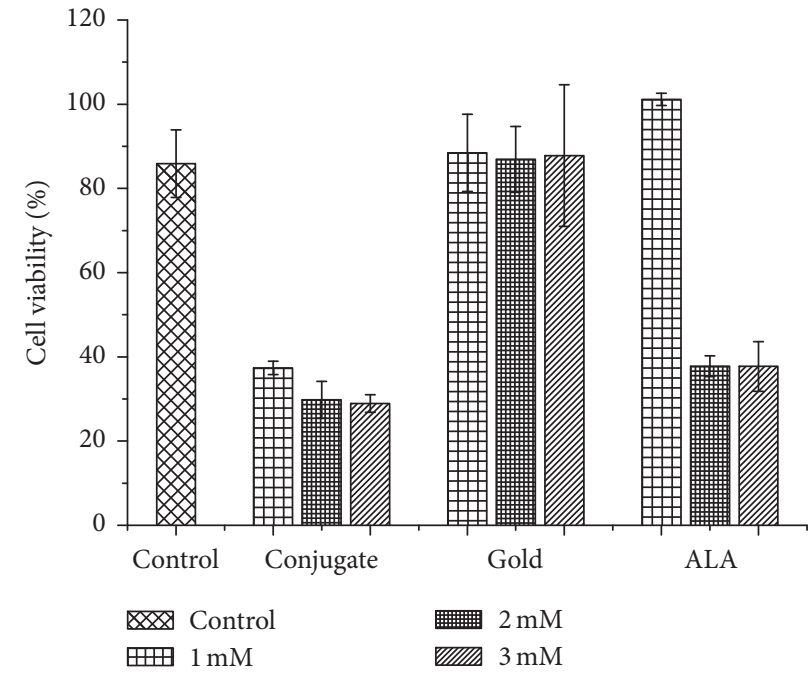

(a)

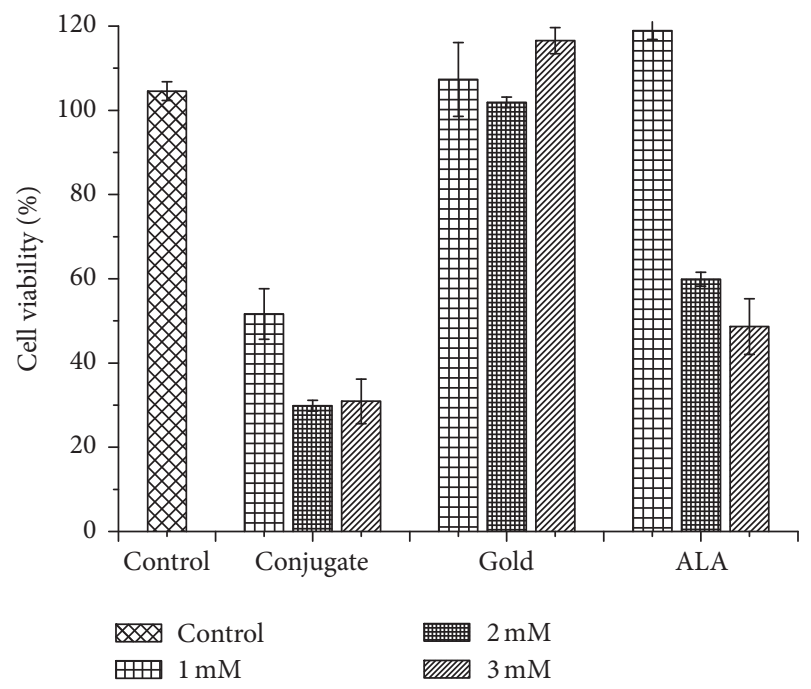

(c)

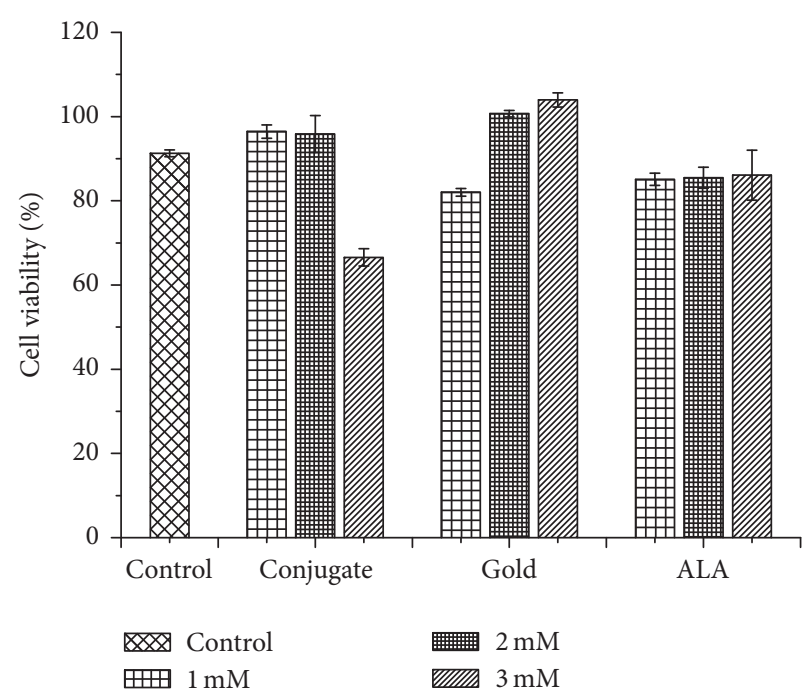

(b)

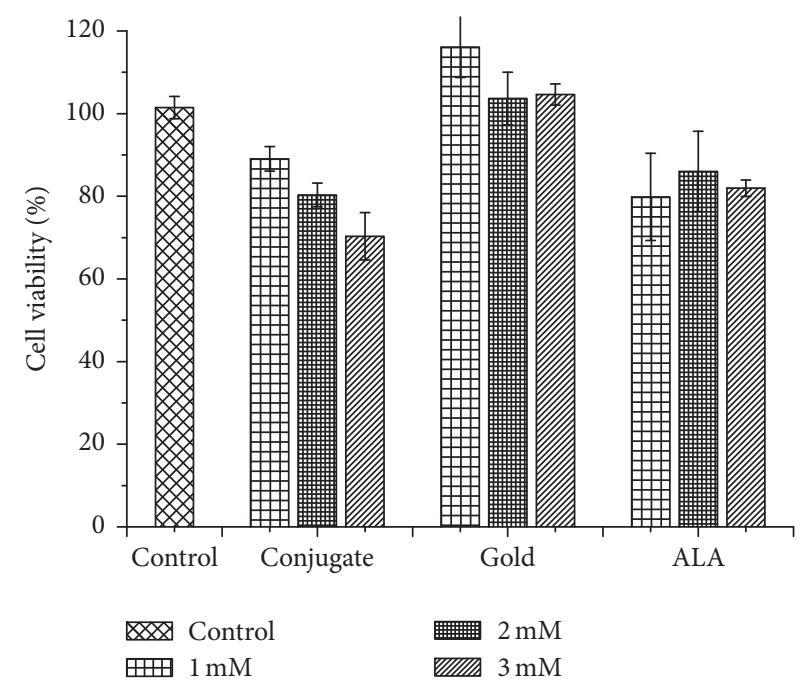

(d)

FIGURE 6: Viability of K562 cell after irradiation of various light sources. CCK-8 assays were performed when incubated $24 \mathrm{~h}$ after irradiation with (a) mercury arc lamp; (b) purple light LED; (c) green light; (d) red light LED. Notes: cell viability of their controls with no drug is also shown. The data are representative of three duplicated experiments. CCK-8, Cell Counting Kit 8; LED, light-emitting diode [19].

but the conjugate of Au-5-ALA could improve cancer cell killing for very light sources (Figure 6).

Subsequently, Cheng et al. synthesized PEGylated gold nanoparticle-silicon phthalocyanine 4 (Pc 4) conjugates, which can be used to deliver hydrophobic drug to its site of PDT action for its water-soluble and biocompatible properties. The drug release experiment results in vitro and in vivo (intravenous injection into mouse's tail) indicate that the delivery of drug is highly efficient (Figure 7), and passive accumulation prefers the tumor site. Compared to conventional PDT drug delivery in vivo, PEGylated GNPs accelerated the Pc 4 administration by about 2 orders of magnitude. The in vivo treatment showed no apparent side effects, except that Pc 4 were found all over the mouse body, including the lung and the kidneys.
After PDT, the tumors became necrotic within 1 week, and then the tumor size shrank, which was due to the effect of the treatment [45].

Following intravenous injection of C11Pc (phthalocyanine derivative) conjugated AuNP in amelanotic melanoma (B78H1 cells) subcutaneously transplanted on mice, another in vivo PDT efficacy was studied by Camerin et al. [117]. The same as the results of Cheng, compared to free Cl1Pc, AuNP-C11Pc conjugates were found to target cancer tissues more selectively. Moreover, it can induce more extensive PDT response by promoting an antiangiogenic response by causing extensive damage to the blood capillaries and the endothelial cells. However, the AuNP-C11Pc conjugates were taken up by liver and spleen, with a prolonged persistence in the liver without any apparent decrease of the PS, for up to a week. In order to limit the accumulation of the nanoparticle 


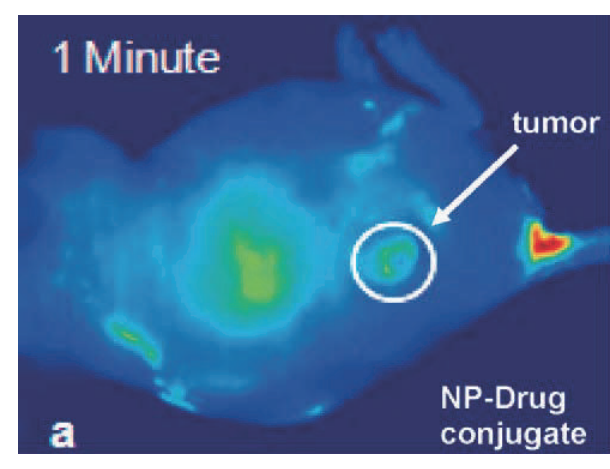

(a)

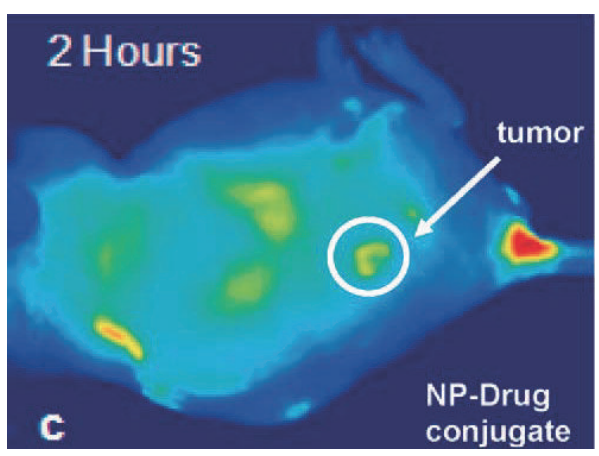

(c)

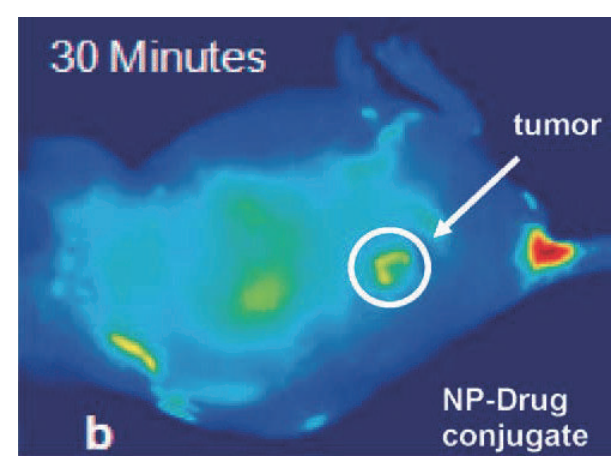

(b)

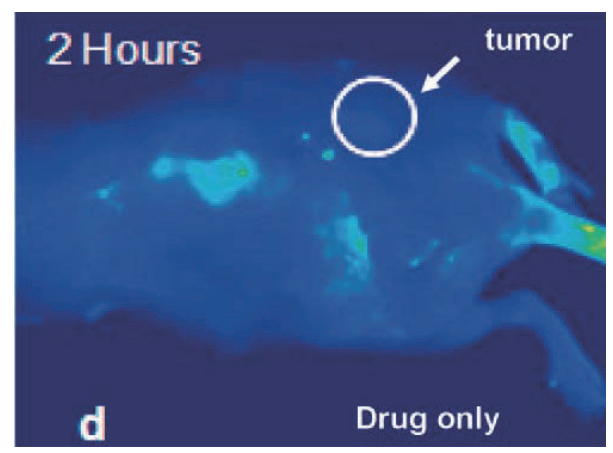

(d)

FIGURE 7: Fluorescence images of a tumor-bearing mouse after being injected with AuNP-Pc 4 conjugates in normal saline $(0.9 \% \mathrm{NaCl}, \mathrm{pH}$ 7.2), (a) $1 \mathrm{~min}$, (b) $30 \mathrm{~min}$, and (c) $120 \mathrm{~min}$ after intravenous tail injection. Any bright signal is due to Pc 4 fluorescence, without which no fluorescence signals were detected from the mouse. (To reduce autofluorescence, the animal was fed a special diet for more than 2 weeks before the experiment.) Unprecedented delivery efficiency and accumulation rate of the drug in the tumor are monitored via the fluorescence increase in the tumor area (white circle). For comparison, a mouse that got only a Pc 4 formulation without the AuNP vector injected is shown in panel (d). No circulation of the drug in the body or into the tumor was detectable $2 \mathrm{~h}$ after injection without the AuNP as drug vector. Reprinted with permission from [45]. Copyright (2008) American Chemical Society.

associated PS in important organs such as liver and spleen, Russell et al. firstly reported targeted delivery of PEGylated AuNP-C11Pc conjugates to breast-cancer cells, by attaching anti-HER2 monoclonal antibodies to the PEG chain (HSPEG-COOH 3000). In vitro experiments demonstrated selective targeting of the 4-component "antibody-C11Pc-PEGAuNPs" conjugate to breast-cancer cells that overexpress HER2 epidermal growth factor receptor and its efficacy in PDT applications, although no in vivo results were presented [118]. Subsequently they also used jacalin to target the cancer cells [119]. They found that there are similar targeted PDT efficacies of the two (jacalin and anti-HER2 antibody) biofunctionalized C11Pc-PEG gold nanoparticles [120]. In the same manner, Savarimuthu et al. used folic acid as mark to target cancer cells and just performed in vitro study, too [121]. Meyers et al. developed a novel approach of targeted PDT using epidermal growth factor peptide-targeted gold nanoparticles (EGF(pep)-GNPs) as delivery carrier [122]. It is demonstrated in in vitro studies that $\mathrm{EGF}$ (pep)-AuNP-Pc 4 can increase localization in early endosomes compared to free Pc 4, resulting in being twofold better at killing tumor cells. Similarly, in vivo studies prove Pc 4 accumulation threefold enhancement in subcutaneous tumors through EGF(pep)GNP-Pc 4 compared to untargeted GNPs. Pc 4 fluorescence test in vivo showed that EGF(pep)-GNP-Pc 4 could decrease the initial uptake by reticuloendothelial system (RES) and increase the amount of GNPs circulation in the blood after intravenous injection, which impacts biodistribution of the GNPs.

Cheng et al. compared covalent and noncovalent attachment of silicon phthalocyanine 4 (SiPc4) on PEGylated AuNP and found that, in contrast to efficient drug release into HeLa cancer cells and efficient PDT of noncovalent adsorption to PS, a covalent thiol bond to the gold nanoparticle leads to slow intracellular release and no PDT effect [123]. Subsequently, they investigated the drug delivery mechanism and pharmacokinetics following intravenous administration of noncovalently bound PEG-SiPc4-AuNP conjugates over a period of 7 days. In vivo experiments revealed that noncovalent attachment of PS to AuNP provided efficient release and penetration of the PEGSiPc4-AuNP conjugate fast and deep into the tumors. It is found that the renal clearance and the hepatobiliary system excrete the drug and GNPs quickly from the body, even if a relatively longer retention time exists for GNPs in body, especially in liver and spleen [46] (Figure 8).

Gamaleia et al. synthesized a conjugate of hematoporphyrin with gold nanoparticles for PDT; they compared the 

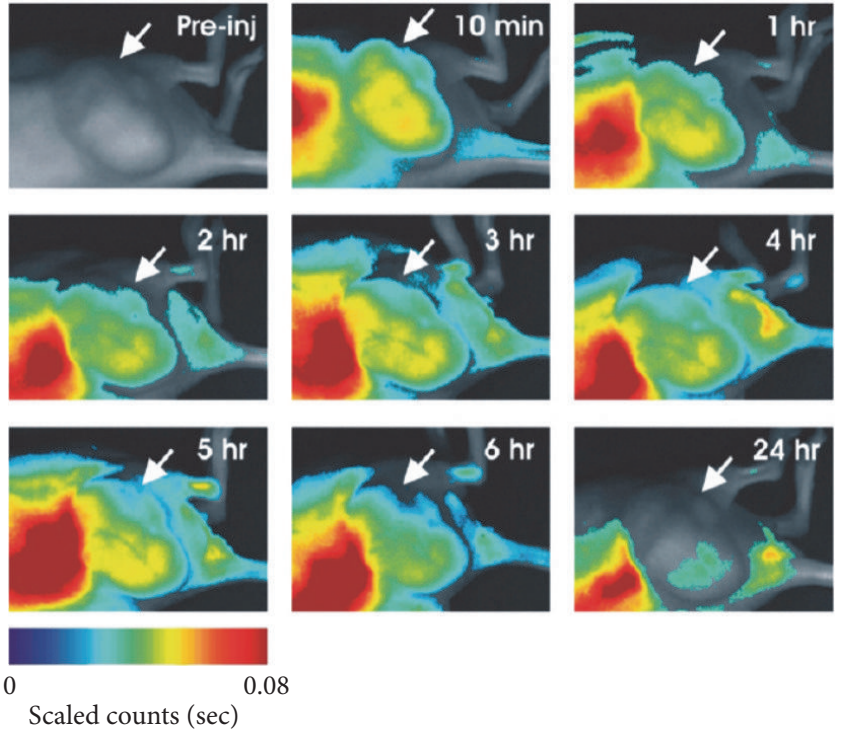

(a)

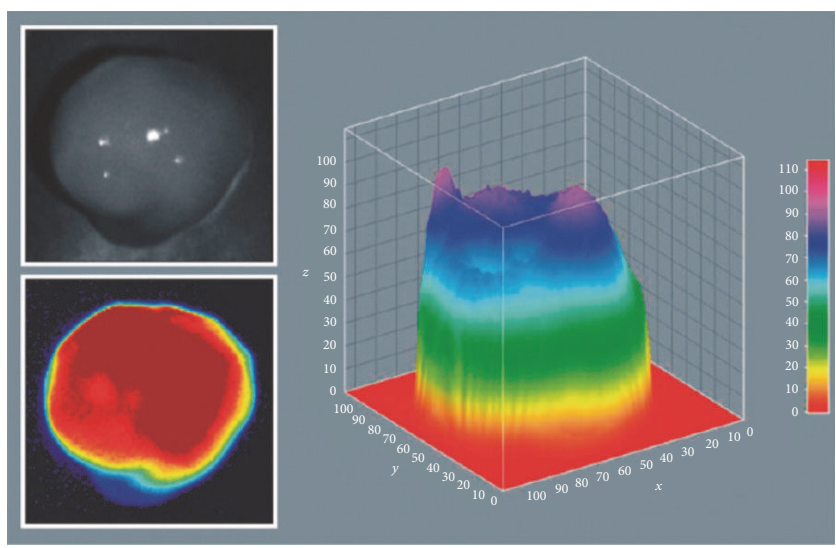

(c)

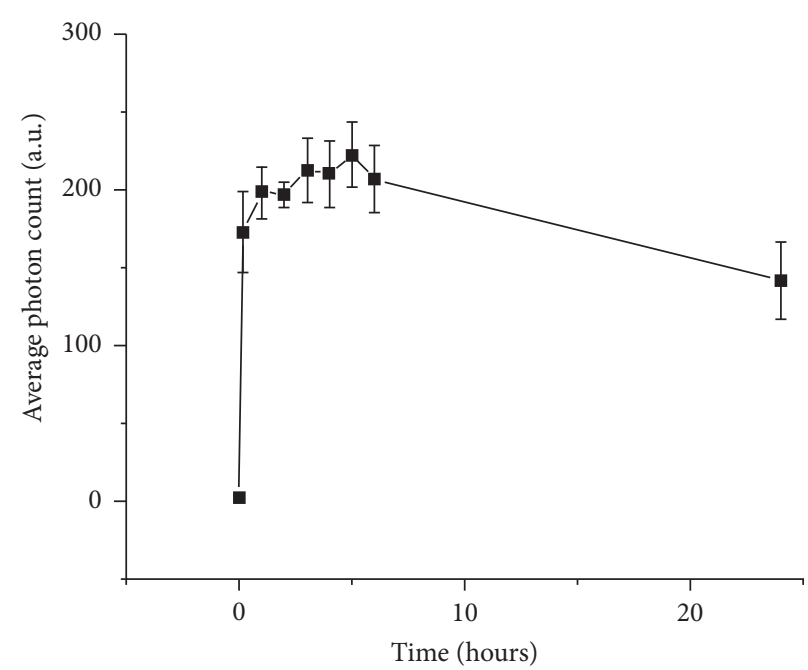

(b)

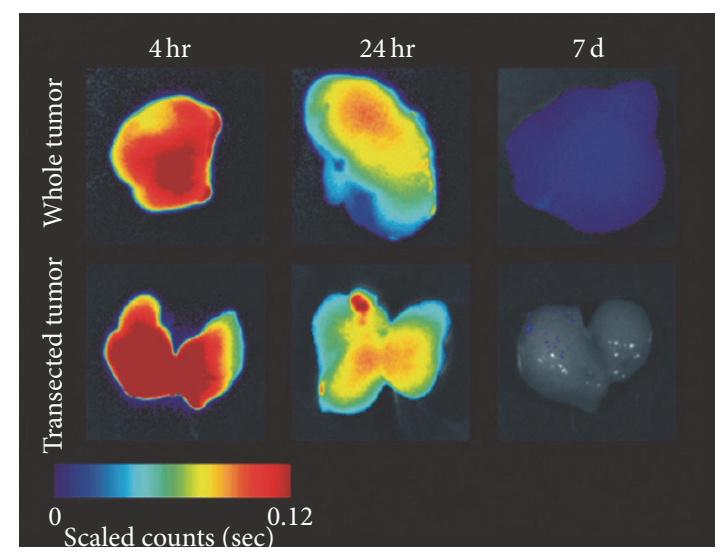

(d)

FIGURE 8: In vivo fluorescence imaging of AuNP-Pc 4 conjugates. Tumor-bearing mice were injected intravenously with AuNP-Pc 4 conjugates at a Pc 4 dosage of $1 \mathrm{mg} \mathrm{kg}-1$ mouse. (a) In vivo fluorescence imaging of a AuNP-Pc 4 conjugate injected mouse at various time points within $24 \mathrm{~h}$. Arrows indicate tumor location. (b) The average fluorescence intensities from the tumor areas of 24 -h postinjection mice $(n=5)$. (c) Picture of the tumor at $4 \mathrm{~h}$ after injection (left) and the corresponding 3D surface plot (right) of pixel intensities (Pc 4 fluorescence) obtained from ImageJ. (d) Comparison of the fluorescence images in whole versus transected tumors at $4 \mathrm{~h}, 24 \mathrm{~h}$, and 7 days after injection. Reprinted with permission from [46]. Copyright (2011) American Chemical Society.

PDT efficiency in vitro of hematoporphyrin-gold nanocomposites with different diameter. Because the bigger the particles are, the more the porphyrin molecules can be transported into malignant cells, their results indicate a better operation of the nanostructure with GNPs of $45 \mathrm{~nm}$ compared to that of $15 \mathrm{~nm}$ [115]. Wang et al. and our group had similar conclusion about the gold nanoparticle size $[28,124]$. In the report of Wang's group, it said that the enhanced generation of ROS from PpIX by GNPs was size-dependent. GNPs with larger size have stronger ability to elevate the ROS generation of photosensitizer because of the stronger scattering EM field around the particles compared to those with smaller size. However, the cellular PDT efficacies were dependent on not only ROS generations but also the size-dependent cellular uptake of AuNPs [124]. Our group has simulated the local electric magnetic field enhancement around a single GNP coated by photosensitizer with a static sphere-shell model and found this enhancing effect of ROS generation by GNP depended not only on the size of GNP but also on the wavelength of the exciting light [28].

The studies have shown that both photothermal and photodynamic therapy are very useful for cancer treatment; the strategy of combining them into a single treatment modality was considered to have better cell killing efficacy. Kah et al. combined PTT and PDT using anti-EGFR conjugated gold nanoshells (absorption spectrum shows a rather broad extinction band of wavelength $>580 \mathrm{~nm}$ ) and hypericin (peak absorbance at $595 \mathrm{~nm}$ ) excited by a $100 \times 50 \mathrm{~cm}$ light with a wide band illumination above $585 \mathrm{~nm}$. Their in vitro experiment results showed that the combination of 


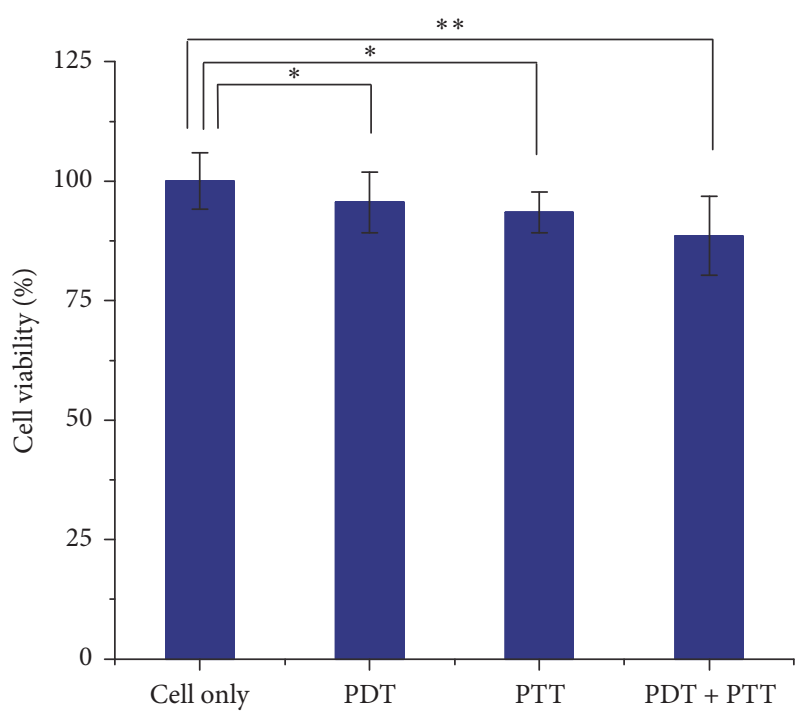

(a)

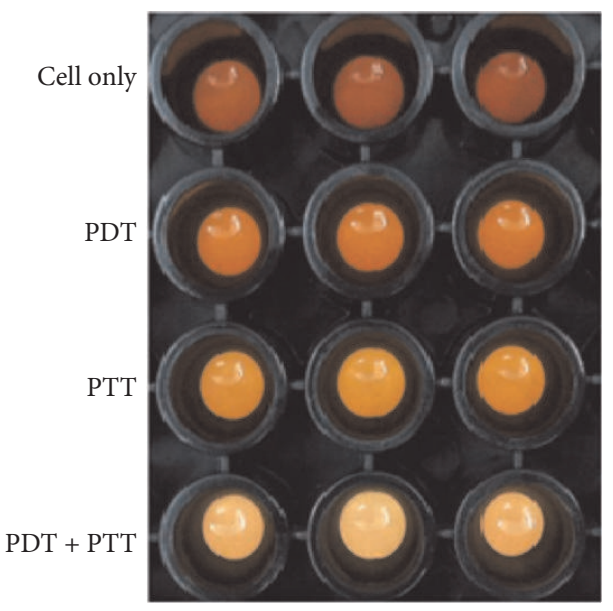

(b)

FIGURE 9: Cell viability data (a) and imaging (b) of CCRF-CEM cells incubated with Ce6-ASP-T32-NRs without light irradiation (cells only) and under white light irradiation (PDT) and under $812 \mathrm{~nm}$ laser irradiation (PTT) and PDTtPTT, respectively. Cells, 200k/sample; probes, $0.2 \mathrm{nM}$. $p$ values were calculated by Student's $t$-test: ${ }^{*} p<0.05,{ }^{* *} p<0.0001$, and $n=3$. Reprinted with permission from [47]. Copyright (2012) American Chemical Society.

PDT and PTT strategy exhibited more effective treatment versus conventional PDT or emerging PTT treatment [125]. However, development of multifunctional AuNP offering synergistic therapeutic approaches, such as photothermal therapy and PDT, has been a topic of interest in the field of nanotechnology [38].

Kuo et al. firstly used gold nanorods to simultaneously destroy and image A549 malignant cells; there GNRs served not only as PTT and PDT but also as optical contrast agents [126]. In their work, A549 cancer cells treated with the conjugants of GNRs and photosensitizer (indocyanine green ICG) were irradiated by $808 \mathrm{~nm}$ infrared laser to implement PDT and hyperthermia. The results showed that combination strategy killed cancer cells efficiently as compared to PDT or PTT alone. Subsequently, they demonstrated that both gold nanoparticles and gold nanorods conjugated with indocyanine green could accomplish dual-modality PDT and PTT [127]. Other groups also demonstrated the synergistic influence of hyperthermia on PDT with different light, different photosensitizer, different gold nanostructure, and different cell lines [128-131]. Differently, Gao et al. synthesized a new nanostructure using lipid-loaded hypocrellin B (HB) to coated gold nanocages. The assembly of photosensitizer and photothermal agent was irradiated with $790 \mathrm{~nm}$ NIR laser by two-photon techniques, which induces one-off administration and irradiation for antitumor treatment [132]. Similarly, Wang et al. designed chlorin e6- (Ce6-) aptamer switch probe- (ASP-) gold nanorods (AuNRs) composites for multimodal cancer therapy. In their study, as the composites come into contact with target cancer cells, Ce6 molecules migrate away from the gold surface by structural change of ASP, thereby generating singlet oxygen under light irradiation for PDT. At the same time, GNRs can also kill cells through
PTT modality for their high absorption efficiencies (Figure 9) [47]. Wang et al. also have designed a Ce6-pHLIPss-GNR conjugate with ( $\mathrm{PH}$ value) $\mathrm{pH}_{\mathrm{e}}$-driven targeting ability for synergistic PDT/PTT [133].

In vivo study should be performed before clinical trials were initiated. Jang et al. demonstrated a 95\% reduction in tumor growth in vivo using a GNR AlPcS4 composite exposure to 810 and $670 \mathrm{~nm}$ lasers irradiation [25]. They found that tumor sites could be clearly identified as early as one hour after intravenous injection of the GNR-AlPcS4 composite in in vivo near-infrared fluorescence imaging studies. The tumor-to-background ratio changed with time and was 3.7 at 24 hours; there was a $79 \%$ decrease in tumor growth with PDT alone and 95\% decrease with dual PPT and PDT (Figure 10). Khlebtsov et al. developed nanocomposite containing a gold-silver nanocage core and a mesoporous silica shell modified with the photosensitizer (Yb-2,4-dimethoxyhematoporphyrin, Yb-Hp) for in vivo PDT studies. The synthesized composite nanoparticles generated singlet oxygen under excitation at $630 \mathrm{~nm}$ and induced hyperthermia upon light irradiation at the plasmon resonance wavelength $(750-800 \mathrm{~nm})$ [134]. Wang et al. used a GNR rose-bengal $(\mathrm{Rb})$ complex to implement in vivo PDT and PTT of oral cancer with $532 \mathrm{~nm}$ and $810 \mathrm{~nm}$ irradiation [32].

In further research, Lin et al. have developed a novel multifunctional theranostic platform for cancer treatment and imaging, in which a monolayer of assembled GNPs were as vesicles to be loaded with Ce6 photosensitizer. The gold vesicles have a strong absorption at wavelength $650-800 \mathrm{~nm}$, so the neighboring GNPs in the vesicular membranes can plasmonically couple with each other. This enables excitation of both gold vesicles and Ce6 with $671 \mathrm{~nm}$ laser irradiation 

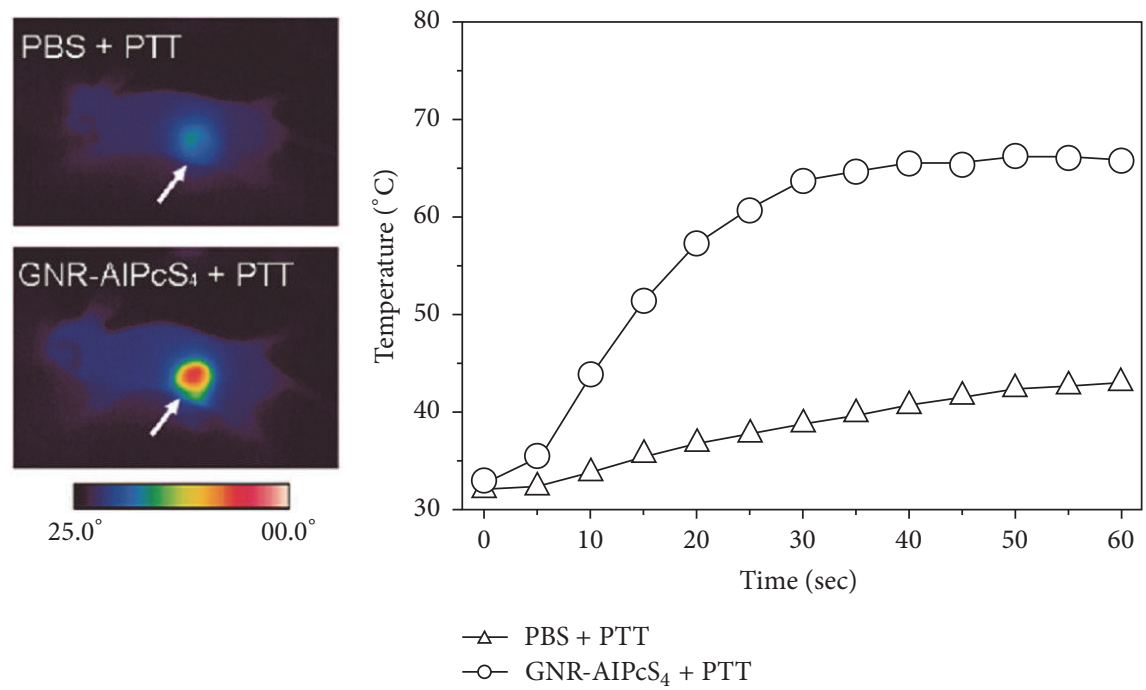

(a)
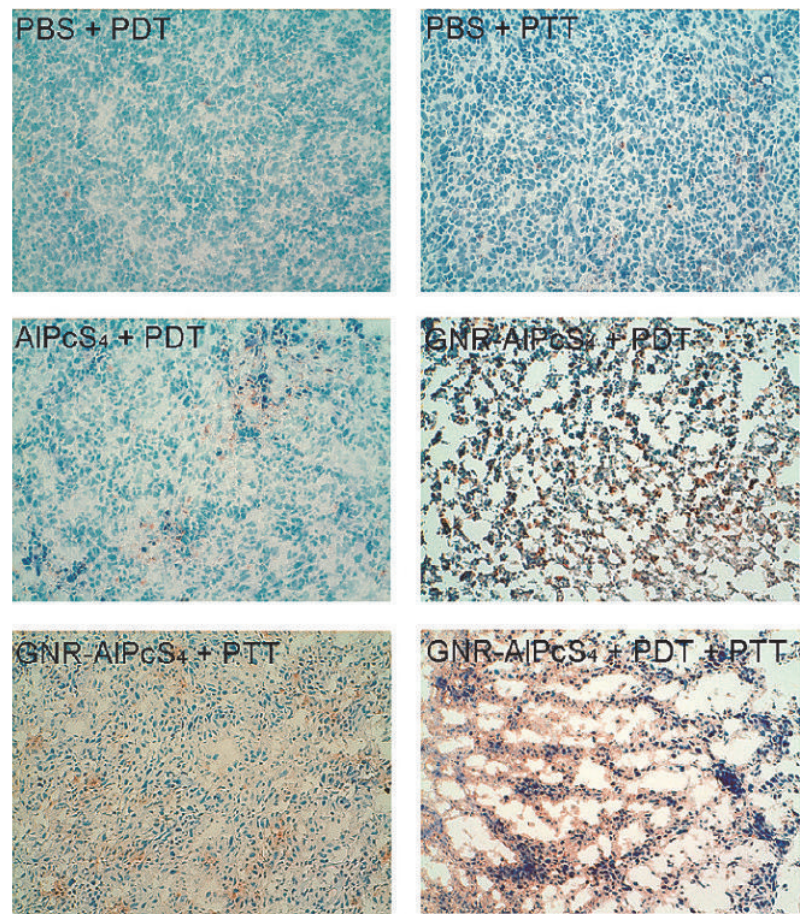

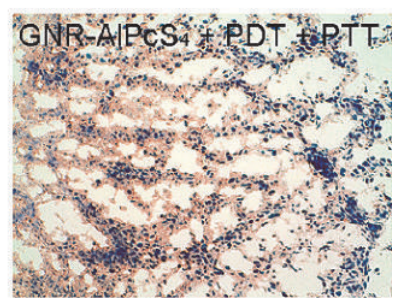

(b)

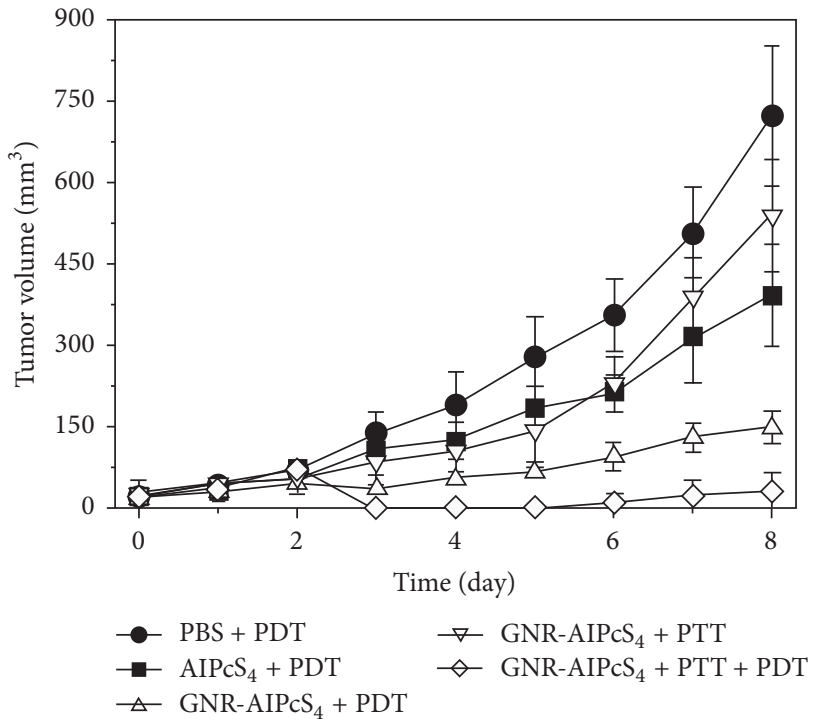

(c)

FIGURE 10: In vivo PDT and PTT. (a) Thermographic images captured after 1 min of light illumination and thermographic monitoring in the tumors of GNR-AlPcS4-injected and PBS-injected mice. (b) TUNEL staining of the tissue sections (magnification $\times 20$ ). Normal or apoptotic cell nuclei are shown in green and brown, respectively. Empty areas in the tissue sections (GNR-AlPcS4 complex t PDT and GNR-AlPcS4 complex t PTT t PDT) are due to washout of the destroyed tumor cells during the staining procedure. (c) Tumor size after each therapy session. Points, mean; bars, standard deviation; PBS t PDT $(n=7)$; free AlPcS4 t PDT $(n=7)$; GNR-AlPcS4 complex t PDT $(n=7)$; GNR-AlPcS4 complex t PTT $(n=5)$; GNR-AlPcS4 complex t PTT t PDT $(n=7) ; n=$ number of tumors involved. Reprinted with permission from [25]. Copyright \{2011\} American Chemical Society [25].

to generate hyperthermia and singlet oxygen for cancer cells killing. Both in vitro and in vivo therapeutic results demonstrated that the treatment efficiency of GV-Ce6 was improved versus that of either individual PTT or PDT alone, or the sum of PTT/PDT owing to the coordinated effect [135]. However, Wang et al. have constructed gold
nanoshell-PEG-Ce6 for combined PDT/PTT with single CW laser excitation both in vitro and in vivo [136]. Terentyuk et al. used $\mathrm{GNR} / \mathrm{SiO}_{2}-\mathrm{HP}$ (hematoporphyrin) complex to implement synergistic PDT + PTT treatments of large (about $3 \mathrm{~cm}^{3}$ ) solid tumors in vivo for the first time. Large area tumor necrosis occurred and tumor volumes decreased 


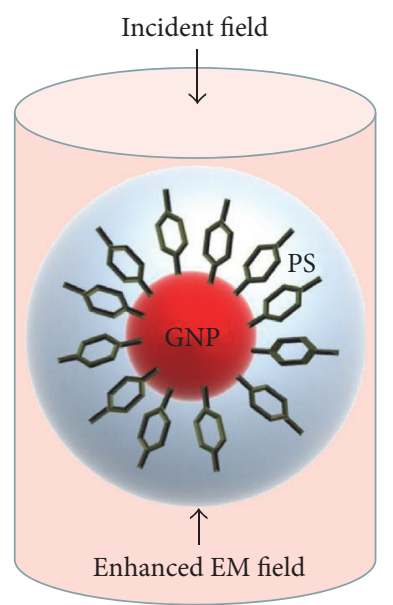

(a)

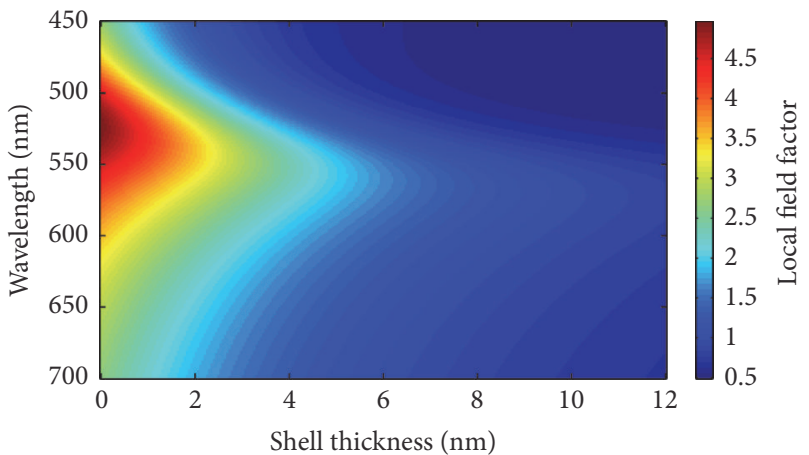

(b)

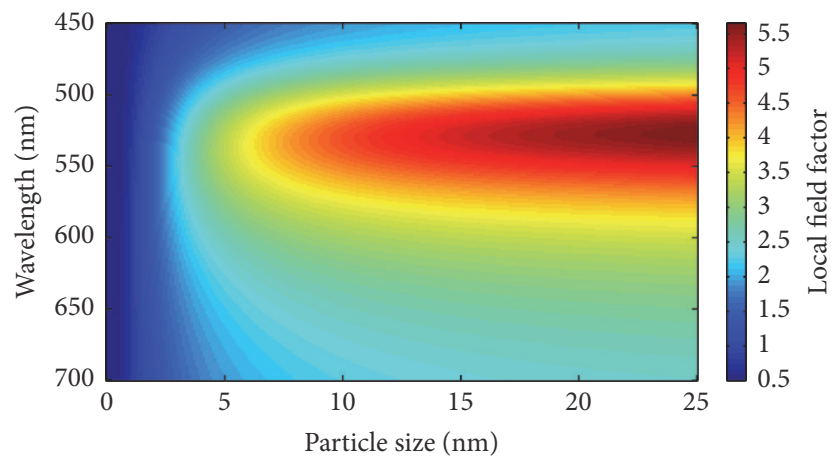

(c)

Figure 11: Static sphere-shell model shows that photosensitizer-coated GNP generates a local enhanced EM field upon irradiation. (a) The calculated local field enhancing factor changes with excitation wavelength and photosensitizer shell thickness (b) and GNP size (c) [28].

dramatically with coordinated PDT + PTT therapy comparing with PDT alone [137]. Using similar method, Vankayala et al. demonstrated that gold nanoshells can actually mediate the bimodal PDT and PTT effects in vivo at ultralow doses (about $150 \mathrm{~mW} / \mathrm{cm}^{2}$ ) of NIR light [30]. From then on, much work has been done to improve the efficacy of photodynamic therapy in vitro and in vivo. Vijayaraghavan employed novel multibranched gold nanoechinus as agent to conduct dual modal PDT and PTT upon NIR light irradiation in the second biological window (1000-1350 nm) [138]. Recently, Yu et al. reported a HAuNS-pHLIP-Ce6 antitumor platform, where hollow gold nanospheres (HAuNS) were synthesized to shift localized surface plasmon resonance (LSPR) peak, and then the $\mathrm{pH}$ insertion peptide ( $\mathrm{pHLIP}$ ) and Chlorin e6 (Ce6) were adhered to HAuNS by absorption. The antitumor complex can reach tumor site for the $\mathrm{PH}$-diriven ability of $\mathrm{pHLIP}$. After irradiation, the HAuNS was heated to result in PTT, and at the same time Ce6 was released from gold sphere and generated reactive oxygen species (ROS). Herein, HAuNS performed PTT and PDT synchronously [139].

In spite of the photothermal effect, with SPR resonant excitation, an enhanced electromagnetic (EM) field can be generated at the surface of GNPs [140]. There were some reports that demonstrated that the SOG species $\left(1 \mathrm{O}^{2}\right)$ and particularly ROS by the excited photosensitizer (PS) can be elevated by the GNP enhanced EM and increase the treatment efficiency of photodynamic therapy [124, 141]. Oo et al. first found this phenomenon when they used GNP as vehicle to transport a photosensitizer PpIX [116]. Our group also reported the same experimental results using GNPs to deliver 5-aminolevulinic acid (5-ALA) [19]. And, in a subsequent report of Wang's group, it said that the enhanced generation of ROS from PpIX by GNPs was size-dependent [124]. GNPs with larger size have stronger ability to enhance the ROS generation of photosensitizer because of the stronger scattering EM field around the particles compared to those with smaller size. Our group had similar result by simulating the local enhanced electric magnetic field around a single GNP coated by photosensitizer (Figure 11) [28]. Therefore, using GNPs as the carrier can both improve the cell uptake and the ROS generation of photosensitizers and enhance the treatment efficacy of PDT.

Beside the ability to elevate the ROS generation of photosensitizer, previously in 2011, it was also observed that GNP itself can also generate signlet oxygen under irradiation at LSPR absorption bands of GVPs [142]. Pasparakis demonstrated the SOG with naked GNPs in aqueous media upon CW and pulsed laser irradiation and proposed two possible mechanisms. One is a plasmon-activated pathway, in which the plasmons and hot electrons interact with 
molecular oxygen; the other one is indirect photothermal pathway-when the GNPs were powerfully irradiated with pulsed laser, inducing extreme heat to fragment particles and increase thermionic electron emission [143]. Then Hwang's group systematically analyzed the photosensitization and SOG by gold and silver nanoparticles and found it was highly morphology dependent [144]. They declared that singlet $\mathrm{O}^{2}$ can be photosensitized and generated upon irradiation on gold nanostructures with an $\mathrm{Au}(110)$ surface, instead of the $\mathrm{Au}(111)$ and $\mathrm{Au}(100)$ surfaces. The special designed GNP can act as a photosensitizer in PDT.

In contrast to the conventional organic dyes, GNP photosensitizer possesses 4-6 orders higher extinction coefficient and is much more resistant to both enzymatic and photochemical degradation [145]. It means that a much smaller amount of GNP photosensitizers is required to be taken up by cancer cells in order to get to the threshold concentration for effective PDT treatment. Moreover, Xu's group demonstrated that gold nanorods exhibited high SOG efficacy under two-photon excitation [146], which means GNP can also be applied as the photosensitizer in twophoton photodynamic therapy (TP-PDT). Therefore, with the addition of the photothermal effect, GNP is not just a drug delivery vector, but also it can be an excellent and promising dual functional photomedicine itself.

2.3. Gold Nanoparticle-Aided Radiotherapy. Radiotherapy is the use of X-rays and similar rays (such as $\gamma$ rays, electron beams, and protons) and so forth with high-energy to treat disease. It works by destroying cancer cells in the area that is treated, thus slowing down or even prohibiting the growth of a tumor. Similar to PTT and PDT, X-ray radiotherapy is a method for specific treatment that only affects the irradiated area. However, the X-ray used for radiotherapy offers much deeper penetration than the NIR light used to trigger PTT and PDT.

The main challenge of X-ray radiotherapy is the lack of selectivity, which means that radiation therapy usually destroys not only cancer tissue but also normal tissue for its unlocal control of the primary tumor. In contrast to normal radiation therapy, radiosensitizer-aided radiation therapy can enhance tumor harm efficiency because radiosensitizing adjuvants can improve the dose specifically absorbed by tumor tissue [147]. For this goal, various types of radiosensitizers have been developed [148]. Particularly, gold nanomaterials have been demonstrated as radiosensitizers for X-ray radiotherapy for their high density, large energy absorption coefficient, and low toxicity $[149,150]$. Hainfeld et al. first demonstrated the enhancement of X-ray radiotherapy with $1.9 \mathrm{~nm}$ gold clusters [48]. A high dose of gold clusters $(2.7 \mathrm{~g}$ of $\mathrm{Au} / \mathrm{kg}$ of mice body weight) was intravenously injected into tumor-bearing mice before therapeutic treatment. The experimental results indicate that the mice treated with gold nanoparticles and X-ray irradiation lead to a one-year survival of $86 \%$ in contrast to $20 \%$ with only X-rays or gold nanoparticles alone (Figure 12). After treatment, the small gold nanoparticles could be readily cleared through the kidney, minimizing the potential side effects due to gold

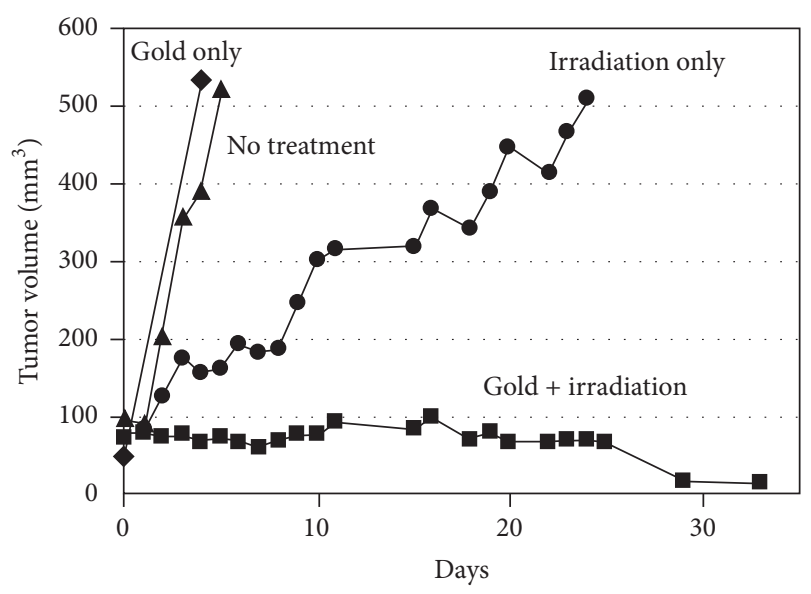

FIgURE 12: Average tumor volume after the following: (a) no treatment (triangles, $n=12$ ); (b) gold only (diamonds, $n=4$ ); (c) irradiation only ( $30 \mathrm{~Gy}, 250 \mathrm{kVp}$, circles, and $n=11)$; (d) intravenous gold injection $(1.35 \mathrm{~g} \mathrm{Au} / \mathrm{kg})$ followed by irradiation (squares, $n=10$ ) [48]. (C) Institute of Physics and Engineering in Medicine. Reproduced by permission of IOP Publishing and the authors. All rights reserved.

accumulation inside the body. Furthermore, GNPs can improve the contrast of the X-ray unit mammography through imaging the gold distribution in the tumor (Figure 13), which could be used to diagnose tumor earlier. Subsequently, similar results were reported by Chien et al., who used $20 \mathrm{~nm}$ gold nanoparticles as radiosensitizers for $\mathrm{X}$-ray radiotherapy [151]. In Chang et al.'s in vivo research, GNPs accumulation was observed inside cancer cells, which induced efficiency enhancement of ionizing radiation, cancer cell apoptosis, tumor growth inhibition, and a high chance survival of tumor-bearing mice [152]. Similar efficiency enhancement of cancer cell killing has been demonstrated in neck and head squamous cell carcinoma [153] and prostate cancer [154].

For gold nanoparticles-based radiosensitizers, modifying the surfaces with a cell targeting ligand can greatly improve the cellular uptake and thereby the treatment efficiency. Xing et al. functionalized the surface of $10.8 \mathrm{~nm}$ GNPs with thioglucose (Glu) to increase their uptake by a breast-cancer cell line (MCF-7). A benign breast-cancer cell line (MCF$10 \mathrm{~A})$ was used as a control in their study. It is demonstrated that functional Glu-GNPs uptake by tumor cells is far more than naked GNPs through transmission electron microscopy (TEM) imaging. And the radiotherapy results showed that the killing of MCF-7 cells in the presence of Glu-conjugated GNPs was enhanced relative to the MCF-10A cells. This observation indicates that the Glu-gold nanoparticles only entered the malignant cancer cells and enhanced their radiation sensitivity, rather than the benign cells, which can be potentially used to achieve targeted cancer treatment [155]. Similar targeted radio enhancement has been shown by Geng et al. in ovarian cancer and cervical cancer [141, 156]. Although glioma cells and brain tumors are kept from the circulation by the blood-brain barrier, they can be targeted and effectively radiosensitized by PEGylated 


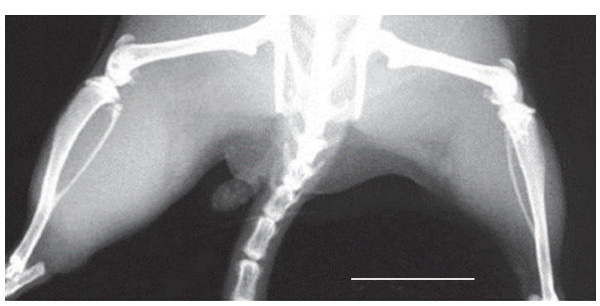

(a)

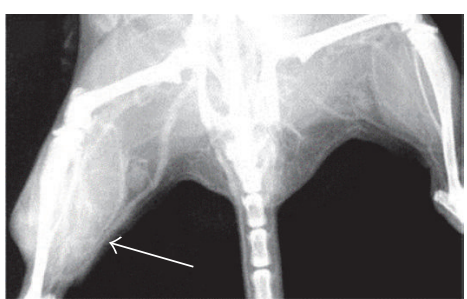

(b)

FIGURE 13: Radiographs of mouse hind legs before and after gold nanoparticle injection. (a) Before injection. (b) 2 min after i.v. gold injection $(2.7 \mathrm{~g} \mathrm{Au} / \mathrm{kg}$ ). Significant contrast (white) from the gold is seen in the leg with the tumor (arrow) compared with the normal contralateral leg. $6 \mathrm{~s}$ exposures at $22 \mathrm{kVp}$ and $40 \mathrm{~mA} \mathrm{~s}$. Bar $=1 \mathrm{~cm}$ [48]. () Institute of Physics and Engineering in Medicine. Reproduced by permission of IOP Publishing and the authors. All rights reserved.

gold nanoparticles, inducing DNA damage enhancement, cancer cell eradication, and survival improvement [147]. Now, radiotherapy with modified gold nanoparticles by targeting molecules such as glucose, folate, cisplatin, peptides, antiEGFR, and thioglucose and combination with imaging and other therapy are the tendency [141, 157-163]

Moreover, Polf et al. found that killing of GNPs laden prostate cancer cells was enhanced by about $15 \%-20 \%$ by proton beam radiotherapy compared to that of cancer cells alone [164]. Khoshgard et al. treated HeLa tumor cells with various common low energy levels of orthovoltage X-rays and megavoltage gamma-rays (Co-60) to study the cell killing efficacy in the presence of folate modified GNPs and nonfunctionalized GNPs. With the same dose enhancement factor, there existed enormous distinction among different experimental groups with and without folate modification from their study. For both of the GNPs, researchers got the maximum dose enhancement factor with the $180 \mathrm{kVp}$ X-ray beam. Many cancer cells are often folate receptor positive, so folate modified GNPs are very useful for cancer cell killing enhancement of orthovoltage X-ray energies in superficial radiotherapy techniques [157].

As discussed above, many groups have investigated the gold nanoparticle radiosensitization (GNP-RS), and much work was focused on the experimental phenomena instead of sensitization mechanisms, so the mechanism still remains unclear. It was normally considered that photoelectric photon absorption by high-Z materials at kilovoltage photon energies can be enhanced through GNP-RS. However, in clinical use megavoltage energies are employed, which induced no prediction of the therapeutic effect by this physical mechanism [60]. In order to introduce this new technology into clinic and optimize the effect, it would be important to know the effect of GNP concentration and size and distance from target and surface coating on GNP-aided radiosensitization. Normally, Monte Carlo calculation was used to predict the arguments. In Geng et al's research, they found that GNPs-mediated radiotherapy can elevate therapeutic efficiency of ovarian cancer, in which levels of ROS production enhancement were observed by the interaction of X-ray radiation with GNPs [156]. Some group described the physics and potential underlying biological mechanisms that occur in GNP-mediated radiotherapy in detail $[165,166]$.
2.4. Targeted Delivery Systems Based on Gold Nanoparticles. Although gold nanoparticles themselves could be used as a kind of therapeutic agents to destroy tumor cells, they can also be employed to trigger drug release in controlled drug release system. In this system, gold nanoparticles were incorporated in different materials to fabricate nanostructures for targeted drug delivery, for example, thermal-sensitive microcapsules, hydrogels, and films [167-171]. When the nanostructures arrive at the target area, upon the irradiation of a light within their LSPR region gold nanoparticles generate heat and lead to the destruction of the nanostructure, and finally drugs will be released from the nanostructure [172-174]. There are four major scenarios for the fabrication of targeted drug delivery nanostructures using photothermal effect of gold nanoparticles [49]: first one: the drug is inserted in a polymeric matrix surrounded by gold nanoparticles. When exposed to light irradiation within their LSPR spectrum, gold nanoparticles would generate heat. The generated heat destroys the structure of the polymer to trigger the drug release. Second one: drug and gold nanoparticles are decorated in liposomes; the converted heat destroys the liposomes, allowing for the drug release. Third one: the drug is covalently bonded to a spacer molecule which is bound to the gold nanoparticles, and heat breaks the bond, inducing the drug liberation. The last one: the drug is not covalently bound to the gold nanoparticles usually through inserting the drug in a silica matrix. The heat triggers the drug release (as shown in Figure 14). Kwon and coworkers [173] constructed gold cluster modified thermosensitive liposomes (G-TSL) that could be triggered for DOX delivery and liberation in the tumor microenvironment upon external near-infrared (NIR) irradiation. It is found the DOX release from DOX/G-TSL was improved $70 \%$ upon NIR irradiation in contrast with TSL alone. Sierpe and coworkers reported a ternary system, in which $1: 1 \beta$-cyclodextrin-phenylethylamine ( $\beta$ CD-PhEA) encapsulated composites were synthesized, and then the composite was bounded by GNPs [174].

The photothermal effect of gold nanoparticles enables the guest PhEA release effectively under continuous laser exposure. The photothermal effect of gold nanoparticles makes it a good choice for targeted drug delivery.

The targeted delivery systems based on gold nanostructured platforms to facilitate the tumor detection and 


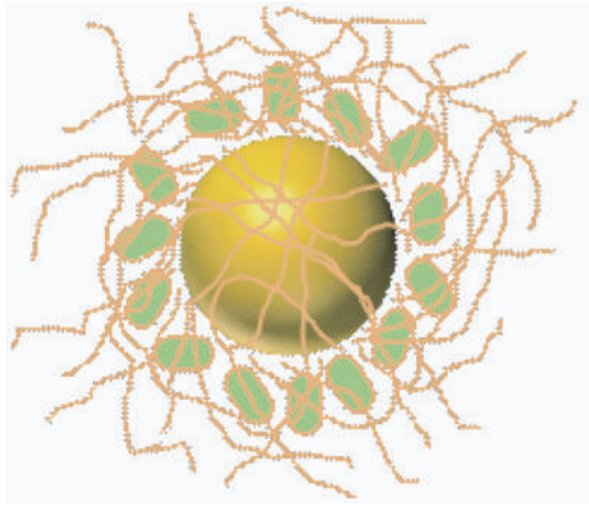

(a)

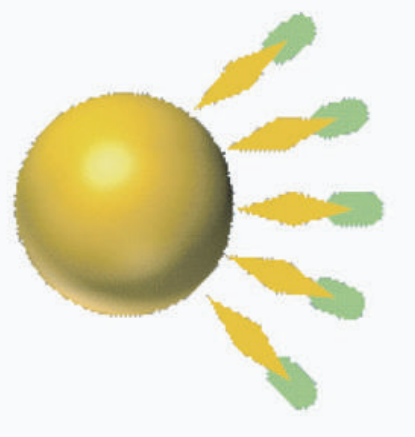

(c)

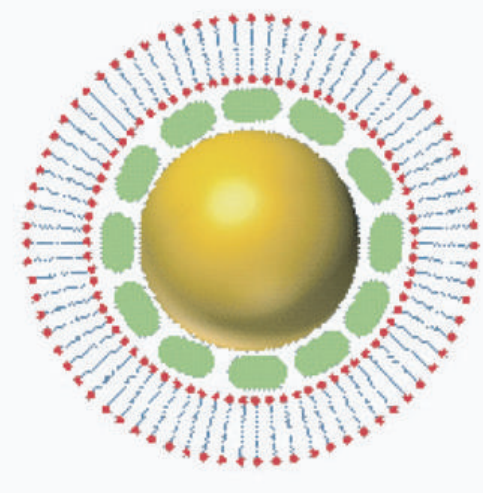

(b)

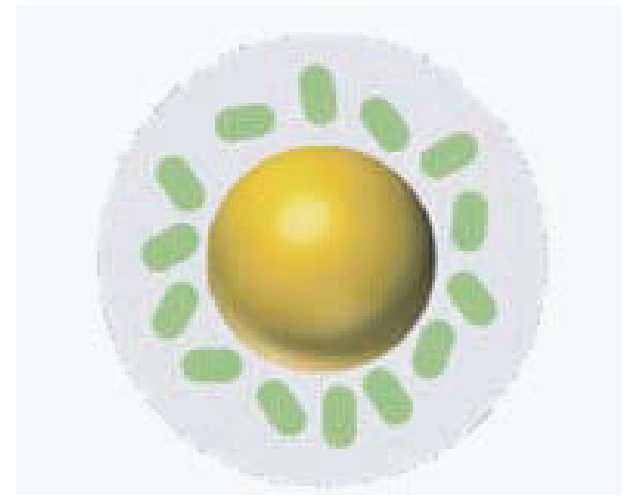

(d)

Figure 14: Four scenarios for trigger drug delivery using the photothermal effect. (a) The drug (green capsules) is embedded in a polymeric matrix surrounding the nanoparticle. (b) The drug and the nanoparticle are embedded in liposomes. (c) The drug is covalently bonded to a spacer molecule (yellow diamonds), which is bound to the nanoparticle. (d) The drug is not covalently bound to the AuNPs [49].

therapy is an important research field. Tumors of poor lymphatic drainage and abnormal vessel development can promote nanoparticles accumulation inside them through the enhanced permeability and retention effect (EPR effect), which is the traditional tumor targeting strategy and known as passive targeting [175]. Therefore, many researchers have studied on the synthesis of polymeric gold nanoparticulate formulations to deliver different cytotoxic agents, photosensitizer, and so on. For example, Coelho and coworkers developed a drug delivery platform based on colloidal PEGylated gold nanoparticles (PEG-AuNPs) conjugated with the tyrosine kinase inhibitor Afatinib which can passively target tumor [176]. The results demonstrate that the nanoparticulate formulation has an excellent anticancer therapy response while having lower side effects compared to conventional Afatinib. The paclitaxel-loaded hybrid drug delivery system containing GNP and liposome were synthesized with a simple and easy preparation by Zhang and collaborators, exhibiting more accurate site and time release mode for cancer therapy using antitumor chemical therapeutic agents [177]. The significant antitumor effects were demonstrated in this work. Xu et al. developed 5-aminolevulinic acid- (5-ALA) GNPs to enhance the efficiency of PDT. The results show greater cytotoxicity induced by PDT [19].
However, it has been widely accepted that the side effects of cytotoxic agents particularly cannot be controlled by passive targeting strategy [178]. Therefore, active targeting delivery strategy is put forward that gold nanocarrier conjugated with high-affinity specific ligands, which can selectively accumulate at the target site. Common specific ligands include folic acid, carbohydrates, peptides, proteins, antibodies, antibody fragments, and aptamers (Figure 15) [50].

Folic acid receptor has been found overexpressed in many types of tumor, such as breast carcinoma, ovary carcinoma, lung cancer, nasopharynx cancer, throat cancer, colon cancer, cerebral cancer, uterine sarcoma and osteosarcoma, the chronic and acute myelogenous leukemias, and the non-Hodgkin's lymphomas [179-181]. Therefore, folate is widely used as a targeting ligand which specifically binds to folate receptors on the tumor cell surface and internalized by the cancer cells. Gold nanoparticles loaded by different cytotoxic agents or photosensitizer conjugated with folate have been developed by many researchers, enhancing cancer cell accumulation of drug, improving the cytotoxicity of the anticancer agents overcoming anticancer drug resistance [182-184]. The glucocorticoid responsive genes, a specific category of "endogenous" genes, upregulate 


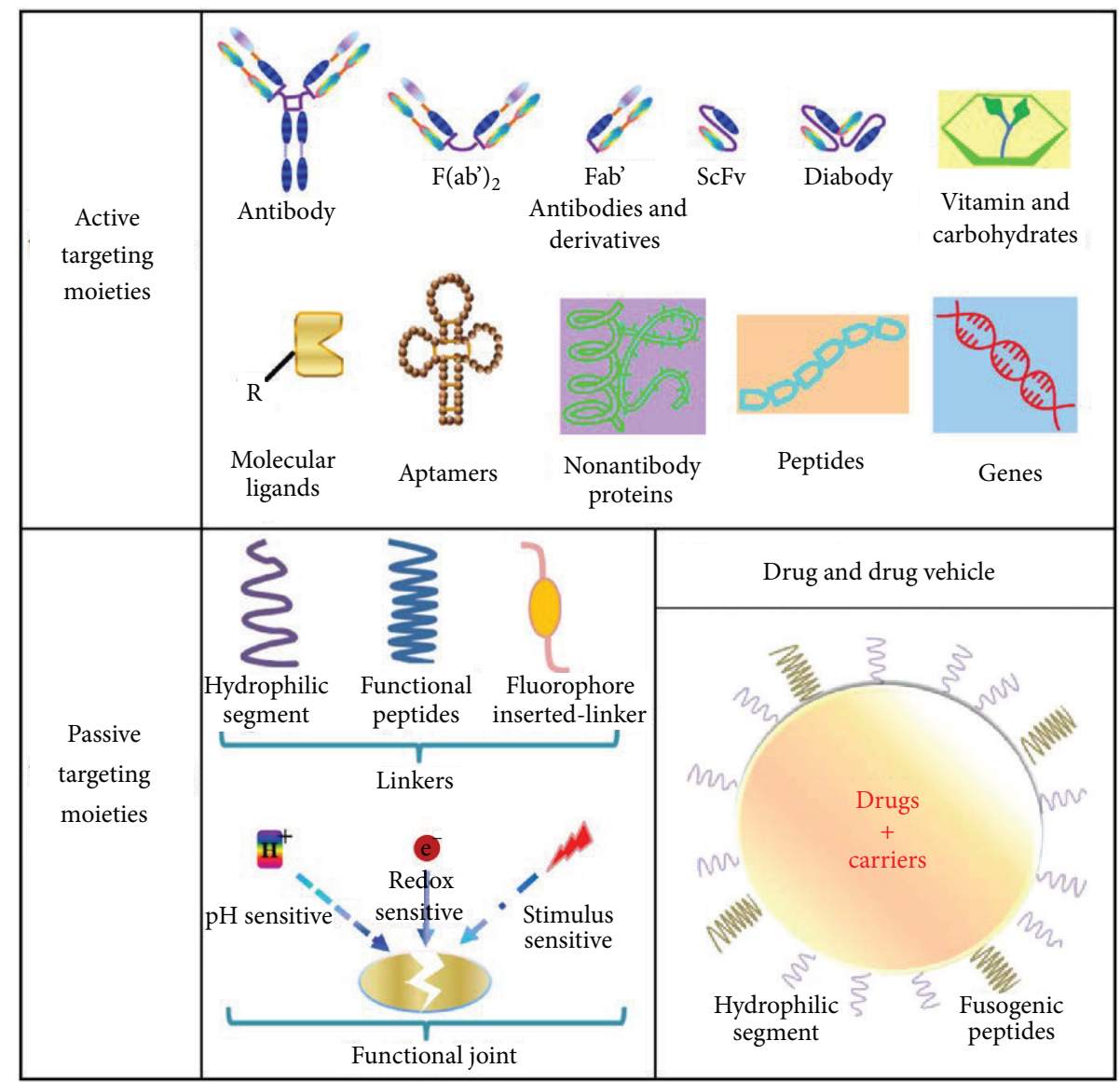

FIGURE 15: The toolbox for assembling passive and targeted drug delivery systems [50].

in only cancer cells [185]. Therefore, Sau and collaborators designed and synthesized glucocorticoid receptor-targeted gold nanoparticles that can be used in targeting and modulating genetic information in tumor, which contributes to development of novel anticancer therapy strategy [186]. Peptides can be used as a specific ligand because of their satisfactory pharmacokinetics, tissue distribution patterns, increased permeability, low toxicity, low immunogenicity, and considerable flexibility in chemical modification [187]. Yuan and coworkers developed functionalized gold nanostars based on TAT peptide to improve intracellular delivery and photothermolysis efficiency of gold nanoparticles [188]. Proteins, antibodies, and antibody fragments are effective ligands and can selectively target antigens or receptors overexpressed on cancer cells [189]. Transferrin, a membrane glycoprotein, plays an important role in supporting the transport of iron to rapidly proliferating cells. Transferrin receptors (TfRs) overexpressed in tumors because of the high demands of iron in tumorous tissues can be used for the targeting delivery system [190]. It has been reported that transferrin conjugated with nanoparticles can selectively bind to cancer cells, resulting in its endocytosis and anticancer drug release, and then increased antitumor ability reduced the side effect of cytotoxic agents [191]. Amreddy et al. chose transferrin as specific targeting ligand to develop gold nanorod-doxorubicin-transferrin-nanoparticles, targeting drug delivery system. Gold nanorod-doxorubicintransferrin-nanoparticles exhibited higher selective targeting ability and higher cancer cell accumulation of drug [192]. Kotagiri and colleagues developed transferrin-coated $\mathrm{TiO}_{2}$ nanoparticles to accomplish depth-independent Cerenkovradiation-mediated therapy [190]. The results show that the transferrin-coated $\mathrm{TiO}_{2}$ nanoparticles can be selectively taken up by tumor cells and then destruct cancerous cells by activating the immune system, achieving the significant antigrowth activities and inducing apoptosis ability. Aptamers because of fine properties (short, synthetic, single-stranded oligonucleotides, and high affinity and specificity) have become a new kind of targeting ligands [193]. Aptamer-conjugated gold nanomaterials can be used as a novel, efficient, and less harmful strategy for specific tumor recognition and targeted tumor therapy [194]. Gold nanomaterials bounded to aptamer and then loaded by different cytotoxic agents or photosensitizers have been synthesized for the tumor diagnosis and treatment and exhibited to improve the accumulation of agents and increase specificity and efficacy as well as reduce toxicity [195, 196]. Choi and coworkers designed a smart PDT therapy agent using polyethylene glycol-coated (PEGylated) GNRs functionalized with antiepidermal growth factor receptor aptamer 


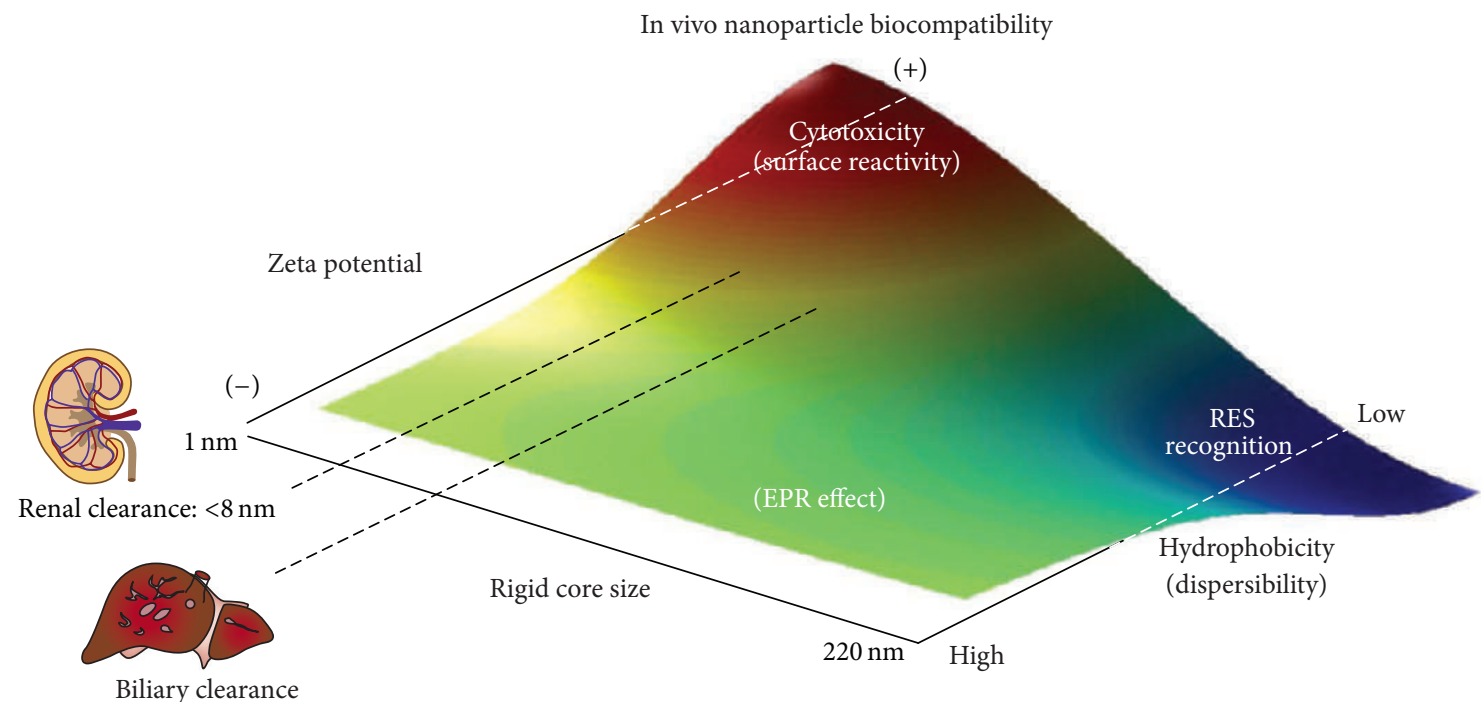

FIGURE 16: Physical characteristics of nanoparticles determine in vivo biocompatibility. The three-dimensional phase diagram displays the qualitative biocompatibility trends revealed after in vivo screening of around 130 nanoparticles intended for therapeutic use. The main independent particle variables that determine the in vivo biocompatibility (colour spectrum) are size, zeta potential (surface charge), and dispersibility (particularly the effect of hydrophobicity). Biocompatibility is reflected in the colour spectrum, with red representing likely toxicity, blue likely safety, and blue-green-yellow intermediate levels of safety (in the same order). Cationic particles or particles with high surface reactivity are more likely to be toxic (red hue) than the larger relatively hydrophobic or poorly dispersed particles, which are rapidly and safely (blue hue) removed by the reticuloendothelial system (RES). Particles that promote enhanced permeation and retention (EPR) effects-and are therefore optimal for chemotherapeutic drug delivery to cancers-generally have midrange sizes and relatively neutral surface charges. Reprinted by permission from Macmillan Publishers Ltd.: [Nature Materials] [51]. Copyright 2009.

(AptEGFR). The experimental results showed that the agent can excellently target cancer cells towards developing an effective tumor therapy by photothermal ablation [197]. In general, although the targeted delivery systems based on high-affinity specific ligands are emerging as a promising platform for the tumor diagnosis and treatment, much work remains to be done to facilitate the translation of these materials and strategies into clinical practice.

\section{Toxicity of Gold Nanoparticles}

Although gold nanomaterials have numerous advancements in new drugs development, there still are a lot of problems before moving these applications into the clinics. Toxicity is the most important issue to hamper the efficacy/efficiency or cause adverse effects.

Some toxicity may rise due to the native characters of the gold nanoparticles. In a case, GNPs with a diameter of $1.4 \mathrm{~nm}$ have potentially high toxicity due to the possibility of irreversible binding to key biopolymers [198]. It indicates gold nanoparticles with the size of 1 to $2 \mathrm{~nm}$ need to be specially considered before clinic [199]. Currently, the International Alliance for NanoEHS Harmonization (IANH) have organized interlaboratory cooperations to compare different methods investigating the potential biological effects of nanostructures including nanoparticle size and surface charge [200]. Another case is the PEGylation gold nanoparticles. Although the prolonged circulation of nanostructures can be achieved through PEGylation, PEGylation with large PEG molecules will increase the hydrodynamic diameter of nanostructures [201] and drastically alter their biodistribution and pharmacokinetics [40]. It revealed the modification of gold nanoparticles may also impact the toxicity. Figure 16 has shown a universal toxicity scale of different nanomaterials (from highly toxic to biocompatible). The researchers should seriously consider these characters in the particles design [51].

The concentration also is an important issue which needs to be considered in the gold nanoparticles application. In a $14 \mathrm{~nm}$ citrate-coated GNPs research, various concentrations of gold nanoparticles were added to a fibroblast cell culture [202]. The results have shown the high concentration may harm actin filaments and affect cells' motility, proliferation, and adhesive abilities.

All these above toxicities can be overcome by avoiding the drawbacks carefully and specific handling in different situations. However, the gold nanoparticle is hardly digested by enzymes within the body which is one of the major barriers to limit the clinical use of the most Au-based agents. Therefore, how to eliminate them from the body has become a very important issue. As one of the two most important natural systems to eliminate wastes in human body, renal clearance plays very essential roles. Currently, biodegradable gold 
TABLE 2: The summary of various phototherapy of gold nanoparticles.

\begin{tabular}{|c|c|c|c|c|c|c|}
\hline Approaches & GNP type & Differences & $\begin{array}{c}\text { Particular } \\
\text { requirements }\end{array}$ & Applications & Properties & Ref. \\
\hline \multirow{3}{*}{ PTT } & \multirow{3}{*}{ Gold sphere } & \multirow{3}{*}{ In vitro } & $\begin{array}{l}\text { Visible light, specific } \\
\text { targeted }\end{array}$ & $\begin{array}{l}\text { Cell elimination } \\
\text { in vitro }\end{array}$ & SPR & {$[18,65,68]$} \\
\hline & & & $\begin{array}{l}\text { Visible and NIR } \\
\text { light, targeted cells } \\
\text { with two specific } \\
\text { antibodies to form } \\
\text { nanocluster }\end{array}$ & $\begin{array}{l}\text { Cell elimination } \\
\text { in vitro }\end{array}$ & SPR & {$[69,70]$} \\
\hline & & & $\begin{array}{c}\text { NIR fs laser, specific } \\
\text { targeted }\end{array}$ & $\begin{array}{c}\text { Cell elimination } \\
\text { in vitro }\end{array}$ & SHM and TPA & {$[66]$} \\
\hline \multirow{4}{*}{ PTT } & \multirow{4}{*}{$\begin{array}{c}\text { Gold } \\
\text { nanorod }\end{array}$} & \multirow{4}{*}{$\begin{array}{l}\text { Deep penetration, } \\
\text { in vivo }\end{array}$} & $\begin{array}{l}\text { NIR light, specific } \\
\text { targeted }\end{array}$ & $\begin{array}{l}\text { Cell elimination } \\
\text { in vitro }\end{array}$ & SPR & {$[41,75,76]$} \\
\hline & & & $\begin{array}{l}\text { Two-photon laser, } \\
\text { polypyrrole- } \\
\text { stabilized gold } \\
\text { nanorods, } \\
\text { nontargeted }\end{array}$ & $\begin{array}{l}\text { Cell elimination } \\
\text { in vitro }\end{array}$ & TPA & [79] \\
\hline & & & $\begin{array}{l}\text { NIR light, } \\
\text { nontargeted }\end{array}$ & $\begin{array}{c}\text { Cancer } \\
\text { treatment in } \\
\text { vivo }\end{array}$ & $\begin{array}{c}\text { SPR and EPR } \\
\text { effect }\end{array}$ & {$[77,80]$} \\
\hline & & & $\begin{array}{c}\text { NIR light, specific } \\
\text { targeted GNRs laden } \\
\text { macrophages }\end{array}$ & $\begin{array}{c}\text { Cancer } \\
\text { treatment in } \\
\text { vivo } \\
\end{array}$ & SPR & {$[58,78]$} \\
\hline \multirow{3}{*}{ PTT } & \multirow{3}{*}{$\begin{array}{c}\text { Gold } \\
\text { nanoshell } \\
(\mathrm{SiO} 2 @ \mathrm{Au})\end{array}$} & \multirow{3}{*}{$\begin{array}{l}\text { Deep, in vivo, } \\
\text { higher } \\
\text { photothermal } \\
\text { efficiency }\end{array}$} & $\begin{array}{l}\text { NIR light, PEG } \\
\text { coated, nontargeted }\end{array}$ & $\begin{array}{c}\text { Cancer } \\
\text { treatment in } \\
\text { vivo }\end{array}$ & $\begin{array}{l}\text { SPR and EPR } \\
\text { effect }\end{array}$ & {$[52,67,83-88]$} \\
\hline & & & $\begin{array}{l}\text { NIR light, PEG } \\
\text { coated, specific } \\
\text { targeted }\end{array}$ & $\begin{array}{l}\text { Cell elimination } \\
\text { in vitro }\end{array}$ & SPR & {$[89,90]$} \\
\hline & & & $\begin{array}{l}\text { NIR light, Au-laden } \\
\text { monocytes/ } \\
\text { macrophages }\end{array}$ & $\begin{array}{l}\text { Center of solid } \\
\text { tumors } \\
\text { treatment in } \\
\text { vitro }\end{array}$ & SPR & {$[92,93]$} \\
\hline \multirow{2}{*}{ PTT } & \multirow{2}{*}{$\begin{array}{c}\text { Gold } \\
\text { nanocages }\end{array}$} & \multirow{2}{*}{$\begin{array}{l}\text { Deep, in vivo, } \\
\text { higher specific } \\
\text { surface area }\end{array}$} & $\begin{array}{l}\text { NIR light, specific } \\
\text { targeted }\end{array}$ & $\begin{array}{c}\text { Cells } \\
\text { elimination in } \\
\text { vitro }\end{array}$ & SPR & [95] \\
\hline & & & $\begin{array}{l}\text { NIR light, PEG } \\
\text { coated nanocage } \\
\text { specific targeted }\end{array}$ & $\begin{array}{c}\text { Cancer } \\
\text { treatment in } \\
\text { vivo }\end{array}$ & SPR & {$[100]$} \\
\hline PTT & $\begin{array}{c}\text { Gold } \\
\text { nanoring }\end{array}$ & $\begin{array}{c}\text { LSPR } \\
\text { 1000-1300 nm, } \\
\text { deeper } \\
\end{array}$ & $\begin{array}{l}\text { NIR light, specific } \\
\text { targeted }\end{array}$ & $\begin{array}{c}\text { Cells } \\
\text { elimination in } \\
\text { vitro } \\
\end{array}$ & SPR & {$[103]$} \\
\hline PTT & $\begin{array}{l}\text { Gold } \\
\text { nanoflower }\end{array}$ & Low toxicity & $\begin{array}{l}\text { NIR light, } \\
\text { nontargeted }\end{array}$ & $\begin{array}{c}\text { Cancer } \\
\text { treatment in } \\
\text { vitro and in vivo }\end{array}$ & $\begin{array}{l}\text { SPR and EPR } \\
\text { effect }\end{array}$ & {$[44,104]$} \\
\hline \multirow{3}{*}{ PDT } & \multirow{3}{*}{$\begin{array}{l}\text { Gold sphere } \\
\text { (GNP) }\end{array}$} & \multirow{3}{*}{$\begin{array}{l}\text { Deliver PS into } \\
\text { cells efficiently }\end{array}$} & $\begin{array}{l}\text { Broad light, PS } \\
\text { coated GNP, } \\
\text { nontargeted }\end{array}$ & $\begin{array}{c}\text { PS delivery, } \\
\text { cancer } \\
\text { treatment in } \\
\text { vitro and in vivo }\end{array}$ & EPR effect & {$[19,24,28,45,46,115-117]$} \\
\hline & & & $\begin{array}{l}\text { One light source, PS } \\
\text { stabilized GNPs, } \\
\text { specific targeted }\end{array}$ & $\begin{array}{c}\text { PS delivery, } \\
\text { cancer } \\
\text { treatment in } \\
\text { vitro and in vivo }\end{array}$ & EPR effect & [118-123] \\
\hline & & & $\begin{array}{l}\text { One light source } \\
\text { both for PDT and } \\
\text { PTT, PS coated } \\
\text { GNPs, nontargeted } \\
\text { [129], specific } \\
\text { targeted [139] }\end{array}$ & $\begin{array}{l}\text { PS delivery, } \\
\text { cancer } \\
\text { treatment in } \\
\text { vitro }\end{array}$ & $\begin{array}{l}\text { SPR and EPR } \\
\text { effect }\end{array}$ & {$[129,139]$} \\
\hline
\end{tabular}


TABLe 2: Continued.

\begin{tabular}{|c|c|c|c|c|c|c|}
\hline Approaches & GNP type & Differences & $\begin{array}{l}\text { Particular } \\
\text { requirements }\end{array}$ & Applications & Properties & Ref. \\
\hline \multirow{2}{*}{ PDT } & \multirow{2}{*}{$\begin{array}{l}\text { Gold } \\
\text { nanorod } \\
(\mathrm{GNR})\end{array}$} & \multirow{2}{*}{$\begin{array}{c}\text { PTT and PDT for } \\
\text { deeper } \\
\text { penetration }\end{array}$} & $\begin{array}{l}\text { One light source } \\
\text { both for PDT and } \\
\text { PTT, PS coated } \\
\text { GNRs, nontargeted } \\
\text { [130], specific } \\
\text { targeted }\end{array}$ & $\begin{array}{l}\text { PS delivery, cells } \\
\text { elimination in } \\
\text { vitro }\end{array}$ & $\begin{array}{l}\text { SPR and EPR } \\
\text { effect }\end{array}$ & {$[47,126-128,130]$} \\
\hline & & & $\begin{array}{l}\text { Two light source for } \\
\text { PTT and PDT, } \\
\text { respectively, PS } \\
\text { coated GNRs, } \\
\text { specific targeted } \\
\text { [133], nontargeted }\end{array}$ & $\begin{array}{l}\text { PS delivery, } \\
\text { cancer } \\
\text { treatment in } \\
\text { vitro [133] and } \\
\text { in vivo }\end{array}$ & $\begin{array}{l}\text { SPR and EPR } \\
\text { effect }\end{array}$ & {$[25,32,133,137]$} \\
\hline \multirow{2}{*}{ PDT } & \multirow{2}{*}{$\begin{array}{l}\text { Gold } \\
\text { nanoshell } \\
\text { (GNS) }\end{array}$} & \multirow{2}{*}{ Lower light dose } & $\begin{array}{c}\text { A two-photon } \\
\text { femtosecond pulsed } \\
\text { laser for both PDT } \\
\text { and PTT, PS coated } \\
\text { GNSs, nontargeted }\end{array}$ & $\begin{array}{l}\text { PS delivery, cells } \\
\text { elimination in } \\
\text { vitro }\end{array}$ & SPR and TPA & {$[132]$} \\
\hline & & & $\begin{array}{l}\text { Two light sources for } \\
\text { PDT and PTT, } \\
\text { respectively, specific } \\
\text { targeted }\end{array}$ & $\begin{array}{l}\text { Cells } \\
\text { elimination in } \\
\text { vitro }\end{array}$ & SPR & {$[30,125,131,136]$} \\
\hline PDT & $\begin{array}{c}\text { Gold } \\
\text { nanocages }\end{array}$ & More PS carriers & $\begin{array}{l}\text { Two light sources for } \\
\text { PTT and PDT, } \\
\text { respectively, PS } \\
\text { coated nanocages, } \\
\text { nontargeted }\end{array}$ & $\begin{array}{l}\text { PS delivery, } \\
\text { cancer } \\
\text { treatment in } \\
\text { vitro and in vivo }\end{array}$ & $\begin{array}{l}\text { SPR and EPR } \\
\text { effect }\end{array}$ & {$[134,135]$} \\
\hline PDT & $\begin{array}{c}\text { Gold } \\
\text { nanostar }\end{array}$ & $\begin{array}{l}\text { More SPR hot } \\
\text { spots }\end{array}$ & $\begin{array}{c}\text { One light source } \\
\text { both for PTT andfor } \\
\text { PDT, } \\
\text { photosensitizer- } \\
\text { coated nanostars, } \\
\text { nontargeted }\end{array}$ & $\begin{array}{l}\text { PS delivery, } \\
\text { cancer } \\
\text { treatment in } \\
\text { vivo }\end{array}$ & $\begin{array}{l}\text { SPR and EPR } \\
\text { effect }\end{array}$ & {$[59]$} \\
\hline PDT & $\begin{array}{l}\text { Specific } \\
\text { GNPs }\end{array}$ & $\begin{array}{c}\text { SPR } \\
1000-1350 \mathrm{~nm}\end{array}$ & $\begin{array}{l}\text { One light source } \\
\text { both for PTT and } \\
\text { for PDT, no } \\
\text { photosensitizer, } \\
\text { nontargeted } \\
\end{array}$ & $\begin{array}{c}\text { Cancer } \\
\text { treatment in } \\
\text { vivo }\end{array}$ & SPR and SOG & {$[138]$} \\
\hline \multirow[b]{2}{*}{ radiotherapy } & \multirow{2}{*}{$\begin{array}{c}\text { Gold } \\
\text { nanoparticles }\end{array}$} & \multirow{2}{*}{$\begin{array}{l}\text { Selective cancer } \\
\text { cell sensitization } \\
\text { to IR }\end{array}$} & $\begin{array}{l}\text { Irradiation with } \\
\text { X-ray, nontargeted }\end{array}$ & $\begin{array}{l}\text { Cancer cells } \\
\text { elimination in } \\
\text { vitro and cancer } \\
\text { treatment in } \\
\text { vivo }\end{array}$ & $\begin{array}{l}\text { Radiosensitivity } \\
\text { enhancement } \\
\text { and EPR effect }\end{array}$ & {$[48,151-155,160,163,164]$} \\
\hline & & & $\begin{array}{l}\text { Irradiation with } \\
\text { X-ray, specific } \\
\text { targeted }\end{array}$ & $\begin{array}{l}\text { Cancer cells } \\
\text { elimination in } \\
\text { vitro and cancer } \\
\text { treatment in } \\
\text { vivo }\end{array}$ & $\begin{array}{l}\text { Radiosensitivity } \\
\text { enhancement }\end{array}$ & {$[156-159,161,162]$} \\
\hline & & & $\begin{array}{l}\text { Irradiation with } \\
\text { laser light, specific } \\
\text { functionalized } \\
\text { GNPs [197] }\end{array}$ & $\begin{array}{c}\text { Drug delivery } \\
\text { and controlled } \\
\text { release in vivo } \\
{[168,197] \text { and in }} \\
\text { vitro }\end{array}$ & $\begin{array}{l}\text { SPR and EPR } \\
\text { effect }\end{array}$ & {$[168,172,174,197]$} \\
\hline Drug delivery & $\begin{array}{c}\text { Gold } \\
\text { nanosphere }\end{array}$ & Lager surface & $\begin{array}{l}\text { Specific } \\
\text { functionalized GNPs }\end{array}$ & $\begin{array}{c}\text { Targeted drug } \\
\text { delivery in vitro } \\
\text { and in vivo [186] }\end{array}$ & Large surface & {$[182,184,186,195]$} \\
\hline
\end{tabular}


TABLE 2: Continued.

\begin{tabular}{|c|c|c|c|c|c|c|}
\hline Approaches & GNP type & Differences & $\begin{array}{c}\text { Particular } \\
\text { requirements }\end{array}$ & Applications & Properties & Ref. \\
\hline & & & $\begin{array}{l}\text { Specific conjugated } \\
\text { with drug }\end{array}$ & $\begin{array}{c}\text { Targeted drug } \\
\text { delivery in vitro } \\
{[176] \text { and in vivo }} \\
{[177]}\end{array}$ & EPR effect & {$[176,177]$} \\
\hline \multirow{3}{*}{ Drug delivery } & \multirow{3}{*}{$\begin{array}{c}\text { Gold } \\
\text { nanorods }\end{array}$} & \multirow{3}{*}{$\begin{array}{c}\text { Deeper } \\
\text { penetration }\end{array}$} & $\begin{array}{c}\text { Irradiation with } \\
\text { near-infrared light, } \\
\text { specific } \\
\text { functionalized } \\
\text { GNRs [171] }\end{array}$ & $\begin{array}{l}\text { Controlled drug } \\
\text { release }\end{array}$ & $\begin{array}{l}\text { SPR and EPR } \\
\text { effect }\end{array}$ & {$[167,171]$} \\
\hline & & & $\begin{array}{l}\text { Irradiation with } \\
\text { laser light, specific } \\
\text { functionalized } \\
\text { GNRs }\end{array}$ & $\begin{array}{l}\text { Cell elimination } \\
\text { in vitro }\end{array}$ & SPR & {$[183]$} \\
\hline & & & $\begin{array}{c}\text { Appropriate } \mathrm{pH} \\
\text { value }\end{array}$ & $\begin{array}{c}\text { Targeted drug } \\
\text { delivery in vitro }\end{array}$ & Large surface & {$[192]$} \\
\hline Drug delivery & $\begin{array}{c}\text { Gold } \\
\text { nanoshells }\end{array}$ & More drug carrier & $\begin{array}{c}\text { Irradiation with } \\
\text { near-infrared light, } \\
\text { chemical } \\
\text { functionalized GNSs }\end{array}$ & $\begin{array}{l}\text { Controlled drug } \\
\text { release in vitro }\end{array}$ & $\begin{array}{l}\text { SPR and EPR } \\
\text { effect }\end{array}$ & {$[169,170]$} \\
\hline Drug delivery & Gold cluster & $\begin{array}{l}\text { Enhance drug } \\
\text { release efficiency }\end{array}$ & $\begin{array}{c}\text { Irradiation with } \\
\text { near-infrared light, } \\
\text { chemical } \\
\text { functionalized gold } \\
\text { cluster }\end{array}$ & $\begin{array}{l}\text { Controlled drug } \\
\text { release in vivo }\end{array}$ & $\begin{array}{l}\text { SPR and EPR } \\
\text { effect }\end{array}$ & {$[173]$} \\
\hline Drug delivery & $\begin{array}{c}\text { Gold } \\
\text { nanostars }\end{array}$ & $\begin{array}{l}\text { Higher } \\
\text { conversion } \\
\text { efficiency }\end{array}$ & $\begin{array}{c}\text { TAT-peptide } \\
\text { functionalized } \\
\text { GNPs, irradiation } \\
\text { with light }\end{array}$ & $\begin{array}{c}\text { Chemical } \\
\text { delivery, cancer } \\
\text { cell elimination } \\
\text { in vitro }\end{array}$ & $\begin{array}{l}\text { SPR and EPR } \\
\text { effect }\end{array}$ & {$[188]$} \\
\hline
\end{tabular}

"core-satellite" superstructures connected by DNA linkers have been designed to achieve reasonable renal clearance with good tumor targeting abilities [203]. With the development of gold nanoparticles, more new gold nanostructures will be developed to become easily digested and completely cleared after the treatment.

\section{Conclusion}

Photodynamic therapy is definitely a promising therapeutic option in cancer treatment. However, it has still not gained acceptance as a first-line treatment option mainly due to the disadvantages of classical PSs. The application of nanoparticles, especially gold nanoparticles, in the field of PDT is an extremely promising method for future technological breakthroughs, while gold nanoparticles hold tremendous potential for tumor therapy. For PPT, PDT, and drug delivery function in cancer treatment, there still exist a few limitations for clinical application to be addressed. Firstly the amount of nanoparticles accumulation in tumors should be effectively quantified. In order to completely eradicate tumor, the quantification methods have to be combined with standard illumination geometries of tumors in specific organs [88]. Currently, most of the in vivo investigations have been implemented on subcutaneous cancer diseases by NIR light through the skin surface for a few inches of penetration depth of the light. For deep cancer tissue therapeutic modality, fiber optic probes should be exploited to deliver NIR light, and specific imaging modalities should be combined to monitor treatment [87]. Compared with other gold nanoparticlesbased phototherapy, gold nanoparticles aided radiation therapy can treat tumors deep within the body; however, there are controversial results about the impact of photon energy and GNP size in recently published articles [204].

In summary, the area of GNP-based treatment of cancer has attracted extensive research in recent years due to its high selectivity and minimized side effects. Gold nanoparticles have exhibited great promise as light-heat converter, local field enhancement, drug carriers, and radiation sensitizer for cancer treatment to effectively damage cancerous lesions both in vitro and in vivo (see Table 2). Moreover, considerable advances have been made in developing GNP-mediated multifunctional nanoparticles systems which provides great possibility of introducing combination therapy strategy for enhancing cancer therapeutic efficiency in near future. However, significant barriers must be overcome before these applications can be moved into the clinics, such as nonbiodegradability of GNPs and low penetration depth of light. Therefore, further research is required for enhancement of in vivo behavior of the nanostructure, and the long term impacts of GNPs remaining in organs like liver and spleen should be better understood. All in all, with the development 
of science and technology, GNPs-mediated therapies should be very likely to be used for cancer clinical treatment with minimally invasive character.

\section{Competing Interests}

The authors declare that there is no conflict of interests regarding the publication of this paper.

\section{Acknowledgments}

This study was supported by the National Nature Science Foundation of China (Grant nos. 61575156, 61120106013, and 11274249).

\section{References}

[1] K. K. Jain, "Role of nanobiotechnology in developing personalized medicine for cancer," Technology in Cancer Research and Treatment, vol. 4, no. 6, pp. 645-650, 2005.

[2] J. Li, C. C. Sharkey, D. Huang, and M. R. King, "Nanobiotechnology for the therapeutic targeting of cancer cells in blood," Cellular and Molecular Bioengineering, vol. 8, no. 1, pp. 137-150, 2015.

[3] A. S. Thakor and S. S. Gambhir, "Nanooncology: the future of cancer diagnosis and therapy," CA: A Cancer Journal for Clinicians, vol. 63, no. 6, pp. 395-418, 2013.

[4] L. Brannon-Peppas and J. O. Blanchette, "Nanoparticle and targeted systems for cancer therapy," Advanced Drug Delivery Reviews, vol. 64, pp. 206-212, 2012.

[5] A. Llevot and D. Astruc, "Applications of vectorized gold nanoparticles to the diagnosis and therapy of cancer," Chemical Society Reviews, vol. 41, no. 1, pp. 242-257, 2012.

[6] C. Iancu, L. Mocan, C. Bele et al., "Enhanced laser thermal ablation for the in vitro treatment of liver cancer by specific delivery of multiwalled carbon nanotubes functionalized with human serum albumin," International Journal of Nanomedicine, vol. 6, pp. 129-141, 2011.

[7] S. Jain, D. G. Hirst, and J. M. O’Sullivan, "Gold nanoparticles as novel agents for cancer therapy," British Journal of Radiology, vol. 85, no. 1010, pp. 101-113, 2012.

[8] C. R. Patra, R. Bhattacharya, E. Wang et al., "Targeted delivery of gemcitabine to pancreatic adenocarcinoma using cetuximab as a targeting agent," Cancer Research, vol. 68, no. 6, pp. 19701978, 2008.

[9] C. R. Patra, R. Bhattacharya, D. Mukhopadhyay, and P. Mukherjee, "Application of gold nanoparticles for targeted therapy in cancer," Journal of Biomedical Nanotechnology, vol. 4, no. 2, pp. 99-132, 2008.

[10] P. Mukherjee, R. Bhattacharya, N. Bone et al., "Potential therapeutic application of gold nanoparticles in B-chronic lymphocytic leukemia (BCLL): enhancing apoptosis (vol 5, 4, 2007)," Journal of Nanobiotechnology, vol. 11, 2013.

[11] K. Marycz, J. Kolankowski, J. Grzesiak, M. Hecold, O. Rac, and H. Teterycz, "Application of gold nanoparticles of different concentrations to improve the therapeutic potential of autologous conditioned serum: potential implications for equine regenerative medicine," Journal of Nanomaterials, vol. 2015, Article ID 521207, 9 pages, 2015.
[12] J. Cardinal, J. R. Klune, E. Chory et al., "Noninvasive radiofrequency ablation of cancer targeted by gold nanoparticles," Surgery, vol. 144, no. 2, pp. 125-132, 2008.

[13] E. S. Glazer, C. H. Zhu, K. L. Massey et al., "Noninvasive radiofrequency field destruction of pancreatic adenocarcinoma xenografts treated with targeted gold nanoparticles," Clinical Cancer Research, vol. 16, no. 23, pp. 5712-5721, 2010.

[14] L. Karmani, V. Bouchat, C. Bouzin et al., " ${ }^{89}$ Zr-labeled antiendoglin antibody-targeted gold nanoparticles for imaging cancer: implications for future cancer therapy," Nanomedicine, vol. 9, no. 13, pp. 1923-1937, 2014.

[15] F. Fay and C. J. Scott, "Antibody-targeted nanoparticles for cancer therapy," Immunotherapy, vol. 3, no. 3, pp. 381-394, 2011.

[16] C. J. Gannon, C. R. Patra, R. Bhattacharya, P. Mukherjee, and S. A. Curley, "Intracellular gold nanoparticles enhance noninvasive radiofrequency thermal destruction of human gastrointestinal cancer cells," Journal of Nanobiotechnology, vol. 6, article 2, 2008.

[17] M. P. Antosh, D. D. Wijesinghe, S. Shrestha et al., "Enhancement of radiation effect on cancer cells by gold-pHLIP," Proceedings of the National Academy of Sciences of the United States of America, vol. 112, no. 17, pp. 5372-5376, 2015.

[18] X. Qu, C. Yao, J. Wang, Z. Li, and Z. Zhang, "Anti-CD30targeted gold nanoparticles for photothermal therapy of L-428 Hodgkin's cell," International journal of nanomedicine, vol. 7, pp. 6095-6103, 2012.

[19] H. Xu, C. Liu, J. Mei et al., "Effects of light irradiation upon photodynamic therapy based on 5-aminolevulinic acid-gold nanoparticle conjugates in K562 cells via singlet oxygen generation," International Journal of Nanomedicine, vol. 7, pp. 50295038, 2012.

[20] W. Roa, X. Zhang, L. Guo et al., "Gold nanoparticle sensitize radiotherapy of prostate cancer cells by regulation of the cell cycle," Nanotechnology, vol. 20, no. 37, Article ID 375101, 2009.

[21] I. Naslund, P. Wersall, E. Castellanos, C. Beskow, and S. Nyrén, "Fine-needle Marker for IGRT, a new fiducial gold anchor for high-precision radiotherapy," International Journal of Radiation Oncology ${ }^{\star}$ Biology ${ }^{\star}$ Physics, vol. 75, no. 3, pp. S608-S609, 2009.

[22] M. Triesscheijn, P. Baas, J. H. M. Schellens, and F. A. Stewart, "Photodynamic therapy in oncology," Oncologist, vol. 11, no. 9, pp. 1034-1044, 2006.

[23] D. C. Hone, P. I. Walker, R. Evans-Gowing et al., "Generation of cytotoxic singlet oxygen via phthalocyanine-stabilized gold nanoparticles: a potential delivery vehicle for photodynamic therapy," Langmuir, vol. 18, no. 8, pp. 2985-2987, 2002.

[24] M. E. Wieder, D. C. Hone, M. J. Cook, M. M. Handsley, J. Gavrilovic, and D. A. Russell, "Intracellular photodynamic therapy with photosensitizer-nanoparticle conjugates: cancer therapy using a 'Trojan horse"' Photochemical \& Photobiological Sciences, vol. 5, no. 8, pp. 727-734, 2006.

[25] B. Jang, J.-Y. Park, C.-H. Tung, I.-H. Kim, and Y. Choi, "Gold nanorod-photosensitizer complex for near-infrared fluorescence imaging and photodynamic/photothermal therapy in vivo," ACS Nano, vol. 5, no. 2, pp. 1086-1094, 2011.

[26] Y. Zhang, K. Aslan, M. J. R. Previte, and C. D. Geddes, "Plasmonic engineering of singlet oxygen generation," Proceedings of the National Academy of Sciences of the United States of America, vol. 105, no. 6, pp. 1798-1802, 2008.

[27] S. M. Mooi and B. Heyne, "Amplified production of singlet oxygen in aqueous solution using metal enhancement effects," Photochemistry and Photobiology, vol. 90, no. 1, pp. 85-91, 2014. 
[28] Z. Zhang, S. Wang, H. Xu, B. Wang, and C. Yao, "Role of 5aminolevulinic acid-conjugated gold nanoparticles for photodynamic therapy of cancer," Journal of Biomedical Optics, vol. 20, no. 5, Article ID 051043, 2015.

[29] R. Vankayala, Y.-K. Huang, P. Kalluru, C.-S. Chiang, and K. C. Hwang, "First demonstration of gold nanorods-mediated photodynamic therapeutic destruction of tumors via near infrared light activation," Small, vol. 10, no. 8, pp. 1612-1622, 2014.

[30] R. Vankayala, C.-C. Lin, P. Kalluru, C.-S. Chiang, and K. C. Hwang, "Gold nanoshells-mediated bimodal photodynamic and photothermal cancer treatment using ultra-low doses of near infra-red light," Biomaterials, vol. 35, no. 21, pp. 5527-5538, 2014.

[31] E. S. Tuchina, F. Ratto, B. N. Khlebtsov et al., "Combined near infrared photothermolysis and photodynamic therapy by association of gold nanoparticles and an organic dye," in Proceedings of the Plasmonics in Biology and Medicine VIII, vol. 7911 of Proceedings of SPIE, San Francisco, Calif, USA, January 2011.

[32] B. W. Wang, J.-H. Wang, Q. Liu et al., "Rose-bengal-conjugated gold nanorods for in vivo photodynamic and photothermal oral cancer therapies," Biomaterials, vol. 35, no. 6, pp. 1954-1966, 2014.

[33] E. S. Shibu, M. Hamada, N. Murase, and V. Biju, "Nanomaterials formulations for photothermal and photodynamic therapy of cancer," Journal of Photochemistry and Photobiology C: Photochemistry Reviews, vol. 15, no. 1, pp. 53-72, 2013.

[34] W. Ngwa, R. Kumar, S. Sridhar et al., "Targeted radiotherapy with gold nanoparticles: current status and future perspectives," Nanomedicine, vol. 9, no. 7, pp. 1063-1082, 2014.

[35] M. Babaei and M. Ganjalikhani, "A systematic review of gold nanoparticles as novel cancer therapeutics," Nanomedicine Journal, vol. 1, no. 4, pp. 211-219, 2014.

[36] P. Ghosh, G. Han, M. De, C. K. Kim, and V. M. Rotello, "Gold nanoparticles in delivery applications," Advanced Drug Delivery Reviews, vol. 60, no. 11, pp. 1307-1315, 2008.

[37] J. M. Bergen, H. A. Von Recum, T. T. Goodman, A. P. Massey, and S. H. Pun, "Gold nanoparticles as a versatile platform for optimizing physicochemical parameters for targeted drug delivery," Macromolecular Bioscience, vol. 6, no. 7, pp. 506-516, 2006.

[38] S. S. Lucky, K. C. Soo, and Y. Zhang, "Nanoparticles in photodynamic therapy," Chemical Reviews, vol. 115, no. 4, pp. 1990-2042, 2015.

[39] E. C. Dreaden, A. M. Alkilany, X. Huang, C. J. Murphy, and M. A. El-Sayed, "The golden age: gold nanoparticles for biomedicine," Chemical Society Reviews, vol. 41, no. 7, pp. 2740 2779, 2012.

[40] X. Yang, M. Yang, B. Pang, M. Vara, and Y. Xia, "Gold nanomaterials at work in biomedicine," Chemical Reviews, vol. 115, no. 19, pp. 10410-10488, 2015.

[41] X. Huang, I. H. El-Sayed, W. Qian, and M. A. El-Sayed, "Cancer cell imaging and photothermal therapy in the nearinfrared region by using gold nanorods," Journal of the American Chemical Society, vol. 128, no. 6, pp. 2115-2120, 2006.

[42] V. Dixit, J. Van Den Bossche, D. M. Sherman, D. H. Thompson, and R. P. Andres, "Synthesis and grafting of thioctic acid-PEGfolate conjugates onto Au nanoparticles for selective targeting of folate receptor-positive tumor cells," Bioconjugate Chemistry, vol. 17, no. 3, pp. 603-609, 2006.

[43] M. K. Popp, I. Oubou, C. Shepherd, Z. Nager, C. Anderson, and L. Pagliaro, "Photothermal therapy using gold nanorods and near-infrared light in a murine melanoma model increases survival and decreases tumor volume," Journal of Nanomaterials, vol. 2014, Article ID 450670, 8 pages, 2014.

[44] J. Han, J. Li, W. Jia et al., "Photothermal therapy of cancer cells using novel hollow gold nanoflowers," International Journal of Nanomedicine, vol. 9, no. 1, pp. 517-526, 2014.

[45] Y. Cheng, A. C. Samia, J. D. Meyers, I. Panagopoulos, B. Fei, and C. Burda, "Highly efficient drug delivery with gold nanoparticle vectors for in vivo photodynamic therapy of cancer," Journal of the American Chemical Society, vol. 130, no. 32, pp. 10643-10647, 2008.

[46] Y. Cheng, J. D. Meyers, A.-M. Broome, M. E. Kenney, J. P. Basilion, and C. Burda, "Deep penetration of a PDT drug into tumors by noncovalent drug-gold nanoparticle conjugates," Journal of the American Chemical Society, vol. 133, no. 8, pp. 2583-2591, 2011.

[47] J. Wang, G.-Z. Zhu, M.-X. You et al., "Assembly of aptamer switch probes and photosensitizer on gold nanorods for targeted photothermal and photodynamic cancer therapy," ACS Nano, vol. 6, no. 6, pp. 5070-5077, 2012.

[48] J. F. Hainfeld, D. N. Slatkin, and H. M. Smilowitz, “The use of gold nanoparticles to enhance radiotherapy in mice," Physics in Medicine and Biology, vol. 49, no. 18, pp. N309-N315, 2004.

[49] A. R. Guerrero, N. Hassan, C. A. Escobar, F. Albericio, M. J. Kogan, and E. Araya, "Gold nanoparticles for photothermally controlled drug release," Nanomedicine, vol. 9, no. 13, pp. 20232039, 2014.

[50] D. Liu and D. T. Auguste, "Cancer targeted therapeutics: from molecules to drug delivery vehicles," Journal of Controlled Release, vol. 219, pp. 632-643, 2015.

[51] A. E. Nel, L. Mädler, D. Velegol et al., "Understanding biophysicochemical interactions at the nano-bio interface," Nature Materials, vol. 8, no. 7, pp. 543-557, 2009.

[52] D. P. O’Neal, L. R. Hirsch, N. J. Halas, J. D. Payne, and J. L. West, "Photo-thermal tumor ablation in mice using near infraredabsorbing nanoparticles," Cancer Letters, vol. 209, no. 2, pp. 171176, 2004.

[53] P. K. Jain, X. Huang, I. H. El-Sayed, and M. A. El-Sayed, "Noble metals on the nanoscale: optical and photothermal properties and some applications in imaging, sensing, biology, and medicine," Accounts of Chemical Research, vol. 41, no. 12, pp. 1578-1586, 2008.

[54] X. Huang, P. K. Jain, I. H. El-Sayed, and M. A. El-Sayed, "Plasmonic photothermal therapy (PPTT) using gold nanoparticles," Lasers in Medical Science, vol. 23, no. 3, pp. 217-228, 2008.

[55] S. Link and M. A. El-Sayed, "Shape and size dependence of radiative, non-radiative and photothermal properties of gold nanocrystals," International Reviews in Physical Chemistry, vol. 19, no. 3, pp. 409-453, 2000.

[56] D. Boyer, P. Tamarat, A. Maali, B. Lounis, and M. Orrit, "Photothermal imaging of nanometer-sized metal particles among scatterers," Science, vol. 297, no. 5584, pp. 1160-1163, 2002.

[57] C. J. Orendorff, T. K. Sau, and C. J. Murphy, "Shape-dependent plasmon-resonant gold nanoparticles," Small, vol. 2, no. 5, pp. 636-639, 2006.

[58] Z. Li, H. Huang, S. Tang et al., "Small gold nanorods laden macrophages for enhanced tumor coverage in photothermal therapy," Biomaterials, vol. 74, pp. 144-154, 2016.

[59] G. Chirico, P. Pallavicini, and M. Borzenkov, "Physical properties of gold nanostars," in Gold Nanostars, pp. 25-42, Springer, Berlin, Germany, 2015. 
[60] S. M. R. Safaee, M. Janipour, and M. A. Karami, "Modeling and analysis of optical properties of a gold nanoring based on electric and magnetic dipoles," Applied Optics, vol. 54, no. 28, pp. 8313-8317, 2015.

[61] C. M. Cobley, L. Au, J. Chen, and Y. Xia, "Targeting gold nanocages to cancer cells for photothermal destruction and drug delivery," Expert Opinion on Drug Delivery, vol. 7, no. 5, pp. 577-587, 2010.

[62] A. Hatef, S. Fortin-Deschênes, E. Boulais, F. Lesage, and M. Meunier, "Photothermal response of hollow gold nanoshell to laser irradiation: continuous wave, short and ultrashort pulse," International Journal of Heat and Mass Transfer, vol. 89, pp. 866871, 2015.

[63] J.-L. Li, L. Wang, X.-Y. Liu et al., "In vitro cancer cell imaging and therapy using transferrin-conjugated gold nanoparticles," Cancer Letters, vol. 274, no. 2, pp. 319-326, 2009.

[64] M. Abdulla-Al-Mamun, Y. Kusumoto, A. Mihata, M. S. Islam, and B. Ahmmad, "Plasmon-induced photothermal cell-killing effect of gold colloidal nanoparticles on epithelial carcinoma cells," Photochemical and Photobiological Sciences, vol. 8, no. 8, pp. 1125-1129, 2009.

[65] I. H. El-Sayed, X. Huang, and M. A. El-Sayed, "Selective laser photo-thermal therapy of epithelial carcinoma using anti-EGFR antibody conjugated gold nanoparticles," Cancer Letters, vol. 239, no. 1, pp. 129-135, 2006.

[66] X. Huang, W. Qian, I. H. El-Sayed, and M. A. El-Sayed, "The potential use of the enhanced nonlinear properties of gold nanospheres in photothermal cancer therapy," Lasers in Surgery and Medicine, vol. 39, no. 9, pp. 747-753, 2007.

[67] C. Iancu, "Photothermal therapy of human cancers (PTT) using gold nanoparticles," Biotechnology, Molecular Biology and Nanomedicine, vol. 1, no. 1, pp. 53-60, 2013.

[68] C. M. Pitsillides, E. K. Joe, X. B. Wei, R. R. Anderson, and C. P. Lin, "Selective cell targeting with light-absorbing microparticles and nanoparticles," Biophysical Journal, vol. 84, no. 6, pp. 40234032, 2003.

[69] D. Lapotko, E. Lukianova, M. Potapnev, O. Aleinikova, and A. Oraevsky, "Method of laser activated nano-thermolysis for elimination of tumor cells," Cancer Letters, vol. 239, no. 1, pp. 36-45, 2006.

[70] V. P. Zharov, E. N. Galitovskaya, C. Johnson, and T. Kelly, "Synergistic enhancement of selective nanophotothermolysis with gold nanoclusters: potential for cancer therapy," Lasers in Surgery and Medicine, vol. 37, no. 3, pp. 219-226, 2005.

[71] K.-H. Su, Q.-H. Wei, X. Zhang, J. J. Mock, D. R. Smith, and S. Schultz, "Interparticle coupling effects on plasmon resonances of nanogold particles," Nano Letters, vol. 3, no. 8, pp. 1087-1090, 2003.

[72] W. I. Choi, J.-Y. Kim, C. Kang, C. C. Byeon, Y. H. Kim, and G. Tae, "Tumor regression in vivo by photothermal therapy based on gold-nanorod-loaded, functional nanocarriers," ACS Nano, vol. 5, no. 3, pp. 1995-2003, 2011.

[73] G. P. Goodrich, L. Bao, K. Gill-Sharp, K. L. Sang, J. Wang, and J. Donald Payne, "Photothermal therapy in a murine colon cancer model using near-infrared absorbing gold nanorods," Journal of Biomedical Optics, vol. 15, no. 1, Article ID 018001, 2010.

[74] E. B. Dickerson, E. C. Dreaden, X. Huang et al., "Gold nanorod assisted near-infrared plasmonic photothermal therapy (PPTT) of squamous cell carcinoma in mice," Cancer Letters, vol. 269, no. 1, pp. 57-66, 2008.

[75] A. M. Alkilany, L. B. Thompson, S. P. Boulos, P. N. Sisco, and C. J. Murphy, "Gold nanorods: their potential for photothermal therapeutics and drug delivery, tempered by the complexity of their biological interactions," Advanced Drug Delivery Reviews, vol. 64, no. 2, pp. 190-199, 2012.

[76] K. C. L. Black, J. Yi, J. G. Rivera, D. C. Zelasko-Leon, and P. B. Messersmith, "Polydopamine-enabled surface functionalization of gold nanorods for cancer cell-targeted imaging and photothermal therapy," Nanomedicine, vol. 8, no. 1, pp. 17-28, 2013.

[77] U. Dembereldorj, S. Y. Choi, E.-O. Ganbold et al., "Gold nanorod-assembled pegylated graphene-oxide nanocomposites for photothermal cancer therapy," Photochemistry and Photobiology, vol. 90, no. 3, pp. 659-666, 2014.

[78] O. Betzer, R. Ankri, M. Motiei, and R. Popovtzer, “Theranostic approach for cancer treatment: multifunctional gold nanorods for optical imaging and photothermal therapy," Journal of Nanomaterials, vol. 2015, Article ID 646713, 7 pages, 2015.

[79] C. Du, A. Wang, J. Fei, J. Zhao, and J. Li, "Polypyrrole-stabilized gold nanorods with enhanced photothermal effect towards twophoton photothermal therapy," Journal of Materials Chemistry $B$, vol. 3, no. 22, pp. 4539-4545, 2015.

[80] T. Sugiura, D. Matsuki, J. Okajima et al., "Photothermal therapy of tumors in lymph nodes using gold nanorods and nearinfrared laser light with controlled surface cooling," Nano Research, vol. 8, no. 12, pp. 3842-3852, 2015.

[81] F. Caruso, M. Spasova, V. Salgueiriño-Maceira, and L. M. Liz-Marzán, "Multilayer assemblies of silica-encapsulated gold nanoparticles on decomposable colloid templates," Advanced Materials, vol. 13, no. 14, pp. 1090-1094, 2001.

[82] S. J. Oldenburg, R. D. Averitt, S. L. Westcott, and N. J. Halas, "Nanoengineering of optical resonances," Chemical Physics Letters, vol. 288, no. 2-4, pp. 243-247, 1998.

[83] L. R. Hirsch, R. J. Stafford, J. A. Bankson et al., "Nanoshellmediated near-infrared thermal therapy of tumors under magnetic resonance guidance," Proceedings of the National Academy of Sciences of the United States of America, vol. 100, no. 23, pp. 13549-13554, 2003.

[84] J. M. Stern, J. Stanfield, W. Kabbani, J.-T. Hsieh, and J. A. Cadeddu, "Selective prostate cancer thermal ablation with laser activated gold nanoshells," Journal of Urology, vol. 179, no. 2, pp. 748-753, 2008.

[85] J. M. Stern, J. T. Hsieh, S. Park, J. Qiu, and J. Cadeddu, "Gold nanoshell assisted laser ablation of a prostate cancer cell line," Journal of Endourology, vol. 20, p. A193, 2006.

[86] A. M. Gobin, M. H. Lee, N. J. Halas, W. D. James, R. A. Drezek, and J. L. West, "Near-infrared resonant nanoshells for combined optical imaging and photothermal cancer therapy," Nano Letters, vol. 7, no. 7, pp. 1929-1934, 2007.

[87] S. Lal, S. E. Clare, and N. J. Halas, "Nanoshell-enabled photothermal cancer therapy: impending clinical impact," Accounts of Chemical Research, vol. 41, no. 12, pp. 1842-1851, 2008.

[88] J. M. Stern, J. Stanfield, W. Kabbani, J.-T. Hsieh, and J. A. Cadeddu, "Selective prostate cancer thermal ablation with laser activated gold nanoshells," The Journal of Urology, vol. 179, no. 2, pp. 748-753, 2008.

[89] C. Loo, A. Lowery, N. J. Halas, J. West, and R. Drezek, "Immunotargeted nanoshells for integrated cancer imaging and therapy," Nano Letters, vol. 5, no. 4, pp. 709-711, 2005.

[90] L. B. Carpin, L. R. Bickford, G. Agollah et al., "Immunoconjugated gold nanoshell-mediated photothermal ablation of trastuzumab-resistant breast cancer cells," Breast Cancer Research and Treatment, vol. 125, no. 1, pp. 27-34, 2011. 
[91] H. Maeda, "The enhanced permeability and retention (EPR) effect in tumor vasculature: the key role of tumor-selective macromolecular drug targeting," Advances in Enzyme Regulation, vol. 41, pp. 189-207, 2001.

[92] M.-R. Choi, K. J. Stanton-Maxey, J. K. Stanley et al., "A cellular Trojan horse for delivery of therapeutic nanoparticles into tumors," Nano Letters, vol. 7, no. 12, pp. 3759-3765, 2007.

[93] S. Chhetri, H. Hirschberg, and S. J. Madsen, "Photothermal therapy of human glioma spheroids with gold-silica nanoshells and gold nanorods: a comparative study," in Proceedings of the SPIE 8928, Optical Techniques in Neurosurgery, Neurophotonics, and Optogenetics, vol. 8928, San Francisco, Calif, USA, March 2014.

[94] S. E. Skrabalak, J. Chen, Y. Sun et al., "Gold nanocages: synthesis, properties, and applications," Accounts of Chemical Research, vol. 41, no. 12, pp. 1587-1595, 2008.

[95] J. Chen, D. Wang, J. Xi et al., "Immuno gold nanocages with tailored optical properties for targeted photothermal destruction of cancer cells," Nano Letters, vol. 7, no. 5, pp. 1318-1322, 2007.

[96] J. Chen, F. Saeki, B. J. Wiley et al., "Gold nanocages: bioconjugation and their potential use as optical imaging contrast agents," Nano Letters, vol. 5, no. 3, pp. 473-477, 2005.

[97] A. Camposeo, L. Persano, R. Manco et al., "Metal-Enhanced Near-Infrared Fluorescence by Micropatterned Gold Nanocages," ACS Nano, vol. 9, no. 10, pp. 10047-10054, 2015.

[98] R. Robinson, W. Gerlach, and H. Ghandehari, "Comparative effect of gold nanorods and nanocages for prostate tumor hyperthermia," Journal of Controlled Release, vol. 220, pp. 245252, 2015.

[99] J. R. Melamed, R. S. Edelstein, and E. S. Day, "Elucidating the fundamental mechanisms of cell death triggered by photothermal therapy," ACS Nano, vol. 9, no. 1, pp. 6-11, 2015.

[100] J. Chen, C. Glaus, R. Laforest et al., "Gold nanocages as photothermal transducers for cancer treatment," Small, vol. 6, no. 7, pp. 811-817, 2010.

[101] H. Wang, J. Han, W. Lu, J. Zhang, J. Li, and L. Jiang, "Facile preparation of gold nanocages and hollow gold nanospheres via solvent thermal treatment and their surface plasmon resonance and photothermal properties," Journal of Colloid and Interface Science, vol. 440, pp. 236-244, 2015.

[102] A. M. Gobin, E. M. Watkins, E. Quevedo, V. L. Colvin, and J. L. West, "Near-infrared-resonant gold/gold sulfide nanoparticles as a photothermal cancer therapeutic agent," Small, vol. 6, no. 6, pp. 745-752, 2010.

[103] C.-K. Chu, Y.-C. Tu, Y.-W. Chang et al., "Cancer cell uptake behavior of $\mathrm{Au}$ nanoring and its localized surface plasmon resonance induced cell inactivation," Nanotechnology, vol. 26, no. 7, Article ID 075102, 2015.

[104] J. Huang, M. Guo, H. T. Ke et al., "Rational design and synthesis gamma $\mathrm{Fe}_{2} \mathrm{O}_{3} @ \mathrm{Au}$ magnetic gold nanoflowers for efficient cancer theranostics," Advanced Materials, vol. 27, no. 34, pp. 5049-5056, 2015.

[105] C. Iodice, A. Cervadoro, A. L. Palange et al., "Enhancing photothermal cancer therapy by clustering gold nanoparticles into spherical polymeric nanoconstructs," Optics and Lasers in Engineering, vol. 76, pp. 74-81, 2016.

[106] D. K. Roper, W. Ahn, and M. Hoepfner, "Microscale heat transfer transduced by surface plasmon resonant gold nanoparticles," Journal of Physical Chemistry C, vol. 111, no. 9, pp. 3636-3641, 2007.
[107] H. H. Richardson, M. T. Carlson, P. J. Tandler, P. Hernandez, and A. O. Govorov, "Experimental and theoretical studies of light-to-heat conversion and collective heating effects in metal nanoparticle solutions," Nano Letters, vol. 9, no. 3, pp. 1139-1146, 2009.

[108] J. R. Cole, N. A. Mirin, M. W. Knight, G. P. Goodrich, and N. J. Halas, "Photothermal efficiencies of nanoshells and nanorods for clinical therapeutic applications," Journal of Physical Chemistry C, vol. 113, no. 28, pp. 12090-12094, 2009.

[109] H. Chen, L. Shao, T. Ming et al., "Understanding the photothermal conversion efficiency of gold nanocrystals," Small, vol. 6, no. 20, pp. 2272-2280, 2010.

[110] Z. Qin and J. C. Bischof, "Thermophysical and biological responses of gold nanoparticle laser heating," Chemical Society Reviews, vol. 41, no. 3, pp. 1191-1217, 2012.

[111] D. K. Chatterjee and Z. Yong, "Upconverting nanoparticles as nanotransducers for photodynamic therapy in cancer cells," Nanomedicine, vol. 3, no. 1, pp. 73-82, 2008.

[112] J. H. Hodak, A. Henglein, and G. V. Hartland, "Photophysics of nanometer sized metal particles: electron-phonon coupling and coherent excitation of breathing vibrational modes," The Journal of Physical Chemistry B, vol. 104, no. 43, pp. 9954-9965, 2000.

[113] D. E. J. G. J. Dolmans, D. Fukumura, and R. K. Jain, "Photodynamic therapy for cancer," Nature Reviews Cancer, vol. 3, no. 5, pp. 380-387, 2003.

[114] D. B. Tada and M. S. Baptista, "Photosensitizing nanoparticles and the modulation of ROS generation," Frontiers in Chemistry, vol. 3, article no. 00033, 2015.

[115] N. F. Gamaleia, E. D. Shishko, G. A. Dolinsky, A. B. Shcherbakov, A. V. Usatenko, and V. V. Kholin, "Photodynamic activity of hematoporphyrin conjugates with gold nanoparticles: experiments in vitro," Experimental Oncology, vol. 32, no. 1, pp. 44-47, 2010.

[116] M. K. K. Oo, X. Yang, H. Du, and H. Wang, "5-Aminolevulinic acid-conjugated gold nanoparticles for photodynamic therapy of cancer," Nanomedicine, vol. 3, no. 6, pp. 777-786, 2008.

[117] M. Camerin, M. Magaraggia, M. Soncin et al., "The in vivo efficacy of phthalocyanine-nanoparticle conjugates for the photodynamic therapy of amelanotic melanoma," European Journal of Cancer, vol. 46, no. 10, pp. 1910-1918, 2010.

[118] T. Stuchinskaya, M. Moreno, M. J. Cook, D. R. Edwards, and D. A. Russell, "Targeted photodynamic therapy of breast cancer cells using antibody-phthalocyanine-gold nanoparticle conjugates," Photochemical \& Photobiological Sciences, vol. 10, no. 5, pp. 822-831, 2011.

[119] G. Obaid, I. Chambrier, M. J. Cook, and D. A. Russell, "Targeting the oncofetal thomsen-friedenreich disaccharide using jacalin-PEG phthalocyanine gold nanoparticles for photodynamic cancer therapy," Angewandte Chemie-International Edition, vol. 51, no. 25, pp. 6158-6162, 2012.

[120] G. Obaid, I. Chambrier, M. J. Cook, and D. A. Russell, "Cancer targeting with biomolecules: a comparative study of photodynamic therapy efficacy using antibody or lectin conjugated phthalocyanine-PEG gold nanoparticles," Photochemical \& Photobiological Sciences, vol. 14, no. 4, pp. 737-747, 2015.

[121] W. P. Savarimuthu, P. Gananathan, A. P. Rao, E. Manickam, and G. Singaravelu, "Protoporphyrin IX-gold nanoparticle conjugates for targeted photodynamic therapy - an in-vitro study," Journal of Nanoscience and Nanotechnology, vol. 15, no. 8, pp. 5577-5584, 2015.

[122] J. D. Meyers, Y. Cheng, A.-M. Broome et al., "Peptide-targeted gold nanoparticles for photodynamic therapy of brain cancer," 
Particle \& Particle Systems Characterization, vol. 32, no. 4, pp. 448-457, 2015.

[123] Y. Cheng, A. C. Samia, J. Li, M. E. Kenney, A. Resnick, and C. Burda, "Delivery and efficacy of a cancer drug as a function of the bond to the gold nanoparticle surface," Langmuir, vol. 26, no. 4, pp. 2248-2255, 2010.

[124] M. K. Khaing Oo, Y. Yang, Y. Hu, M. Gomez, H. Du, and H. Wang, "Gold nanoparticle-enhanced and size-dependent generation of reactive oxygen species from protoporphyrin IX," ACS Nano, vol. 6, no. 3, pp. 1939-1947, 2012.

[125] J. C. Y. Kah, R. C. Y. Wan, K. Y. Wong, S. Mhaisalkar, C. J. R. Sheppard, and M. Olivo, "Combinatorial treatment of photothermal therapy using gold nanoshells with conventional photodynamic therapy to improve treatment efficacy: an in vitro study," Lasers in Surgery and Medicine, vol. 40, no. 8, pp. 584-589, 2008.

[126] W.-S. Kuo, C.-N. Chang, Y.-T. Chang et al., "Gold nanorods in photodynamic therapy, as hyperthermia agents, and in nearinfrared optical imaging," Angewandte Chemie-International Edition, vol. 49, no. 15, pp. 2711-2715, 2010.

[127] W.-S. Kuo, Y.-T. Chang, K.-C. Cho et al., "Gold nanomaterials conjugated with indocyanine green for dual-modality photodynamic and photothermal therapy," Biomaterials, vol. 33, no. 11, pp. 3270-3278, 2012.

[128] J. Wang, H. Y. Tang, W. L. Yang, and J. Y. Chen, "Aluminum phthalocyanine and gold nanorod conjugates: the combination of photodynamic therapy and photothermal therapy to kill cancer cells," Journal of Porphyrins and Phthalocyanines, vol. 16, no. 7-8, pp. 802-808, 2012.

[129] K. Hari, A. Pichaimani, and P. Kumpati, "Acridine orange tethered chitosan reduced gold nanoparticles: a dual functional probe for combined photodynamic and photothermal therapy," RSC Advances, vol. 3, no. 43, pp. 20471-20479, 2013.

[130] S.-H. Seo, B.-M. Kim, A. Joe et al., "NIR-light-induced surfaceenhanced Raman scattering for detection and photothermal/photodynamic therapy of cancer cells using methylene blue-embedded gold nanorod@SiO2 nanocomposites," Biomaterials, vol. 35, no. 10, pp. 3309-3318, 2014.

[131] A. J. Trinidad, S. J. Hong, Q. Peng, S. J. Madsen, and H. Hirschberg, "Combined concurrent photodynamic and gold nanoshell loaded macrophage-mediated photothermal therapies: an in vitro study on squamous cell head and neck carcinoma," Lasers in Surgery and Medicine, vol. 46, no. 4, pp. 310-318, 2014.

[132] L. Gao, J. Fei, J. Zhao, H. Li, Y. Cui, and J. Li, "Hypocrellinloaded gold nanocages with high two-photon efficiency for photothermal/photodynamic cancer therapy in vitro," ACS Nano, vol. 6, no. 9, pp. 8030-8040, 2012.

[133] N. N. Wang, Z. L. Zhao, Y. F. Lv et al., "Gold nanorodphotosensitizer conjugate with extracellular $\mathrm{pH}$-driven tumor targeting ability for photothermal/photodynamic therapy," Nano Research, vol. 7, no. 9, pp. 1291-1301, 2014.

[134] B. Khlebtsov, E. Panfilova, V. Khanadeev et al., "Nanocomposites containing silica-coated gold-silver nanocages and $\mathrm{Yb}$ 2,4-dimethoxyhematoporphyrin: multifunctional capability of IR-luminescence detection, photosensitization, and photothermolysis," ACS Nano, vol. 5, no. 9, pp. 7077-7089, 2011.

[135] J. Lin, S. Wang, P. Huang et al., "Photosensitizer-loaded gold vesicles with strong plasmonic coupling effect for imagingguided photothermal/photodynamic therapy," ACS Nano, vol. 7, no. 6, pp. 5320-5329, 2013.
[136] S. Wang, P. Huang, L. Nie et al., "Single continuous wave laser induced photodynamic/plasmonic photothermal therapy using photosensitizer-functionalized gold nanostars," Advanced Materials, vol. 25, no. 22, pp. 3055-3061, 2013.

[137] G. Terentyuk, E. Panfilova, V. Khanadeev et al., "Gold nanorods with a hematoporphyrin-loaded silica shell for dual-modality photodynamic and photothermal treatment of tumors in vivo," Nano Research, vol. 7, no. 3, pp. 325-337, 2014.

[138] P. Vijayaraghavan, C.-H. Liu, R. Vankayala, C.-S. Chiang, and K. C. Hwang, "Designing multi-branched gold nanoechinus for NIR light activated dual modal photodynamic and photothermal therapy in the second biological window," Advanced Materials, vol. 26, no. 39, pp. 6689-6695, 2014.

[139] M. Yu, F. Guo, J. Wang, F. Tan, and N. Li, "Photosensitizerloaded $\mathrm{pH}$-responsive hollow gold nanospheres for single lightinduced photothermal/photodynamic therapy," ACS Applied Materials and Interfaces, vol. 7, no. 32, pp. 17592-17597, 2015.

[140] A. M. Schwartzberg, C. D. Grant, A. Wolcott et al., "Unique gold nanoparticle aggregates as a highly active surface-enhanced raman scattering substrate," Journal of Physical Chemistry B, vol. 108, no. 50, pp. 19191-19197, 2004.

[141] F. Geng, J. Z. Xing, J. Chen et al., "Pegylated glucose gold nanoparticles for improved in-vivo bio-distribution and enhanced radiotherapy on cervical cancer," Journal of Biomedical Nanotechnology, vol. 10, no. 7, pp. 1205-1216, 2014.

[142] R. Vankayala, A. Sagadevan, P. Vijayaraghavan, C.-L. Kuo, and K. C. Hwang, "Metal nanoparticles sensitize the formation of singlet oxygen," Angewandte Chemie-International Edition, vol. 50, no. 45, pp. 10640-10644, 2011.

[143] G. Pasparakis, "Light-induced generation of singlet oxygen by naked gold nanoparticles and its implications to cancer cell phototherapy," Small, vol. 9, no. 24, pp. 4130-4134, 2013.

[144] R. Vankayala, C.-L. Kuo, A. Sagadevan, P.-H. Chen, C.-S. Chiang, and K. C. Hwang, "Morphology dependent photosensitization and formation of singlet oxygen $(1 \Delta \mathrm{g})$ by gold and silver nanoparticles and its application in cancer treatment," Journal of Materials Chemistry B, vol. 1, no. 35, pp. 4379-4387, 2013.

[145] P. K. Jain, K. S. Lee, I. H. El-Sayed, and M. A. El-Sayed, “Calculated absorption and scattering properties of gold nanoparticles of different size, shape, and composition: applications in biological imaging and biomedicine," Journal of Physical Chemistry $B$, vol. 110, no. 14, pp. 7238-7248, 2006.

[146] T. Zhao, X. Shen, L. Li et al., "Gold nanorods as dual photosensitizing and imaging agents for two-photon photodynamic therapy," Nanoscale, vol. 4, no. 24, pp. 7712-7719, 2012.

[147] J. F. Dorsey, L. Sun, D. Y. Joh et al., "Gold nanoparticles in radiation research: potential applications for imaging and radiosensitization," Translational Cancer Research, vol. 2, no. 4, pp. 280-291, 2013.

[148] K. Kobayashi, N. Usami, E. Porcel, S. Lacombe, and C. Le Sech, "Enhancement of radiation effect by heavy elements," Mutation Research/Reviews in Mutation Research, vol. 704, no. 1-3, pp. 123-131, 2010.

[149] D. M. Herold, I. J. Das, C. C. Stobbe, R. V. Iyer, and J. D. Chapman, "Gold microspheres: a selective technique for producing biologically effective dose enhancement," International Journal of Radiation Biology, vol. 76, no. 10, pp. 1357-1364, 2000.

[150] T. Marques, D. Chatterjee, P. Nicolucci, and S. Krishnan, "Enhanced radiosensitization by tumor-targeting gold nanoparticles: a paradigm for energy modulated radiation 
therapy (EMRT)," International Journal of Radiation Oncology ${ }^{*}$ Biology ${ }^{*}$ Physics, vol. 87, no. 2, p. S658, 2013.

[151] C. C. Chien, C. H. Wang, T. E. Hua et al., "Synchrotron X-ray synthesized gold nanoparticles for tumor therapy," Synchrotron Radiation Instrumentation, Pts 1 and 2, vol. 879, pp. 1908-1911, 2007.

[152] M.-Y. Chang, A.-L. Shiau, Y.-H. Chen, C.-J. Chang, H. H.-W. Chen, and C.-L. Wu, "Increased apoptotic potential and doseenhancing effect of gold nanoparticles in combination with single-dose clinical electron beams on tumor-bearing mice," Cancer Science, vol. 99, no. 7, pp. 1479-1484, 2008.

[153] J. F. Hainfeld, F. A. Dilmanian, Z. Zhong, D. N. Slatkin, J. A. Kalef-Ezra, and H. M. Smilowitz, "Gold nanoparticles enhance the radiation therapy of a murine squamous cell carcinoma," Physics in Medicine and Biology, vol. 55, no. 11, pp. 3045-3059, 2010.

[154] X. J. Zhang, J. Z. Xing, J. Chen et al., "Enhanced radiation sensitivity in prostate cancer by gold-nanoparticles," Clinical and Investigative Medicine, vol. 31, no. 3, pp. E160-E167, 2008.

[155] T. Kong, J. Zeng, X. P. Wang et al., "Enhancement of radiation cytotoxicity in breast-cancer cells by localized attachment of gold nanoparticles," Small, vol. 4, no. 9, pp. 1537-1543, 2008.

[156] F. Geng, K. Song, J. Z. Xing et al., "Thio-glucose bound gold nanoparticles enhance radio-cytotoxic targeting of ovarian cancer," Nanotechnology, vol. 22, no. 28, Article ID 285101, 2011.

[157] K. Khoshgard, B. Hashemi, A. Arbabi, M. J. Rasaee, and M. Soleimani, "Radiosensitization effect of folate-conjugated gold nanoparticles on HeLa cancer cells under orthovoltage superficial radiotherapy techniques," Physics in Medicine and Biology, vol. 59, no. 9, pp. 2249-2263, 2014.

[158] S. Setua, M. Ouberai, S. G. Piccirillo, C. Watts, and M. Welland, "Cisplatin-tethered gold nanospheres for multimodal chemoradiotherapy of glioblastoma," Nanoscale, vol. 6, no. 18, pp. 10865-10873, 2014.

[159] A. Vilchis-Juárez, G. Ferro-Flores, C. Santos-Cuevas et al., "Molecular targeting radiotherapy with Cyclo-RGDfK(C) peptides conjugated to ${ }^{177} \mathrm{Lu}$-labeled gold nanoparticles in tumorbearing mice," Journal of Biomedical Nanotechnology, vol. 10, no. 3, pp. 393-404, 2014.

[160] S. W. Botchway, J. A. Coulter, and F. J. Currell, "Imaging intracellular and systemic in vivo gold nanoparticles to enhance radiotherapy," British Journal of Radiology, vol. 88, no. 1054, 2015.

[161] C. H. Wang, Y. H. Jiang, X. H. Li, and L. K. Hu, “Thioglucosebound gold nanoparticles increase the radiosensitivity of a triple-negative breast cancer cell line (MDA-MB-231)," Breast Cancer, vol. 22, no. 4, pp. 413-420, 2015.

[162] P. Li, Y.-W. Shi, B.-X. Li et al., "Photo-thermal effect enhances the efficiency of radiotherapy using Arg-Gly-Asp peptidesconjugated gold nanorods that target $\alpha \mathrm{v} \beta 3$ in melanoma cancer cells," Journal of Nanobiotechnology, vol. 13, article 52, 2015.

[163] P. Diagaradjane, A. Shetty, J. C. Wang et al., "Modulation of in vivo tumor radiation response via gold nanoshell-mediated vascular-focused hyperthermia: characterizing an integrated antihypoxic and localized vascular disrupting targeting strategy," Nano Letters, vol. 8, no. 5, pp. 1492-1500, 2008.

[164] J. C. Polf, L. F. Bronk, W. H. P. Driessen, W. Arap, R. Pasqualini, and M. Gillin, "Enhanced relative biological effectiveness of proton radiotherapy in tumor cells with internalized gold nanoparticles," Applied Physics Letters, vol. 98, no. 19, Article ID 193702, 2011.
[165] J. F. Hainfeld, F. A. Dilmanian, D. N. Slatkin, and H. M. Smilowitz, "Radiotherapy enhancement with gold nanoparticles," Journal of Pharmacy and Pharmacology, vol. 60, no. 8, pp. 977-985, 2008.

[166] K. T. Butterworth, S. J. McMahon, F. J. Currell, and K. M. Prise, "Physical basis and biological mechanisms of gold nanoparticle radiosensitization," Nanoscale, vol. 4, no. 16, pp. 4830-4838, 2012.

[167] K. C. Hribar, M. H. Lee, D. Lee, and J. A. Burdick, "Enhanced release of small molecules from near-infrared light responsive polymer-nanorod composites," ACS Nano, vol. 5, no. 4, pp. 2948-2956, 2011.

[168] J. You, R. Shao, X. Wei, S. Gupta, and C. Li, "Near-infrared light triggers release of paclitaxel from biodegradable microspheres: photothermal effect and enhanced antitumor activity," Small, vol. 6, no. 9, pp. 1022-1031, 2010.

[169] S. R. Sershen, S. L. Westcott, N. J. Halas, and J. L. West, "Temperature-sensitive polymer-nanoshell composites for photothermally modulated drug delivery," Journal of Biomedical Materials Research, vol. 51, no. 3, pp. 293-298, 2000.

[170] M. Bikram, A. M. Gobin, R. E. Whitmire, and J. L. West, "Temperature-sensitive hydrogels with $\mathrm{SiO}_{2}-\mathrm{Au}$ nanoshells for controlled drug delivery," Journal of Controlled Release, vol. 123, no. 3, pp. 219-227, 2007.

[171] M. B. Charati, I. Lee, K. C. Hribar, and J. A. Burdick, "Lightsensitive polypeptide hydrogel and nanorod composites," Small, vol. 6, no. 15, pp. 1608-1611, 2010.

[172] L. Poon, W. Zandberg, D. Hsiao et al., "Photothermal release of single-stranded DNA from the surface of gold nanoparticles through controlled denaturating and Au-S bond breaking," ACS Nano, vol. 4, no. 11, pp. 6395-6403, 2010.

[173] H. J. Kwon, Y. Byeon, H. N. Jeon, S. H. Cho, H. D. Han, and B. C. Shin, "Gold cluster-labeled thermosensitive liposmes enhance triggered drug release in the tumor microenvironment by a photothermal effect," Journal of Controlled Release, vol. 216, pp. 132-139, 2015.

[174] R. Sierpe, E. Lang, P. Jara et al., "Gold nanoparticles interacting with $\beta$-cyclodextrin-phenylethylamine inclusion complex: a ternary system for photothermal drug Release," ACS Applied Materials and Interfaces, vol. 7, no. 28, pp. 15177-15181, 2015.

[175] E. Pérez-Herrero and A. Fernández-Medarde, "Advanced targeted therapies in cancer: drug nanocarriers, the future of chemotherapy," European Journal of Pharmaceutics and Biopharmaceutics, vol. 93, pp. 52-79, 2015.

[176] S. C. Coelho, G. M. Almeida, M. C. Pereira, F. Santos-Silva, and M. A. N. Coelho, "Functionalized gold nanoparticles improve afatinib delivery into cancer cells," Expert Opinion on Drug Delivery, vol. 13, no. 1, pp. 133-141, 2016.

[177] N. Zhang, H. Chen, A.-Y. Liu et al., "Gold conjugate-based liposomes with hybrid cluster bomb structure for liver cancer therapy," Biomaterials, vol. 74, pp. 280-291, 2016.

[178] X. Xu, W. Ho, X. Zhang, N. Bertrand, and O. Farokhzad, "Cancer nanomedicine: from targeted delivery to combination therapy," Trends in Molecular Medicine, vol. 21, no. 4, pp. 223232, 2015

[179] X. Pan and R. J. Lee, "Tumour-selective drug delivery via folate receptor-targeted liposomes," Expert Opinion on Drug Delivery, vol. 1, no. 1, pp. 7-17, 2004.

[180] J. Sudimack and R. J. Lee, "Targeted drug delivery via the folate receptor," Advanced Drug Delivery Reviews, vol. 41, no. 2, pp. 147-162, 2000. 
[181] A. R. Hilgenbrink and P. S. Low, "Folate receptor-mediated drug targeting: from therapeutics to diagnostics," Journal of Pharmaceutical Sciences, vol. 94, no. 10, pp. 2135-2146, 2005.

[182] S. Pandey, R. Shah, A. Mewada, M. Thakur, G. Oza, and M. Sharon, "Gold nanorods mediated controlled release of doxorubicin: nano-needles for efficient drug delivery," Journal of Materials Science: Materials in Medicine, vol. 24, no. 7, pp. 1671-1681, 2013.

[183] H. Jin, P. Yang, J. Cai, J. Wang, and M. Liu, "Photothermal effects of folate-conjugated Au nanorods on HepG2 cells," Applied Microbiology and Biotechnology, vol. 94, no. 5, pp. 1199-1208, 2012.

[184] B. Asadishad, M. Vossoughi, and I. Alamzadeh, "In vitro release behavior and cytotoxicity of doxorubicin-loaded gold nanoparticles in cancerous cells," Biotechnology Letters, vol. 32, no. 5, pp. 649-654, 2010.

[185] T. Kino, "Glucocorticoid receptor," in Endotext, L. J. De Groot, P. Beck-Peccoz, G. Chrousos et al., Eds., MDText.com Inc., South Dartmouth, Mass, USA, 2000.

[186] S. Sau, P. Agarwalla, S. Mukherjee et al., "Cancer cell-selective promoter recognition accompanies antitumor effect by glucocorticoid receptor-targeted gold nanoparticle," Nanoscale, vol. 6, no. 12, pp. 6745-6754, 2014.

[187] K. Chen and X. Chen, "Design and development of molecular imaging probes," Current Topics in Medicinal Chemistry, vol. 10, no. 12, pp. 1227-1236, 2010.

[188] H. Yuan, A. M. Fales, and T. Vo-Dinh, "TAT peptidefunctionalized gold nanostars: enhanced intracellular delivery and efficient NIR photothermal therapy using ultralow irradiance," Journal of the American Chemical Society, vol. 134, no. 28, pp. 11358-11361, 2012.

[189] A. Wicki, D. Witzigmann, V. Balasubramanian, and J. Huwyler, "Nanomedicine in cancer therapy: challenges, opportunities, and clinical applications," Journal of Controlled Release, vol. 200, pp. 138-157, 2015.

[190] N. Kotagiri, G. P. Sudlow, W. J. Akers, and S. Achilefu, "Breaking the depth dependency of phototherapy with Cerenkov radiation and low-radiance-responsive nanophotosensitizers," Nature Nanotechnology, vol. 10, no. 4, pp. 370-379, 2015.

[191] M. Szwed, D. Wrona, K. D. Kania, A. Koceva-Chyla, and A. Marczak, "Doxorubicin-transferrin conjugate triggers prooxidative disorders in solid tumor cells," Toxicology in Vitro, vol. 31, pp. 60-71, 2016.

[192] N. Amreddy, R. Muralidharan, A. Babu et al., "Tumor-targeted and $\mathrm{pH}$-controlled delivery of doxorubicin using gold nanorods for lung cancer therapy," International Journal of Nanomedicine, vol. 10, pp. 6773-6788, 2015.

[193] L. Yang, X. Zhang, M. Ye et al., "Aptamer-conjugated nanomaterials and their applications," Advanced Drug Delivery Reviews, vol. 63, no. 14-15, pp. 1361-1370, 2011.

[194] Q. Liu, C. Jin, Y. Wang et al., "Aptamer-conjugated nanomaterials for specific cancer cell recognition and targeted cancer therapy," NPG Asia Materials, vol. 6, no. 4, article e95, 2014.

[195] D. Kim, Y. Y. Jeong, and S. Jon, "A drug-loaded aptamerGold nanoparticle bioconjugate for combined CT imaging and therapy of prostate cancer," ACS Nano, vol. 4, no. 7, pp. 36893696, 2010.

[196] J. K. Herr, J. E. Smith, C. D. Medley, D. Shangguan, and W. Tan, "Aptamer-conjugated nanoparticles for selective collection and detection of cancer cells," Analytical Chemistry, vol. 78, no. 9, pp. 2918-2924, 2006.
[197] J. Choi, Y. Park, E. B. Choi et al., "Aptamer-conjugated gold nanorod for photothermal ablation of epidermal growth factor receptor-overexpressed epithelial cancer," Journal of Biomedical Optics, vol. 19, no. 5, Article ID 051203, 2014.

[198] M. Semmler-Behnke, W. G. Kreyling, J. Lipka et al., "Biodistribution of 1.4- and 18-nm gold particles in rats," Small, vol. 4, no. 12, pp. 2108-2111, 2008.

[199] N. Khlebtsov and L. Dykman, "Biodistribution and toxicity of engineered gold nanoparticles: a review of in vitro and in vivo studies," Chemical Society Reviews, vol. 40, pp. 1647-1671, 2011.

[200] G. Roebben, S. Ramirez-Garcia, V. A. Hackley et al., "Interlaboratory comparison of size and surface charge measurements on nanoparticles prior to biological impact assessment," Journal of Nanoparticle Research, vol. 13, no. 7, pp. 2675-2687, 2011.

[201] H. Soo Choi, W. Liu, P. Misra et al., "Renal clearance of quantum dots," Nature Biotechnology, vol. 25, no. 10, pp. 1165-1170, 2007.

[202] N. Pernodet, X. Fang, Y. Sun et al., "Adverse effects of citrate/gold nanoparticles on human dermal fibroblasts," Small, vol. 2, no. 6, pp. 766-773, 2006.

[203] L. Y. T. Chou, K. Zagorovsky, and W. C. W. Chan, "DNA assembly of nanoparticle superstructures for controlled biological delivery and elimination," Nature Nanotechnology, vol. 9, no. 2, pp. 148-155, 2014.

[204] A. Mesbahi, "A review on gold nanoparticles radiosensitization effect in radiation therapy of cancer," Reports of Practical Oncology and Radiotherapy, vol. 15, no. 6, pp. 176-180, 2010. 

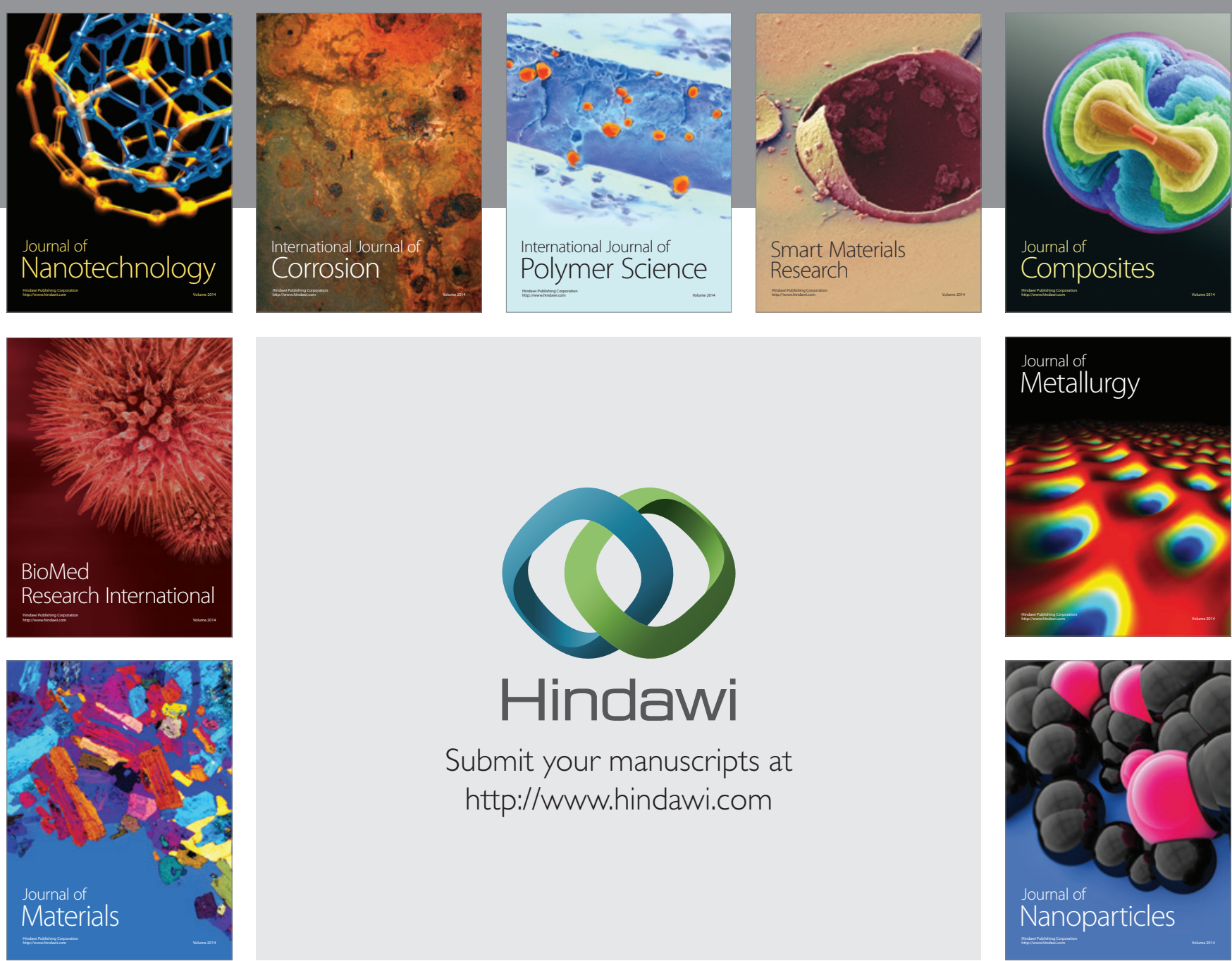

\section{Hindawi}

Submit your manuscripts at

http://www.hindawi.com

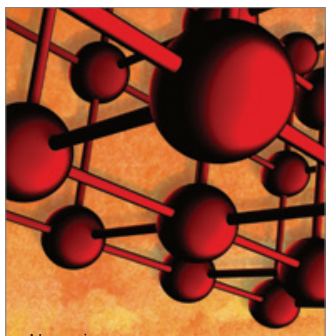

Materials Science and Engineering
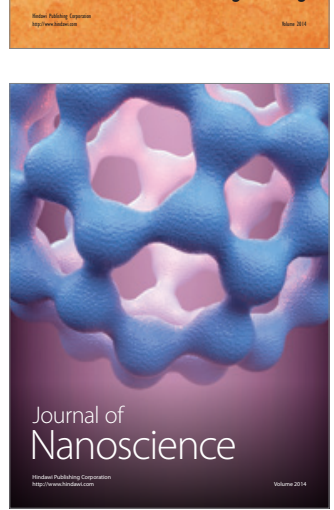
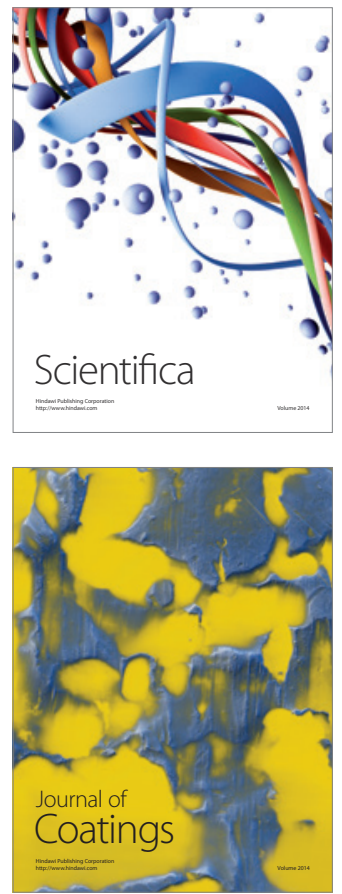
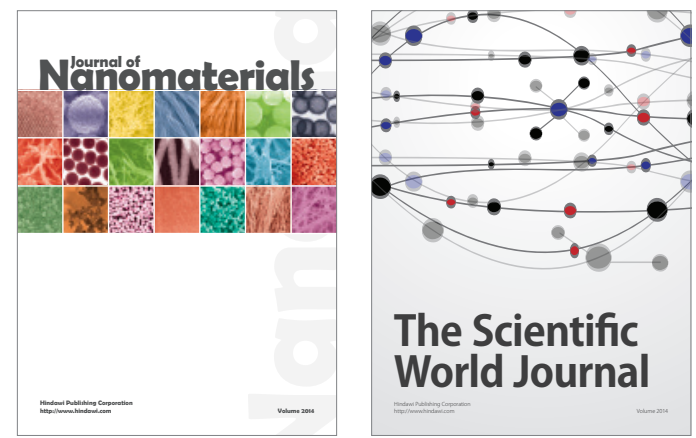

The Scientific World Journal
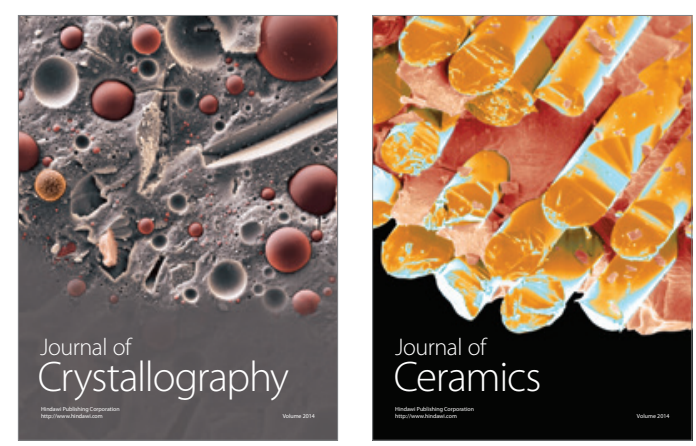
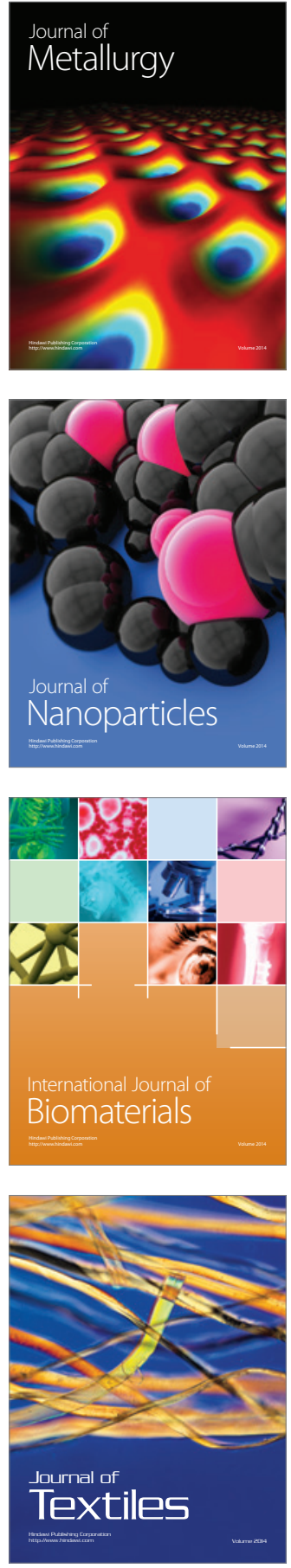